\title{
A Macroeconomic Model with Occasional Financial Crises
}

\author{
Pascal Paul \\ Federal Reserve Bank of San Francisco \\ November 2019 \\ Working Paper 2017-22 \\ http://www.frbsf.org/economic-research/publications/working-papers/2017/22/
}

\section{Suggested citation:}

Pascal Paul. 2019. “A Macroeconomic Model with Occasional Financial Crises,” Federal Reserve Bank of San Francisco Working Paper 2017-22. https://doi.org/10.24148/wp2017-22

The views in this paper are solely the responsibility of the authors and should not be interpreted as reflecting the views of the Federal Reserve Bank of San Francisco or the Board of Governors of the Federal Reserve System. 


\title{
A Macroeconomic Model with Occasional Financial Crises
}

\author{
Pascal Paul \\ Federal Reserve Bank of San Francisco*
}

November 2019

\begin{abstract}
Financial crises occur out of prolonged and credit-fueled boom periods and, at times, they are initiated by relatively small shocks that can have large effects. Consistent with these empirical observations, this paper extends a standard macroeconomic model to include financial intermediation, long-term loans, and occasional financial crises. Within this framework, intermediaries raise their lending and leverage in good times, thereby building up financial fragility. Crises typically occur at the end of a prolonged boom, initiated by a moderate adverse shock that triggers a liquidation of existing investment, a contraction in lending, and ultimately a deep and persistent recession.
\end{abstract}

Keywords: Financial Crises, Financial Intermediation, Financial Stability

JEL codes: E32, E44, E52, G1, G01, G21

\footnotetext{
*Email: pascal.paul@sf.frb.org. First online version: September 2015.

I am particularly thankful for detailed comments by two anonymous referees, Tobias Adrian, Paul Beaudry, Fabrice Collard, Keshav Dogra (discussant), Martin Ellison, Andrea Ferrero, Andrew Foerster, Mark Gertler, Òscar Jordà, Nobuhiro Kiyotaki, Lars Lochstoer (discussant), and Josef Schroth (discussant). I also thank Joseph Pedtke, Michael Tubbs, and Anita Todd for excellent research \& editing assistance and many seminar and conference participants for their insights at Bank of England, Banque de France, CREi, European Central Bank, Federal Reserve Bank of San Francisco, Federal Reserve Board, IMF, the 12th Macro Finance Workshop, New York University, Tilburg University, UC Davis, University of Oxford, the Meeting of the Canadian Macroeconomics Study Group, the German Economists Abroad Meeting, the European Winter Meetings of the Econometric Society, and the New York Fed - Oxford Monetary Economics Conference. A previous version was circulated with the title "Financial Crises \& Debt Rigidities". Financial support by the German Academic Exchange Service, the German National Academic Foundation, and the David Walton Scholarship is gratefully acknowledged. All errors are my own. The views expressed herein are solely those of the author and do not necessarily reflect the views of the Federal Reserve Bank of San Francisco or the Federal Reserve System.
} 


\section{Introduction}

The 2007-09 financial crisis revealed the need for macroeconomic models to incorporate connections between the financial sector and the macroeconomy that can amplify economic shocks and lead to occasional deep economic downturns. Over the past few years, rapid advances have been made to extend standard macroeconomic models and include financial intermediation to account for episodes of severe financial distress.

At the same time, a quickly growing empirical literature has revealed several stylized facts about financial crises. Crises are rare events that are usually preceded by prolonged boom periods and a buildup of macro-financial imbalances. For example, in the run-up to crises, credit usually rises rapidly, and credit growth is a robust early-warning indicator of crises (e.g., Schularick and Taylor, 2012; see also Figure 13 in Appendix A.4.2).

Financial crises are associated with severe recessions that are typically deeper than normal recessions, particularly if they are preceded by a buildup of credit (Jordà, Schularick, and Taylor, 2013). However, the ultimate triggers of crises can be relatively small. With respect to the 2007-09 financial crisis, Gorton and Ordoñez (2014) argue that losses from mortgage-backed securities the relevant shock for the financial sector around that time - were actually quite modest (see also Ospina and Uhlig, 2018).

These empirical facts about crises pose challenges to current macroeconomic models. Why does financial fragility build up in good times? What is the propagation mechanism that turns shocks that are not particularly large into severe macroeconomic events? In this paper, I develop a quantitative macroeconomic model that addresses these questions. In my model, crises are as frequent and severe as in the data, financial fragility endogenously builds up during booms when credit expands, and crises are usually initiated by a moderate adverse shock.

In typical macroeconomic models, two features generally work against a buildup of financial instability in good times. First, agents are risk-averse and therefore prefer to smooth their consumption. When their income temporarily increases, then agents want to save part of it and any prior level of borrowing therefore decreases. Second, in good times, asset prices increase, generally resulting in countercyclical leverage. However, in the model that I consider, these forces are overturned due to agent heterogeneity and limited asset market participation.

At the heart of my model are households, financial intermediaries, and a corporate sector. Financial intermediaries represent the whole modern financial intermediation sector, but I refer to them as banks for short. Households and banks are both risk-averse and consume. However, they differ in their degree of patience as in Kiyotaki and Moore (1997). Banks are less patient and therefore borrow from households in a short-term bond market. Moreover, only banks undertake risky investments in the corporate sector by issuing long-term and defaultable loans. 
Within this framework, I show that bank leverage can be procyclical. In good times, it becomes more profitable to invest in loans, and banks therefore increase their lending. They finance their investment by raising additional borrowing from households. Depending on the calibration, the increase in debt may outweigh the rise in the value and the amount of loans, resulting in procyclical leverage. I show that leverage measured at market values of U.S. financial intermediaries is mildly procyclical in the data, and I calibrate the model to this evidence. ${ }^{1}$ Moreover, I show that this calibration also matches the empirical impulse response of leverage to a technology shock the only aggregate shock in the model.

Given the calibrated model, banks enlarge their balance sheets and raise their leverage during prolonged boom periods. However, by leveraging up in good times, banks may also increase the risk of funding restrictions by creditors, once an adverse shock hits the economy. The model considers this trade-off explicitly by introducing occasional financial crises that are triggered if bank leverage goes above a certain threshold. The increase of leverage in good times moves banks closer to this "cliff", thereby building up financial fragility.

Beyond the cutoff point for leverage, banks face the risk of a creditor run. To avoid a run and therefore insolvency, banks inefficiently liquidate a fraction of their long-term loans. The early liquidation of loans gives banks additional liquidity and eliminates the possibility of a bank run. However, this process is also particularly costly for the economy since ongoing investment projects are stopped and a fraction of capital is lost. In this way, the model is able to account for the sharp contraction of output during financial crises.

While a bank run in the end never materializes, it is the occasional threat of a run that leads to a severe disruption of financial intermediation. The model can therefore account for the fact that most financial intermediaries do not actually experience a bank run that leads to insolvency during a typical financial crisis. Instead, as shown by Chodorow-Reich and Falato (2017) with respect to the 2007-09 financial crisis, banks sharply reduce existing credit to obtain liquidity and thereby avoid a bank run and insolvency. They find that total long-term credit and commitments outstanding contracted by 5.8\% in 2008 and 5.9\% in 2009 because unhealthy banks renegotiated the loan terms or accelerated repayment by a borrower that violated a covenant, similar to the mechanism here. This channel accounts for roughly two-thirds of the total credit reduction by unhealthy banks during the 2007-09 crisis, thus is the dominant channel through which credit contracted.

Taken together, the model includes standard business cycle dynamics, a realistic representation of the financial sector's balance sheet, and endogenous financial crises. I calibrate the model to match both the frequency and the severity of crises in the data. In this calibrated version, I find that the typical path leading to a crisis is characterized by a prolonged and credit-fueled boom,

\footnotetext{
${ }^{1}$ Following Cooley and Prescott (1995), I term leverage to be procyclical if the cyclical component of intermediary leverage and output are positively correlated. Section 3.1.2 and Appendix A.5.8 discuss how the evidence relates to Adrian and Shin (2010, 2014), see also Nuño and Thomas (2017) and Begenau et al. (2018).
} 
followed by a sudden bust that is triggered by a relatively moderate adverse shock.

As in the data, credit growth is a robust predictor of crises (e.g., Schularick and Taylor, 2012). Financial recessions are typically deeper than nonfinancial recessions, in particular if they are preceded by an unusually large buildup of credit, confirming existing empirical evidence (e.g., Jordà et al., 2013). In addition, credit spreads predict the severity of crises (Krishnamurthy and Muir, 2017). The behavior of the economy around nonfinancial recessions is different, since they are not preceded by an expansion of banks' balance sheets, a credit boom, or a buildup of leverage. In addition, I show that the model replicates the occurrence of the 2007-09 financial crisis when confronted with a historical series of structural productivity shocks for the U.S. economy.

For the main quantitative analysis, I treat crises as unanticipated events, as in the benchmark model by Gertler and Kiyotaki (2015). That is, when solving their decision problems, agents do not take into account that crises may occur in the future as a result of future shocks. In an extension, I relax this assumption and consider a slightly modified version that allows for crises to be anticipated. In future work, it would be interesting to take the model with anticipated crises further and consider macro-prudential policy interventions that aim to reduce the likelihood of crises.

Long-term loans are an important ingredient of the model. The illiquidity and possible liquidation of long-term loans determine how often crises occur and how severe they are. To speak to these mechanisms, I model long-term defaultable debt in a novel and tractable way (see, e.g., Chatterjee and Eyigungor (2012), Gomes et al. (2016), and Elenev et al. (2018) for alternative approaches). There is a distinction between newly issued and existing credit, and the two can differ in their riskiness and chance of default, particularly if existing credit is liquidated early. The model can also match the empirical evidence by Demyanyk and Hemert (2011) and Justiniano et al. (2017), who show that loans that were issued closer to the 2007-09 financial crisis in the United States were of lower quality and had higher default rates ex-post.

Related Literature. This paper builds on a vast literature about financial frictions within macroeconomic settings. Among the seminal contributions in this field are Bernanke and Gertler (1989), Kiyotaki and Moore (1997), Carlstrom and Fuerst (1997), and Bernanke, Gertler, and Gilchrist (1999). Before the 2007-09 financial crisis, financial frictions were mostly considered with respect to the balance sheets of nonfinancial firms (e.g., Bernanke et al., 1999). Since then, the literature has quickly progressed. The focus shifted towards modeling financial intermediaries and introducing occasional financial crises explicitly. Without providing a full overview, contributions to this literature include Adrian and Boyarchenko (2012), Akinci and Queralto (2017), Benigno, Foerster, Otrok, and Rebucci (2018), Bianchi (2011), Bocola (2016), Boissay, Collard, and Smets (2016), Brunnermeier and Sannikov (2014), Elenev, Landvoigt, and Van Nieuwerburgh (2018), Faria-eCastro (2017), Gertler and Kiyotaki (2010, 2015), Gorton and Ordoñez (2014, 2016), He and Krishnamurthy (2014), Martinez-Miera and Suarez (2012), and Mendoza (2010). 
Several papers have shown that aggregate lending and investment can suddenly contract when the financial sector's net worth or risk-bearing capacity is reduced (e.g., Gertler and Kiyotaki, 2010). Other contributions have particularly highlighted the nonlinear nature of such mechanisms. An adverse shock can have substantially worse effects if the financial sector is already at or close to its limits on how much funding to raise (e.g., Brunnermeier and Sannikov, 2014). ${ }^{2}$ In addition, when the economy enters a recession, borrowing restrictions for households, firms, and financial institutions may bite at the same time, and the different sectors may pull each other down (e.g., Elenev et al., 2018). A common theme across these papers is therefore that they all provide mechanisms through which the effects of adverse shocks get amplified. The size of the disturbance that is needed to explain the severity of crises in the data may therefore be strongly reduced, however, it may still be large (see, e.g., Gertler and Kiyotaki, 2010). Moreover, in these frameworks, crises are not more likely to occur out of prolonged and credit-intensive booms, as in the data. The goal of this paper is to address these two challenges.

Only a few papers have attempted to provide a theoretical account of both the buildup of fragilities during the boom period that usually precedes crises and the eventual crash. One early contribution that could be interpreted in this way is Lorenzoni (2008). In contrast to his paper, I provide a quantitative analysis of financial crises within a macroeconomic setting. This is also the difference to Gorton and Ordoñez $(2014,2016)$, who build on the idea that debt is informationally insensitive during booms but can suddenly turn informationally sensitive even after small shocks and therefore lead to a contraction in lending.

The closest paper is Boissay et al. (2016), in which crises also follow credit booms and are initiated by moderate adverse shocks. In their paper, households accumulate bank debt during a boom, giving banks incentives to engage in risky activities, which can result in a collapse of the interbank market. In contrast, I present a framework that features a realistic banking sector and the mechanisms through which systemic risk builds up and the eventual crash occurs are both matched to the data. The model replicates the empirical behavior of intermediary leverage, which reflects the financial sector's risk-taking behavior, and determines the buildup of financial crisis risk. ${ }^{3}$ Moreover, the model features long-term loans and therefore a maturity mismatch for banks. Crises are particularly costly because of the early liquidation of legacy loans. Again, I show that this mechanism is supported by the data, given the evidence in Chodorow-Reich and Falato (2017).

The paper is similar to Gertler and Kiyotaki (2015) and Gertler, Kiyotaki, and Prestipino (2017) in that banks are subject to rollover crises. Depending on macroeconomic fundamentals, a run equilibrium occasionally arises. In contrast to these papers, however, a run never materializes since

\footnotetext{
${ }^{2}$ The analysis here is different from the so-called "volatility paradox" in Brunnermeier and Sannikov (2014). They show that systemic risk can increase if the volatility of an aggregate shock is reduced. Here, the volatility of the aggregate shock in the model is not altered, but the shock realizations are analyzed that move the economy into a crisis.

${ }^{3}$ In Adrian and Boyarchenko (2012), bank leverage is also procyclical but depends on an agency problem between banks and their creditors (a value-at-risk constraint). Here, it is due to the heterogeneity of agents and their limited asset market participation. In comparison, I also analyze how leverage contributes to the buildup to crises.
} 
banks engage in an early liquidation of their loans to avoid a run. Such liquidations are costly and result in a sharp contraction in aggregate output, capturing the discrete nature of crises. Gertler, Kiyotaki, and Prestipino (2017) and Bordalo, Gennaioli, and Shleifer (2018) show that models in which agents have optimistic beliefs can also replicate the boom-bust patterns. Boz and Mendoza (2014) demonstrate that the same can be achieved if agents learn about a new financial environment. Here, I abstract from learning mechanisms and optimistic beliefs.

Road Map. The next section outlines the model. The model is calibrated to the data as explained in Section 3. Based on this calibration, the model is analyzed in Section 4. Section 5 concludes.

\section{Model}

I develop an infinite-horizon dynamic general equilibrium model in discrete time. The economy is closed and populated by households, financial intermediaries, and a corporate sector. Financial intermediaries convert households' savings into firm loans. The corporate sector consists of entrepreneurs that borrow from financial intermediaries and invest in the capital stock of a representative good producer. New capital goods in the economy are supplied by a representative capital good producer. Next, I describe the decision problem of each of these agents.

\subsection{Households}

There is a continuum of measure unity of identical households. Following Greenwood, Hercowitz, and Huffman (1988) $(\mathrm{GHH})$, a household values consumption $C_{t}$ and dislikes labor $H_{t}$, captured by the flow utility

$$
U^{H}\left(C_{t}, H_{t}\right)=\log \left(C_{t}-\chi \frac{H_{t}^{1+\phi}}{1+\phi}\right),
$$

where $\phi$ represents the inverse Frisch elasticity of labor supply. ${ }^{4}$ Taking the wage $w_{t}$ and the interest rate $R_{t}$ as given, the household chooses contingent plans for consumption, labor supply, and borrowing in the form of short-term and riskless bonds $B_{t}^{H}$ to maximize expected lifetime utility

$$
E_{t}\left[\sum_{k=0}^{\infty}\left(\beta^{H}\right)^{k} U^{H}\left(C_{t+k}, H_{t+k}\right)\right],
$$

subject to

$$
C_{t}+B_{t-1}^{H} R_{t} \leq w_{t} H_{t}+B_{t}^{H}+T_{t}^{H}
$$

\footnotetext{
${ }^{4} \mathrm{GHH}$ preferences eliminate the wealth effect on labor supply, because the marginal rate of substitution between consumption and labor is independent of changes in consumption. Compared with standard separable preferences, the impulse responses of labor and output shown in Figure (3) are therefore amplified. Moreover, GHH preferences simplify the solution of the model since current output is entirely determined by the current technology level and last period's capital stock.
} 
where $\beta^{H}$ is the household's discount factor and $R_{t}$ is the real interest rate between period $t-1$ and $t$ on savings in short-term bonds, that is, if $B_{t}^{H}$ is negative as implied by the calibration discussed below. Moreover, the household receives lump-sum transfers $T_{t}^{H}$ from firms, described shortly. The solution to the above problem gives the inter- and intratemporal optimality conditions

$$
\begin{aligned}
1 & =E_{t}\left[\Lambda_{t, t+1}\right] R_{t+1}, \\
w_{t} & =\chi H_{t}^{\phi},
\end{aligned}
$$

where

$$
\Lambda_{t, t+1}=\beta^{H}\left(\frac{C_{t}-\chi \frac{H_{t}^{1+\phi}}{1+\phi}}{C_{t+1}-\chi \frac{H_{t+1}^{1+\phi}}{1+\phi}}\right)
$$

is the household's stochastic discount factor.

\subsection{Good Producer}

A representative good producer operates according to a Cobb-Douglas production function

$$
Y_{t}=A_{t} K_{t-1}^{\alpha} H_{t}^{1-\alpha}
$$

combining labor $H_{t}$ with aggregate capital $K_{t-1}$, supplied in period $t-1$, to produce the good $Y_{t}$. The only source of aggregate risk in the model enters via the technology level $A_{t}$,

$$
\begin{aligned}
A_{t} & =e^{a_{t}}, \\
a_{t} & =\rho_{a} a_{t-1}+\epsilon_{t}^{a}, \\
\epsilon_{t}^{a} & \sim N\left(0, \sigma_{a}^{2}\right),
\end{aligned}
$$

where $\epsilon_{t}^{a}$ is termed the technology shock. Labor and capital pay their marginal products,

$$
\begin{aligned}
& w_{t}=(1-\alpha) \frac{Y_{t}}{H_{t}}, \\
& r_{t}^{K}=\alpha \frac{Y_{t}}{K_{t-1}},
\end{aligned}
$$

where $r_{t}^{K}$ is the rental rate per unit of capital.

\subsection{Entrepreneurs}

Risk-neutral entrepreneurs invest in the aggregate capital stock. They take on long-term debt from financial intermediaries to finance their investments. An entrepreneur who acquires a loan in period $t$ is termed a "new entrepreneur" in that period - highlighted by the superscript "new". There is a unit mass of new entrepreneurs. A new entrepreneur has net worth $N_{t}$ available (further described below). Additionally, the entrepreneur acquires a long-term, collateralized, and defaultable loan $Q_{t} L_{t}^{\text {new }}$ from a financial intermediary, where $Q_{t}$ denotes the price of long-term 


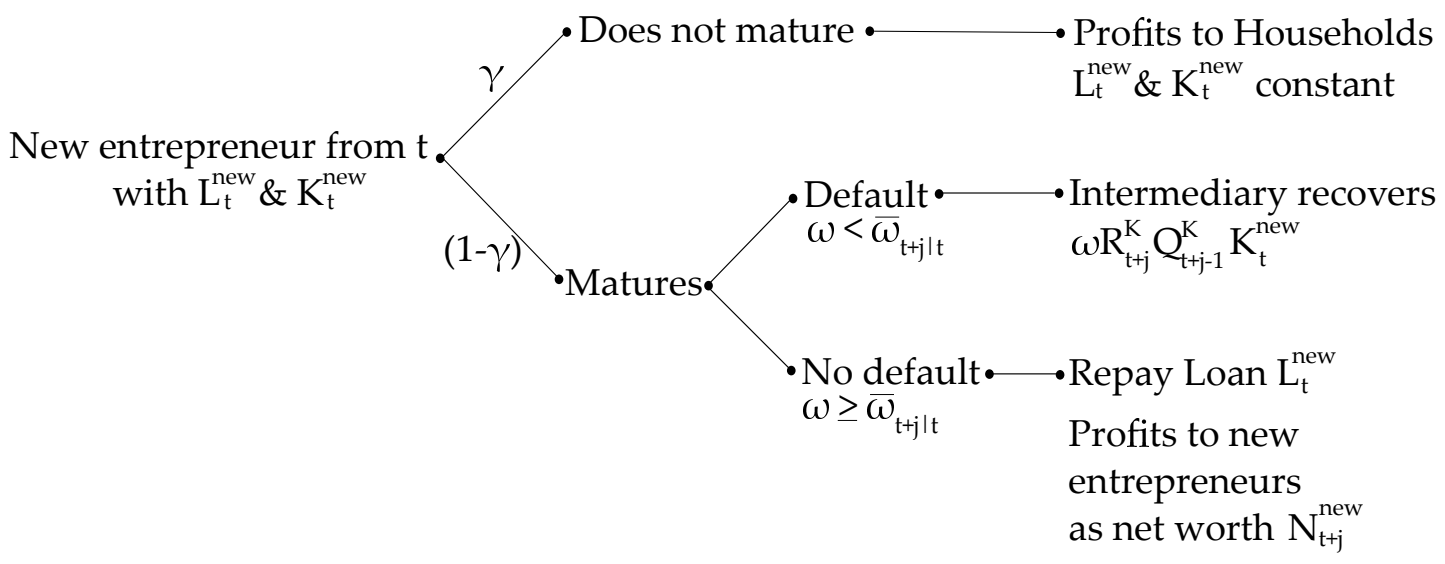

Figure 1: Long-term Debt with Stochastic Maturity and Default.

loans. Combining $N_{t}$ and $Q_{t} L_{t}^{n e w}$, the entrepreneur purchases $K_{t}^{n e w}$ units of capital at the price $Q_{t}^{K}$,

$$
Q_{t}^{K} K_{t}^{n e w}=N_{t}+Q_{t} L_{t}^{n e w}
$$

The face value of the loan is $L_{t}^{\text {new }}$ and the underlying collateral are the units of capital $K_{t}^{\text {new }}$. Next, I describe the evolution of an existing loan which is summarized graphically in Figure 1. Below, I then explain how the loan amount is determined when a loan is initially issued.

Stochastic Maturity. I introduce long-term debt similar to Calvo (1983)'s price rigidity. Each loan has an exogenous stochastic maturity. It matures with probability $1-\gamma$ in the next period. In some future period $t+j$, an entrepreneur with a nonmaturing loan receives the rental rate $r_{t+j}^{K}$ per unit of invested capital from the good producer. I assume that entrepreneurs transfer these profits lump-sum to households. This is a similar assumption as in, e.g., Christiano et al. (2005), and avoids to keep track of the distribution of accumulated profits for entrepreneurs with outstanding loans. In turn, households refurbish depreciated capital of nonmaturing loans through lump-sum transfers. The collateral $K_{t}^{n e w}$ of a loan that was issued in period $t$ therefore stays constant. This assumption is simply made for plausibility and does not impact any of the following results. It ensures that the capital of very old entrepreneurs does not vanish in the long run, but that they continue to invest.

When a loan that was originally issued in period $t$ matures in period $t+j$, then the entrepreneur's project ends as well. In that period, the entrepreneur receives the rental rate $r_{t+j}^{K}$ per unit of capital and sells the remaining capital for the price $Q_{t+j}^{K}$. Additionally, the profits are hit by an idiosyncratic shock $\omega$ as in Bernanke et al. (1999). This shock is drawn from a uniform distribution, $\omega \sim \mathcal{U}[0,2]$, independent across time and entrepreneurs, and normalized to have mean and width 
support unity. ${ }^{5}$ The total profits of a maturing loan are therefore

$$
\omega R_{t+j}^{K} Q_{t+j-1}^{K} K_{t}^{n e w}
$$

where $R_{t+j}^{K}=\frac{Q_{t+j}^{K}(1-\delta)+r_{t+j}^{K}}{Q_{t+j-1}^{K}}$ denotes the aggregate return on capital and $\delta$ is the rate of depreciation.

Default. When a loan matures, then the entrepreneur has to repay $L_{t}^{\text {new }}$ to the financial intermediary and there are no other payments to be made before maturity. However, the entrepreneur can choose to default on this obligation. As in Bernanke et al. (1999), an entrepreneur defaults if the face value of debt $L_{t}^{\text {new }}$ is larger than the entrepreneur's profits in (4). Or stated differently, if the idiosyncratic shock $\omega$ is lower than a particular threshold $\bar{\omega}_{t+j \mid t}$ in period $t+j$, where

$$
\bar{\omega}_{t+j \mid t} \equiv \frac{L_{t}^{n e w}}{R_{t+j}^{K} Q_{t+j-1}^{K} K_{t}^{n e w}}
$$

These default thresholds resemble the ones in Bernanke et al. (1999). However, they are not the same. Here, the default thresholds in period $t+j$ can differ across loan vintages. In particular, loans that were issued with higher loan-to-capital ratios $\frac{L_{t}^{\text {new }}}{K_{t}^{\text {new }}}$ will have higher default rates.

When an entrepreneur from period $t$ defaults in $t+j$, then the profits $\omega R_{t+j}^{K} Q_{t+j-1}^{K} K_{t}^{n e w}$ are recovered by the financial intermediary. If the entrepreneur does not default, then the remaining profits $\omega R_{t+j}^{K} Q_{t+j-1}^{K} K_{t}^{n e w}-L_{t}^{\text {new }}$ are equally split among new entrepreneurs in period $t+j$ and serve as their starting net worth, again as in Bernanke et al. (1999). The net worth $N_{t}$ of a new entrepreneur in period $t$ therefore consists of the profits of all entrepreneurs from any previous period that have a maturing loan and that do not default. At first sight, it may therefore seem necessary to keep track of all previous loan vintages. However, in Appendix A.2.1, I show that $N_{t}$ in fact follows the simple expression

$$
N_{t}=(1-\gamma)\left\{R_{t}^{K} Q_{t-1}^{K} K_{t-1}-L_{t-1}+\frac{1}{4} \frac{x_{t-1}}{R_{t}^{K} Q_{t-1}^{K}}\right\},
$$

where

$$
\begin{aligned}
& K_{t-1}=K_{t-1}^{n e w}+\gamma K_{t-2}, \\
& L_{t-1}=L_{t-1}^{\text {new }}+\gamma L_{t-2}, \\
& x_{t-1}=L_{t-1}^{\text {new }} \cdot \frac{L_{t-1}^{\text {new }}}{K_{t-1}^{\text {new }}}+\gamma x_{t-2},
\end{aligned}
$$

are three endogenous state variables that keep track of aggregate capital, loans, and their loan-tocapital ratios via the variable $x_{t}$, which can be interpreted as a 'loan risk indicator' ${ }^{6} N_{t}$ has an

\footnotetext{
${ }^{5}$ The mean unity ensures that the idiosyncratic shock does not change profits in the aggregate. The width support of one gives a zero lower bound on $\omega$. This implies that a fraction of loans always defaults in equilibrium since there will always be some loans with $\omega R_{t+j}^{K} Q_{t+j-1}^{K} K_{t}^{\text {new }}<L_{t}^{\text {new }}$ if $L_{t}^{\text {new }}>0$, the condition for default as explained in the text.

${ }^{6}$ An important assumption that allows for this aggregation is that the idiosyncratic shock $\omega$ follows a uniform dis-
} 
intuitive form. The first term in the curly bracket states that the higher current profits $R_{t}^{K} Q_{t-1}^{K}$ or previous capital $K_{t-1}$, the larger $N_{t}$. The second and third terms relate to the loan repayment. The larger overall borrowing $L_{t-1}$, the more to repay, lowering $N_{t}$. But the higher loan-to-capital ratios $\frac{L_{t-1}^{n e w 0}}{K_{t-1}^{n e w}}$ via $x_{t-1}$, the more default, lowering repayment and raising $N_{t}$.

Borrowing Constraint. New entrepreneurs consist of all entrepreneurs whose loans matured whether they defaulted or not - such that the total number of entrepreneurs stays constant. I assume that a new entrepreneur faces a borrowing constraint when taking up a loan. Similar to Kiyotaki and Moore (1997), the constraint demands that the face value of the loan has to be less than or equal to a fraction $\theta$ of the value of the assets,

$$
L_{t}^{\text {new }} \leq \theta Q_{t}^{K} K_{t}^{\text {new }}
$$

with $0<\theta<1$. I assume that this borrowing constraint binds continuously for all new entrepreneurs. The solution to a new entrepreneur's decision problem therefore has to satisfy the budget constraint (3) and the binding borrowing constraint (10). The description of the decision problem is omitted for brevity, but stated in Appendix A.1 for completeness. ${ }^{7}$ The binding borrowing constraint also implies a financial-accelerator mechanism that feeds back into future default rates. When $Q_{t}^{K}$ is high, then the borrowing constraint (10) relaxes, allowing for higher

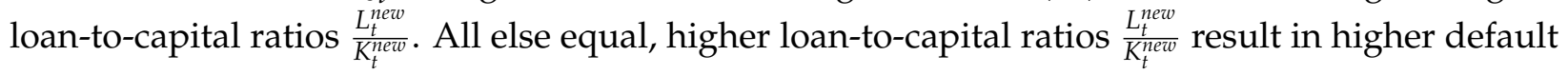
thresholds $\bar{\omega}_{t+j \mid t}$ in any future period $t+j$ according to (5).

\subsection{Financial Intermediaries}

There is a continuum of measure unity of identical financial intermediaries (or short, banks). Banks transform short-term and riskless debt $B_{t}^{F}$ into long-term and risky loans $L_{t}$. Banks invest in the whole market portfolio of loans $L_{t}$ as defined in (8). As in Kiyotaki and Moore (1997), I assume that banks have lower discount factors than households, denoted $\beta^{F}$. The bank values shareholders' flow utility of real dividends $D_{t}$ according to

$$
U^{F}\left(D_{t}\right)=\log \left(D_{t}\right)
$$

and chooses new short-term debt $B_{t}^{F}$, loans $L_{t}$, and dividends $D_{t}$ every period, taking prices and interest rates as given, to maximize expected lifetime shareholder utility

$$
E_{t}\left[\sum_{k=0}^{\infty}\left(\beta^{F}\right)^{k} U^{F}\left(D_{t+k}\right)\right]
$$

tribution, giving convenient expressions for cumulative distribution functions and partial expectations (see Appendix A.2 for details).

${ }^{7}$ Based on a simulation of the calibrated model below, the assumption of a binding borrowing constraint is confirmed since a new entrepreneur's value function is always increasing in the amount of borrowing. 
subject to the budget constraint

$$
D_{t}+Q_{t} L_{t}+B_{t-1}^{F} \widetilde{R}_{t} \leq B_{t}^{F}+R_{t}^{L} Q_{t-1} L_{t-1}+T_{t}^{F}
$$

where $\widetilde{R}_{t}$ denotes the interest rate on borrowing in short-term bonds. ${ }^{8}$ I assume that $\widetilde{R}_{t}$ is different from the interest rate on savings $R_{t}$. Following Schmitt-Grohe and Uribe (2003), $\widetilde{R}_{t}$ is debt-elastic with $\widetilde{R}_{t}=R_{t}+\psi B_{t-1}^{F}$ and $\psi>0$, and taken as given by the intermediary. This assumption has the sensible implication that the cost of borrowing is positively related to the stock of debt. Moreover, the debt-elastic interest rate ensures that the amount of borrowing is uniquely determined in a deterministic steady state and helps with the stationarity of the model. To ensure that these costs do not affect aggregate resources, I assume that the amount $\psi\left(B_{t-1}^{F}\right)^{2}$ is rebated to the intermediary as a lump-sum $T_{t}^{F}$ at time $t$. The calibration of $\psi$ has implications for the dynamics of bank leverage which I discuss in detail in Section 3.1.2.

Each period, a bank receives $R_{t}^{L} Q_{t-1}$ profits per loan, where $R_{t}^{L}$ is the return per loan in period $t$. Note that the profits per loan $R_{t}^{L} Q_{t-1}$ account for an infinite number of loan vintages, each with its own vintage-specific default threshold $\bar{\omega}_{t \mid t-j}=\frac{L_{t-j}^{\text {new }}}{R_{t}^{K} Q_{t-1}^{K} K_{t-j}^{n e w}}$ in period $t$. However, as shown in Appendix A.2.2, it is again not necessary to keep track of the whole distribution of loans. The profits per loan $R_{t}^{L} Q_{t-1}$ can be expressed as

$$
R_{t}^{L} Q_{t-1}=\gamma Q_{t}+(1-\gamma)\left(1-\frac{\bar{\omega}_{t}}{4}\right)
$$

where

$$
\bar{\omega}_{t}=\frac{x_{t-1}}{R_{t}^{K} Q_{t-1}^{K} L_{t-1}}=\sum_{k=1}^{\infty} \frac{\gamma^{k-1} L_{t-k}^{n e w}}{L_{t-1}} \bar{\omega}_{t \mid t-k},
$$

where $L_{t-1}$ and $x_{t-1}$ are the aggregate state variables defined in (8) and (9). Equations (13) and (14) again have intuitive interpretations. The first term in (13) captures profits from nonmatured loans and the second term gives the profits for maturing loans that are either repaid or default. The variable $\bar{\omega}_{t}$ is a weighted default threshold across all previous loan vintages. If the value of outstanding loans $Q_{t}$ is low or $\bar{\omega}_{t}$ is high, then profits per loan $R_{t}^{L} Q_{t-1}$ are low. In turn, $\bar{\omega}_{t}$ is high if either profits to capital $R_{t}^{K} Q_{t-1}^{K}$ are low or the weighted loan riskiness $\frac{x_{t-1}}{L_{t-1}}$ is high.

The distinction between maturing and nonmatured loans plays a key role for the likelihood and the severity of crises as explained below. Moreover, note that the model implies a rich time dependence of the intermediary's asset portfolio. It takes time to change the overall structure of the financial sector's balance sheet since a large fraction of loans does not mature each period. The above problem implies that banks never raise equity, that is, a negative amount of dividends. The

\footnotetext{
${ }^{8}$ The dividends can be interpreted as units of intermediaries' private consumption (see, e.g., Iacoviello, 2015).
} 
solution to the bank's problem is given by

$$
\begin{aligned}
\frac{1}{D_{t}} & =\beta^{F} \mathbb{E}_{t}\left[\frac{1}{D_{t+1}}\right] \widetilde{R}_{t+1}, \\
\frac{1}{D_{t}} & =\beta^{F} \mathbb{E}_{t}\left[\frac{R_{t+1}^{L}}{D_{t+1}}\right] .
\end{aligned}
$$

As explained below, an important variable is bank leverage $\frac{B_{t}^{F}}{Q_{t} L_{t}}$, which turns out to be the key indicator of financial instability in the model.

\subsection{Occasional Financial Crises}

Next, I introduce financial crises into the framework. Similar to Gertler and Kiyotaki (2015), a run equilibrium can occasionally emerge. Such an equilibrium can exist if households do not roll over their debt, acquire and sell the banks' assets, and the revenue is insufficient to cover any outstanding debt, resulting in bank insolvency. However, in contrast to Gertler and Kiyotaki (2015), I assume that banks try to prevent their bankruptcy by inefficiently liquidating a fraction of their long-term loans. The liquidated loans generate additional liquidity for banks and eliminate the possibility of a run. However, they are also costly for the economy, since productive capital is lost due to the early liquidation. ${ }^{9}$ In what follows, I will refer to such a situation as a financial crisis since it is characterized by a severe disruption of financial intermediation.

At the beginning of each period, after the realization of the technology shock $\epsilon_{t}^{a}$, households decide whether to roll over their lending to banks. If households do not roll over their debt, they acquire the bank's assets. I assume that households are less skilled in handling financial assets and can only sell a fraction $\kappa$ of the nonmatured loans, with $0<\kappa<1$. The situation is therefore one in which outsiders (households) are taking over a bankrupt bank. The parameter $\kappa$ stands in for the fact that such outsiders know less about the bank's assets, have to sell them quickly at once, and therefore receive less when selling the assets. Or put differently, long-term loans are illiquid from the households' point of view. ${ }^{10}$

A run equilibrium then opens up if the households' revenue from selling the bank's assets are smaller than the bank's outstanding debt, that is if

$$
B_{t-1}^{F} R_{t}>(1-\gamma)\left(1-\frac{\bar{\omega}_{t}}{4}\right) L_{t-1}+\kappa \gamma Q_{t} L_{t-1}
$$

where the first term on the right-hand side denotes profits from maturing loans and the second term gives profits from nonmatured loans, discounted by $\kappa$. Note that (17) can be satisfied even though the bank would be solvent if its assets were not liquidated, which is the case

\footnotetext{
${ }^{9} \mathrm{~A}$ costly early liquidation of investment is also present in Diamond and Dybvig (1983). However, here, loans are liquidated to avoid a run equilibrium, whereas in their framework an early liquidation occurs in the run equilibrium.

${ }^{10}$ The modeling of illiquidity based on the parameter $\kappa$ resembles the resaleability constraint in Kiyotaki and Moore (2012) and Del Negro et al. (2017), with the difference that it only applies to households here.
} 
if $B_{t-1}^{F} R_{t}<(1-\gamma)\left(1-\frac{\bar{\omega}_{t}}{4}\right) L_{t-1}+\gamma Q_{t} L_{t-1}$. The difference to (17) arises from the discounting by $\kappa$. In fact, in the simulation of the calibrated model below, banks are always solvent.

Condition (17) can be rewritten as

$$
\operatorname{Lev}_{t}^{*}=\frac{B_{t-1}^{F} R_{t}-(1-\gamma)\left(1-\frac{\bar{\omega}_{t}}{4}\right) L_{t-1}}{\gamma Q_{t} L_{t-1}}>\kappa,
$$

which shows that a run is possible whenever the bank's leverage at the beginning of a period Lev* is larger than a threshold $\kappa$. If (18) is satisfied, then it is individually rational for a household not to roll over its debt if it perceives that others will do the same. Hence, two equilibria are possible, one that features a bank run and results in bank failure, and one equilibrium without a run, and a sunspot would determine which one is realized. The economy can therefore occasionally transit into a region where a run equilibrium is possible and endogenous bank leverage determines whether that is the case according to condition (18).

If banks were to experience a run and fail, then their shareholders would not receive any dividends. Since shareholders are risk-averse, this implies an extremely high marginal utility in the bankruptcy state. Hence, if an opportunity would exist, banks would choose to avoid a run at all costs. I assume that banks have such an option available before it is determined whether the run equilibrium occurs, that is, before the sunspot realizes. Banks are able to liquidate a fraction of their loans by demanding entrepreneurs to repay their loan early. Even though this option turns out to be particularly costly, banks always choose it whenever (18) is satisfied to avoid a run. ${ }^{11}$

When loans are liquidated, then their underlying project ends. The associated capital cannot be used in production, resulting in an immediate fall in output. In addition, a fraction $(1-\mu)$, with $0<\mu<1$, of the withdrawn capital is lost due to the early liquidation of projects. When forced to repay its loan early, an entrepreneur from period $t-j$ can sell the remaining fraction $\mu$ of its capital and again receives an idiosyncratic shock $\omega \sim \mathcal{U}[0,2]$ on its revenues. As above, an entrepreneur defaults if the outstanding debt $L_{t-j}^{\text {new }}$ is larger than the proceeds $\omega Q_{t}^{K} \mu(1-\delta) K_{t-j}^{n \text { new }}$. Similar to (14), one can define a weighted default threshold across all vintages of loans that are liquidated early,

$$
\bar{\omega}_{t}^{*}=\frac{x_{t-1}}{Q_{t}^{K} \mu(1-\delta) L_{t-1}}
$$

and each unit of a liquidated loan then generates $\left(1-\frac{\bar{\omega}_{t}^{*}}{4}\right)$ as revenue (see again Appendix A.2.3 for the derivation). ${ }^{12}$

\footnotetext{
${ }^{11}$ A difference to Diamond and Dybvig (1983) and Gertler and Kiyotaki (2015) is that in their models, a sunspot selects the run equilibrium. Here, whenever the economy moves into the region where a run equilibrium could occur, then banks react immediately by liquidating loans and thereby eliminate the possibility of a run to avoid bankruptcy. The model therefore does not require a sunspot to select a crisis.

${ }^{12}$ I assume that the remaining profits of entrepreneurs are transferred lump-sum to households. The following results are much the same if these profits enter as starting net worth of new entrepreneurs.
} 
To avoid a run equilibrium when (18) is satisfied, all banks liquidate a fraction $\tau_{t}$ of their loans at the beginning of a period. The fraction $\tau_{t}$ closes the gap in (17), thereby eliminating the incentives for households to run, and is given by solving

$$
B_{t-1}^{F} R_{t}=L_{t-1}\left\{\tau_{t}\left(1-\frac{\bar{\omega}_{t}^{*}}{4}\right)+\left(1-\tau_{t}\right)\left((1-\gamma)\left(1-\frac{\bar{\omega}_{t}}{4}\right)+\kappa \gamma Q_{t}\right)\right\}
$$

Thus, both the occurrence of a crisis and the amount of liquidated loans are endogenous outcomes, according to (18) and (20). The frequency and the severity of crises in the model are therefore determined by these two conditions and the parameters $\kappa$ and $\mu$. The parameter $\kappa$ governs how often condition (18) is satisfied. The parameter $\mu$ determines the severity of crises by affecting the amount $\tau_{t}$ that needs to be liquidated. These parameters will be chosen to match the frequency and the severity of crises in the data.

For the simulation of the calibrated model below, I verify two necessary conditions. First, the revenue from liquidated loans is always larger than the payoff from long-term illiquid loans to households. This condition ensures that liquidating loans indeed closes the gap in (17) and eliminates the run equilibrium. Second, banks would prefer not to liquidate their loans unless they had to. That is, from the point of view of an individual bank that considers whether to liquidate its loans, taking prices as given and assuming that no one else liquidates, it is never optimal to end loans early. Hence, only if condition (18) is satisfied, banks choose to liquidate loans to avoid bankruptcy. ${ }^{13}$

Appendix A.3 states the equilibrium conditions that change during a crisis. For the simulation of the model, I assume that aggregate prices $Q_{t}, Q_{t}^{K}$, and $R_{t}^{K} Q_{t-1}^{K}$ that would realize absent a crisis enter in conditions (18) and (20). This assumption implies that when households and banks decide whether to run or liquidate their loans, they do not take into account that others will do the same. The assumption simplifies the analysis since one can avoid to keep track of realizations in the run equilibrium, which in the end never realizes, and always obtains a unique value for the fraction of loans that are liquidated.

\subsection{Capital Good Producer}

A representative capital good producer undertakes real investment. Given the price of capital $Q_{t}^{K}$, the capital good producer maximizes profits by choosing the economy-wide investment $I_{t}$

$$
\max _{I_{t}}\left\{Q_{t}^{K} I_{t}-\Phi\left(I_{t}, K_{t-1}\right)\right\}
$$

\footnotetext{
${ }^{13}$ Formally, the first condition is satisfied if $\left(1-\frac{\bar{\omega}_{t}^{*}}{4}\right)>(1-\gamma)\left(1-\frac{\bar{\omega}_{t}}{4}\right)+\kappa \gamma Q_{t}$. The second condition is satisfied if $\left(1-\frac{\bar{\omega}_{t}^{*}}{4}\right)<(1-\gamma)\left(1-\frac{\bar{\omega}_{t}}{4}\right)+\gamma Q_{t}$. The difference between the two conditions is due to the fact that $0<\kappa<1$.
} 
subject to

$$
\Phi\left(I_{t}, K_{t-1}\right)=I_{t}+\frac{\zeta}{2}\left(\frac{I_{t}-\delta K_{t-1}}{K_{t-1}}\right)^{2} K_{t-1}
$$

implying quadratic adjustment costs. The above problem gives the optimality condition

$$
Q_{t}^{K}=1+\zeta\left(\frac{I_{t}}{K_{t-1}}-\delta\right)
$$

and aggregate capital evolves according to

$$
K_{t}=I_{t}+(1-\delta) K_{t-1}
$$

Resource Constraint. Total output is divided between household and intermediary consumption, investment, and the costs of adjusting capital,

$$
Y_{t}=C_{t}+D_{t}+\Phi\left(I_{t}, K_{t-1}\right)
$$

Finally, short-term bonds are in zero net supply, such that household saving in bonds $\left(-B_{t}^{H}\right)$ is

\begin{tabular}{|c|c|c|c|c|}
\hline Agents & Description & Parameter & Value & Target / Source \\
\hline \multirow[t]{5}{*}{ Producers } & St. dev. technology & $\sigma_{a}$ & $0.68 \%$ & TFP series (Fernald, 2014) \\
\hline & Persist. technology & $\rho_{a}$ & 0.93 & TFP series (Fernald, 2014) \\
\hline & Effective capital share & $\alpha$ & 0.3 & Literature \\
\hline & Depreciation rate & $\delta$ & 0.025 & Literature \\
\hline & Capital adjustment cost & $\zeta$ & 3 & He and Krishnamurthy (2014) \\
\hline \multirow[t]{3}{*}{ Households } & Discount factor & $\beta^{H}$ & 0.99 & Literature \\
\hline & Inv. Frisch elasticity & $\phi$ & 0.5 & Literature \\
\hline & Rel. utility weight & $\chi$ & 1.59 & Normalization: $H=1$ in steady state \\
\hline \multirow[t]{2}{*}{ Entrepreneurs } & Borrowing constraint & $\theta$ & 0.15 & Annual Default Rate 3\% \\
\hline & Stochastic maturity & $\gamma$ & 0.9 & Mat. Mismatch U.S. Comm. Banks \\
\hline \multirow[t]{4}{*}{ Banks } & Discount factor & $\beta^{F}$ & 0.985 & Annual Intermediation Cost: $2 \%$ \\
\hline & Premium for borrowing & $\psi$ & 0.0049 & Impulse Response Matching / Cyclicality \\
\hline & Crisis threshold & $\kappa$ & 0.51 & Frequency Crises: $2.14 \%-4 \%$ \\
\hline & Recovered capital & $\mu$ & 0.21 & Severity Crises $\frac{\Delta G D P \text { Fin.Rec. }}{\Delta G D P \text { Ave.Rec. }}: 1.31-1.56$ \\
\hline
\end{tabular}
equal to intermediary borrowing $\left(B_{t}^{F}\right)$. All equilibrium conditions of the model are listed in Appendix A.3. Next, I analyze this model in detail.

\section{Calibration}

Table 1: Calibration of Structural Parameters. 
The model is calibrated to a quarterly frequency for the U.S. economy. The calibration of all structural parameters is shown in Table 1. The persistence and standard deviation of the technology shock are obtained by estimating an AR(1) process to the linearly detrended logarithm of the total factor productivity (TFP) series by Fernald (2014) for the second half of the post-WWII period (1980 Q1-2016 Q4), giving $\rho_{a}=0.93$ and $\sigma_{a}=0.68 \%$. These numbers are close to estimates based on typical business cycle models (e.g., Smets and Wouters, 2007). The capital share $\alpha$ is set to 0.3.

Further, I choose $\beta^{H}=0.99$, giving an annualized real interest rate of around $4 \%$ in steady state. I calibrate $\beta^{F}=0.985$ to give an annualized excess return of intermediary assets over liabilities of $2 \%$ in steady state - in line with the cost of intermediation for the U.S. documented in Philippon (2015). The depreciation rate $\delta$ is set to the standard value of 0.025 and I follow He and Krishnamurthy (2014) in calibrating the capital adjustment cost parameter $\zeta$ to 3 . The inverse Frisch elasticity of labor supply $\phi$ is set to 0.5 and the relative utility weight $\chi$ is chosen to normalize labor supply to one in steady state.

The parameter $\gamma$ determines the maturity mismatch of financial intermediaries. Based on Call Reports for U.S. commercial banks, I find that the average maturity of assets is around 3.49 years, and that of liabilities is around 0.35 years, with a ratio between the two of 9.97 (see Appendix A.4.3 for details). I normalize the maturity of short-term debt to one quarter and choose $\gamma$ to match an average maturity of long-term debt of 9.97 quarters, giving $\gamma=0.9$. The parameter $\theta$ determines how tight the entrepreneurs' borrowing constraint (10) is. I pick $\theta$ to give an annualized default rate of around 3\% in steady state (Bernanke et al., 1999). Hence, the calibration matches closely the maturity mismatch of intermediaries and their exposure to credit risk in the data. Next, I discuss the calibration of the parameters $\psi, \kappa$, and $\mu$.

\subsection{Leverage}

Condition (18) shows that the economy transits into the region where a run is possible whenever bank leverage at the beginning of a period $L e v_{t}^{*}$ is larger than the threshold $\kappa$. If leverage rises, then the economy moves closer to this cliff, and is more likely to experience a crisis. Hence, the cyclicality of leverage and its response to shocks determines whether the model is able to replicate the fact that crises occur out of credit-fueled boom periods. I therefore obtain empirical evidence along these two dimensions and match the model to this evidence.

\subsubsection{Leverage in the Data}

Starting with the work of Adrian and Shin (2010), the cyclicality of financial institutions' leverage has been discussed as a potential indicator of the financial sector's procyclical risk-taking. Adrian and Shin $(2010,2014)$ show that leverage of certain financial institutions is procyclical since changes in book leverage are positively correlated with changes in the overall size of banks' balance sheets, again measured at book values. Here, I use a different definition of cyclicality that naturally fits the business cycle setup of the model. As Cooley and Prescott (1995), I term leverage 
to be procyclical if the cyclical component of output and leverage are positively correlated. In Appendix A.5.8, I show that the model also replicates the evidence in Adrian and Shin (2014) (see also Nuño and Thomas (2017) and Begenau et al. (2018) for additional evidence).

In what follows, I focus on the model's measure of leverage $\frac{B_{t}^{F}}{Q_{t} L_{t}}$ as opposed to beginning-ofperiod leverage $L e v_{t}^{*}$ since the two behave very similarly. Note that $\frac{B_{t}^{F}}{Q_{t} L_{t}}$ is defined at market values. To compare this measure of leverage to the data, I derive an empirical proxy for the U.S. financial sector's market leverage by combining equity and balance sheet data for commercial and investment banks (see Appendix A.4.1 for details). In Appendix A.5.8, I also show how a measure of book leverage in the model compares to the data. Given the series of market leverage, I compute the correlation of the cyclical component of intermediary market leverage and a monthly measure of economic activity. I find that market leverage is mildly procyclical, with a correlation coefficient of $0.04{ }^{14}$ As shown below, such a small positive correlation is in fact enough for the model to generate crises out of boom periods when the model is matched to this evidence.
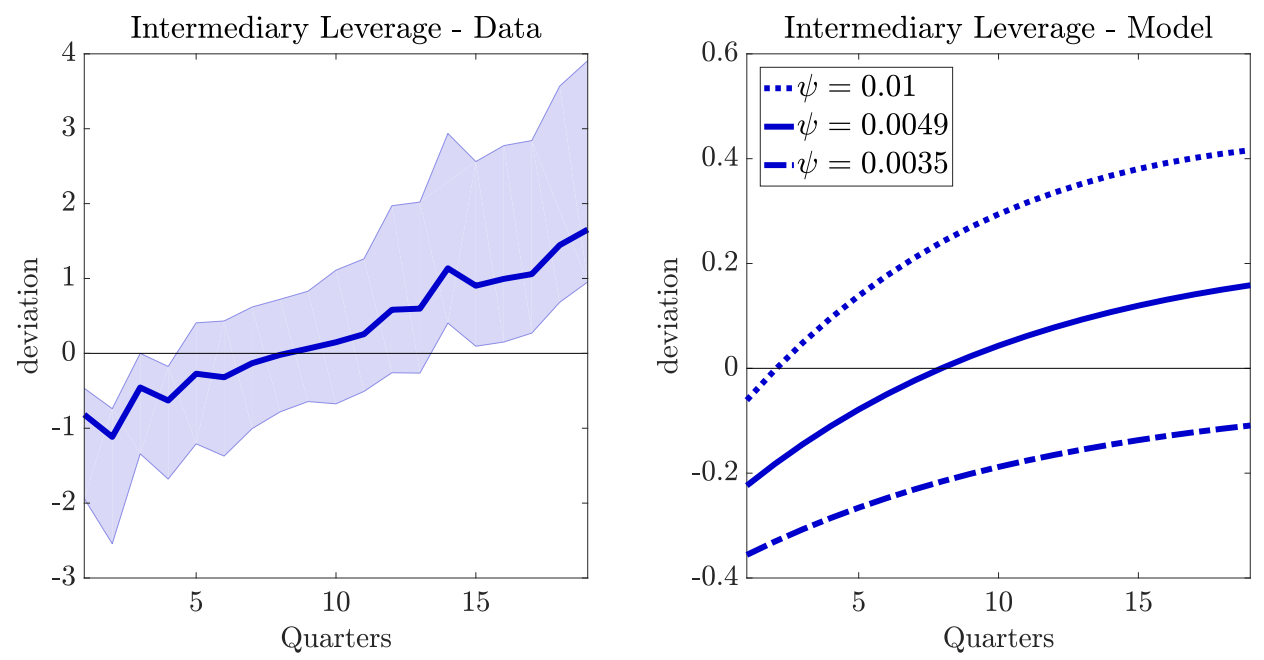

Figure 2: Impulse Response of Market Leverage - Data vs. Model. Left: Impulse response of U.S. financial sector's market leverage to a one-standard-deviation positive technology shock, $95 \%$ confidence bands are shown. Right: Impulse response of intermediary leverage $\frac{B_{t}}{Q_{t} L_{t}}$ to a one-standard-deviation positive technology shock, starting from the deterministic steady state. The correlation of output $Y_{t}$ and leverage $\frac{B_{t}}{Q_{t} L_{t}}$ is 0.52 for $\psi=0.01,0.07$ for $\psi=0.0049$, and -0.73 for $\psi=0.0035$, respectively. The steady-state levels of intermediary leverage $\frac{B_{t}}{Q_{t} L_{t}}$ are 0.26 for $\psi=0.01,0.54$ for $\psi=0.0049$, and 0.75 for $\psi=0.0035$.

In addition to the cyclicality of leverage, I also obtain empirical evidence on the response of leverage to a technology shock, the only aggregate shock in the model. To this end, I use the residual

\footnotetext{
${ }^{14}$ I use a monthly measure of economic activity to capture the correlation with higher-frequency movements in asset prices, as the ones that drive market leverage. Real industrial production is used as a proxy for economic activity at a monthly frequency. However, the results for real GDP at a quarterly frequency are much the same. The logarithm of industrial production and leverage are detrended using a Hodrick-Prescott filter (a smoothing parameter of 129,600 for monthly data is applied following Ravn and Uhlig, 2002). The results are not specific to using this filter and its decomposition. In particular, I find that the results are similar when using a Baxter-King Filter that associates the cycle with frequencies between two months and eight years, i.e. conventional business cycle frequencies, or longerterm cycles up to 12 years that may better capture so-called financial cycles. The sample is 1980 M1-2007 M12. See Appendix A.5.8 for additional details.
} 
from the estimated AR(1) process of the TFP series as a proxy for the series of structural technology shocks, denoted $\hat{\epsilon}_{t}^{a}$, based on the sample 1980 Q1-2016 Q4. Using local projections (Jordà, 2005) and the generalized method of moments (GMM), I simultaneously estimate ${ }^{15}$

$$
\begin{aligned}
\log (\text { TFP })_{t} & =\rho_{a} \log (\text { TFP })_{t-1}+\hat{\epsilon}_{t}^{a} \\
\operatorname{Lev}_{t+k-1}-\operatorname{Lev}_{t-2} & =\beta_{0}^{k}+\beta_{1}^{k} \hat{\epsilon}_{t}^{a}+e_{t+k} \text { for } k \in\{1,2, \ldots, 19\}
\end{aligned}
$$

where $L e v_{t}$ denotes the market leverage of the intermediary sector at time $t$ and $\beta_{1}^{k}$ gives the reaction of leverage to a technology shock at horizon $k$. The left graph in Figure 2 shows the results. Following a positive technology shock, leverage initially declines and then rises over time, turning positive after a few quarters.

\subsubsection{Leverage in the Model}

While typical macro models struggle to generate procyclical leverage, the model here can generate such a pattern. That is because banks expand their balance sheets in response to positive technology shocks, as further shown in the next section. They acquire additional debt from households which may outweigh the rise in the value and the amount of loans, depending on the calibration. In fact, the model is able to replicate the empirical impulse response of intermediary leverage on the left of Figure 2, while matching the cyclicality of leverage in the data at the same time.

Given a calibration for the households' and the banks' discount factors, $\beta^{H}$ and $\beta^{F}$, the key parameter that determines the behavior of leverage is the borrowing cost parameter $\psi \cdot{ }^{16}$ Based on the calibration of the model discussed so far, the right graph in Figure 2 shows impulse responses for intermediary leverage $\frac{B_{t}^{F}}{Q_{t} L_{t}}$ for different values of $\psi$, holding constant all other parameters. The initial response of leverage varies with $\psi$. That is because $\psi$ determines the steady-state level of leverage, which in turn affects the response of leverage. The lower $\psi$, the higher the initial level of leverage, and the more likely that leverage falls after a positive shock, since the increase in asset prices will dominate any change in liabilities or assets. ${ }^{17}$ I find that $\psi=0.0049$ matches well the empirical impulse response and gives a correlation with output of 0.07 that is close to the empirical counterpart of 0.04 .

One caveat is that the calibration results in an asset-to-equity ratio of around 2 for intermediaries in steady state which is lower than in the data. This implies that the model also only generates small quantitative variations in leverage as visible by comparing the left and the right graph in

\footnotetext{
${ }^{15}$ The system is estimated jointly to avoid a generated regressor problem (Newey and McFadden, 1994). GMM requires the choice of a weighting matrix and instruments. Regarding the weighting matrix, a Newey-West correction for heteroskedasticity and autocorrelation is used. The instruments are the regressors in (23) and (24). I consider impulse responses with respect to leverage at time $t-2$ to account for potential news shocks at time $t-1$.

${ }^{16}$ Since I calibrate the difference between $\beta^{H}$ and $\beta^{F}$ to match the cost of intermediation, I choose $\psi$ to match moments of intermediary leverage in the data. Alternatively, one could find a calibration for $\psi$ first, and then choose the difference between $\beta^{H}$ and $\beta^{F}$ to match the evidence.

${ }^{17}$ These differences cannot be explained by the different responses of $B_{t}^{F}, Q_{t}$, or $L_{t}$ on impact which behave very similar across different calibrations of $\psi$ as shown in Figure 14 in Appendix A.5.1, but are instead driven by the different steady-state levels of leverage.
} 
Figure 2. The model can additionally match the level of leverage when allowing for heterogeneous risk-aversion coefficients. For simplicity, I assume that both agents have log-(GHH)-utility since it is not important for the analysis to match the exact level of leverage, as long as the threshold $\kappa$ is chosen to match the frequency of crises as explained in the next section. What is relevant for the upcoming results is that the model matches the procyclicality and the impulse response of leverage to a technology shock. Both determine the leveraging behavior over the business cycle and out of what type of episodes an economy typically transits into a financial crisis.

\subsection{Frequency and Severity of Financial Crises}

Based on the macrohistory data by Jordà et al. (2017) for advanced economies from 1870 to 2013, crises occur around $4 \%$ of the time and $2.14 \%$ when restricting the sample to the post-WWII period (see Appendix A.4.2 for details). I pick $\kappa$ such that the frequency of crises lies within this range (2.4\%). Based on the data by Jordà et al. (2017) for the two mentioned samples, the change in real GDP from peak to trough is between $31 \%$ and $56 \%$ larger during financial recessions $(-5.31 \%$ for $1870-2013$ and $-3.85 \%$ for the post-WWII period) than during average recessions $(-4.05 \%$ and $-2.47 \%$, respectively). I choose a conservative calibration for $\mu$, such that the severity between financial and average recessions in a simulation of the model lies around the lower end of these empirical targets (34\%). ${ }^{18}$ Below, I also show the results for a lower value of $\mu$.

I obtain a nonlinear global solution of the model using a projection algorithm that is described in Appendix A.3.1. The solution algorithm treats crises as unanticipated events. That is, when making their decisions, agents do not take into account that a crisis may occur in the future due to realizations of future shocks. Section 4.5.2 and Appendix A.5.9 describe a slightly modified version of the model that relaxes this assumption. The stochastic steady state resulting from this calibration is given in Appendix A.5.2. Before analyzing the behavior of the economy around crises, I gather some intuition on the effects of a technology shock.

\section{Quantitative Analysis}

\subsection{Impulse Responses}

Figures 3, 4, and 5 show impulse responses to a one-standard-deviation positive technology shock, starting from the stochastic steady state of the model. For these responses, a financial crisis does not occur because intermediary leverage is sufficiently low. Following a positive technology shock, output $Y_{t}$, consumption $C_{t}$, dividends $D_{t}$, labor $H_{t}$, and capital $K_{t}$ all increase.

\footnotetext{
${ }^{18}$ In the model simulation, I determine business cycle peaks and troughs according to the definition that is used by the UK and members of the European Union, among others. A business cycle peak is the quarter before output falls for two consecutive quarters. Following a peak, a trough is reached before output grows again. I further restrict recessions to occur $14.59 \%$ of the time in a simulation of the model (as in the macrohistory data by Jordà et al., 2017) by choosing the ones with larger falls in output from peak to trough. If a financial crisis occurs between a peak and a trough, then such an episode is termed a financial recession. All remaining recessions are called nonfinancial recessions.
} 

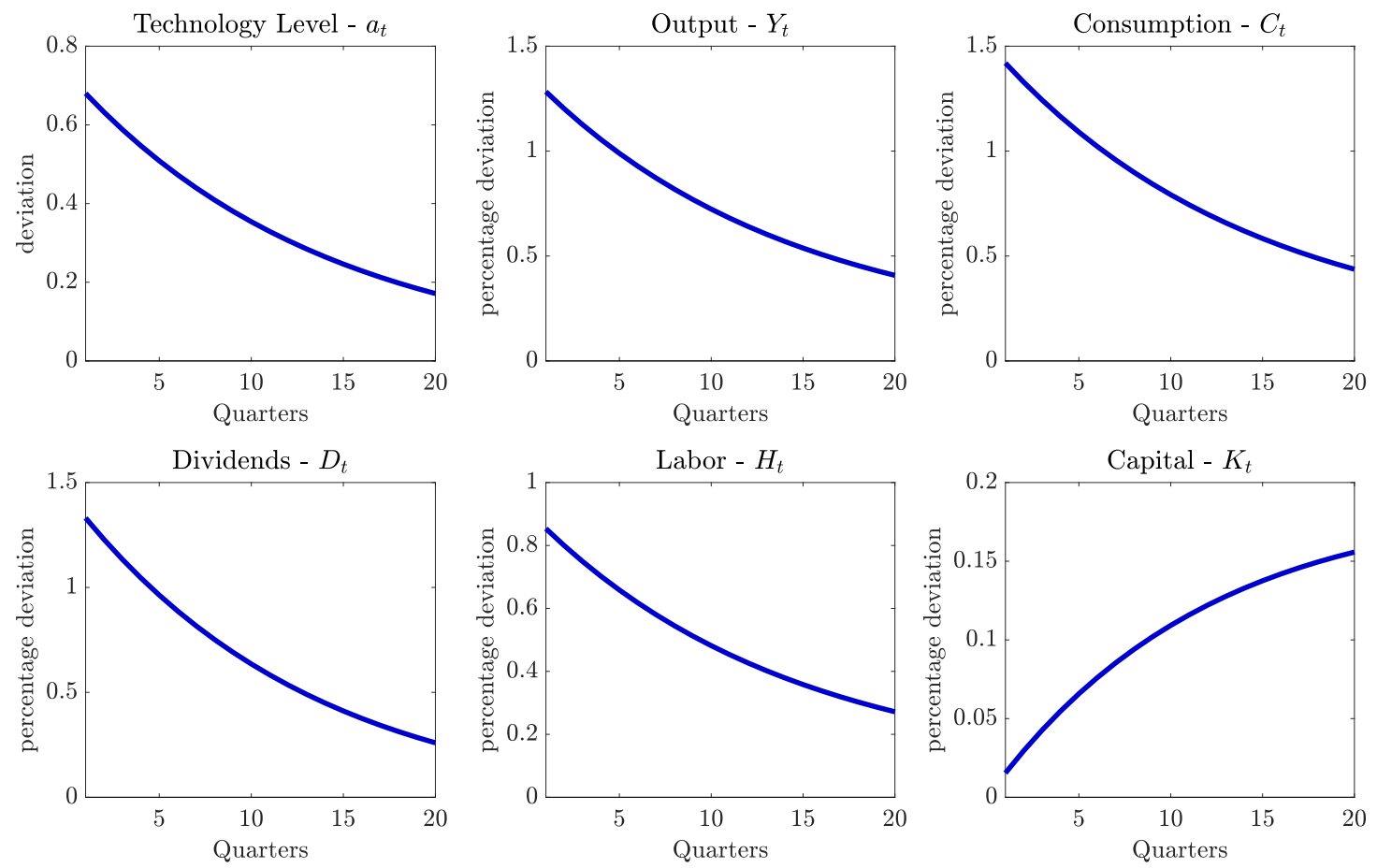

Figure 3: Impulse Responses. Impulse responses to a one-standard-deviation positive technology shock, starting at the stochastic steady state of the model, all deviations are multiplied by 100.
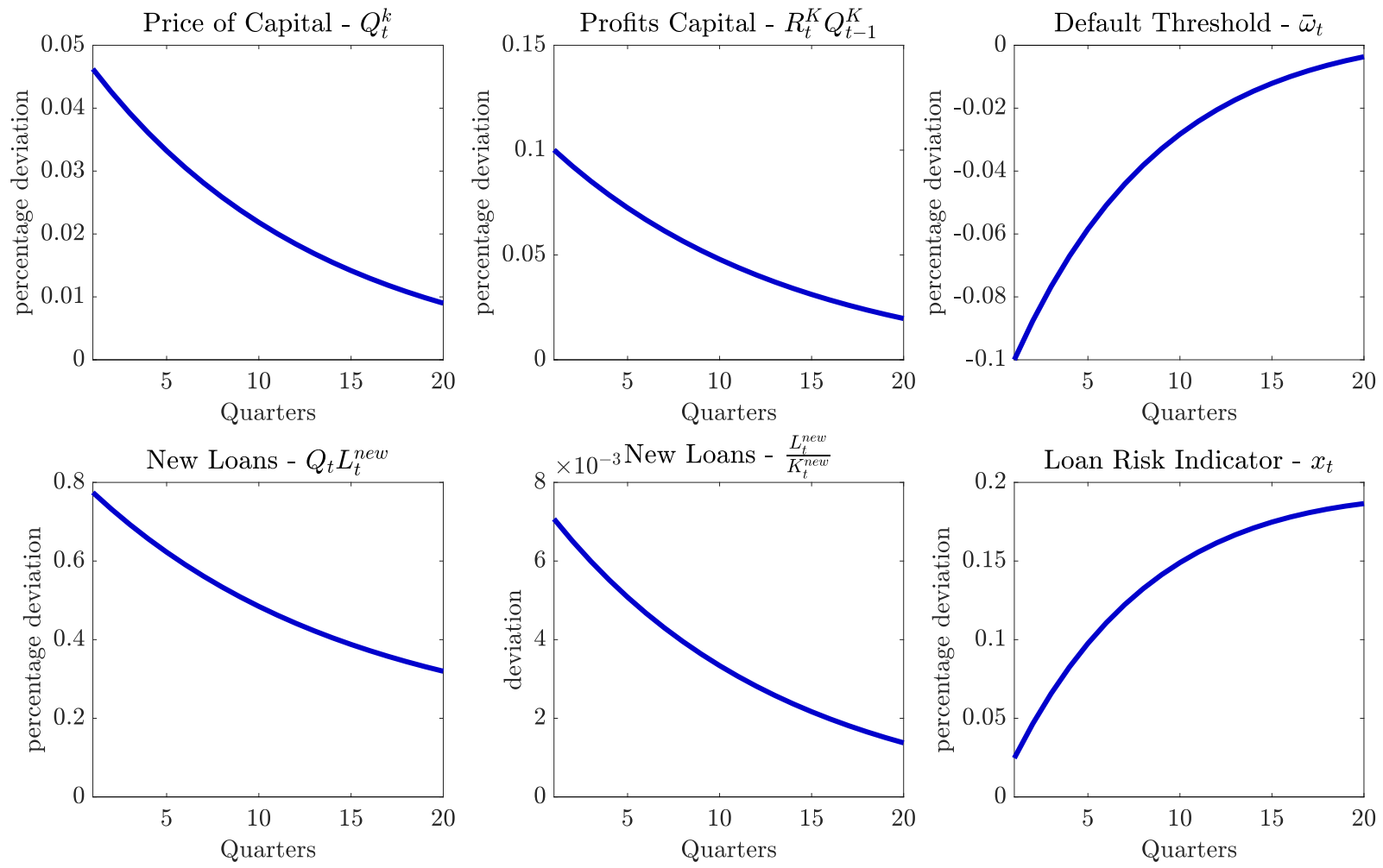

Figure 4: Impulse Responses. Impulse responses to a one-standard-deviation positive technology shock, starting at the stochastic steady state of the model, all deviations are multiplied by 100. 
In addition, the price of capital $Q_{t}^{K}$ and profits to capital $R_{t}^{K} Q_{t-1}^{K}$ rise, which lowers the probability of default of all outstanding loans as indicated by the weighted default threshold $\bar{\omega}_{t}$ (see equation 14). New entrepreneurs' net worth $N_{t}$ rises (see equation 6), allowing them to raise their borrowing $Q_{t} L_{t}^{\text {new }}$ in absolute terms. Moreover, a higher price of capital $Q_{t}^{K}$ additionally allows entrepreneurs to increase their borrowing relative to their units of collateral $\frac{L_{t}^{n e w}}{K_{t}^{\text {new }}}$, as determined by their borrowing constraint (see equation 10). The loan risk indicator $x_{t}$ therefore increases (see equation 9).
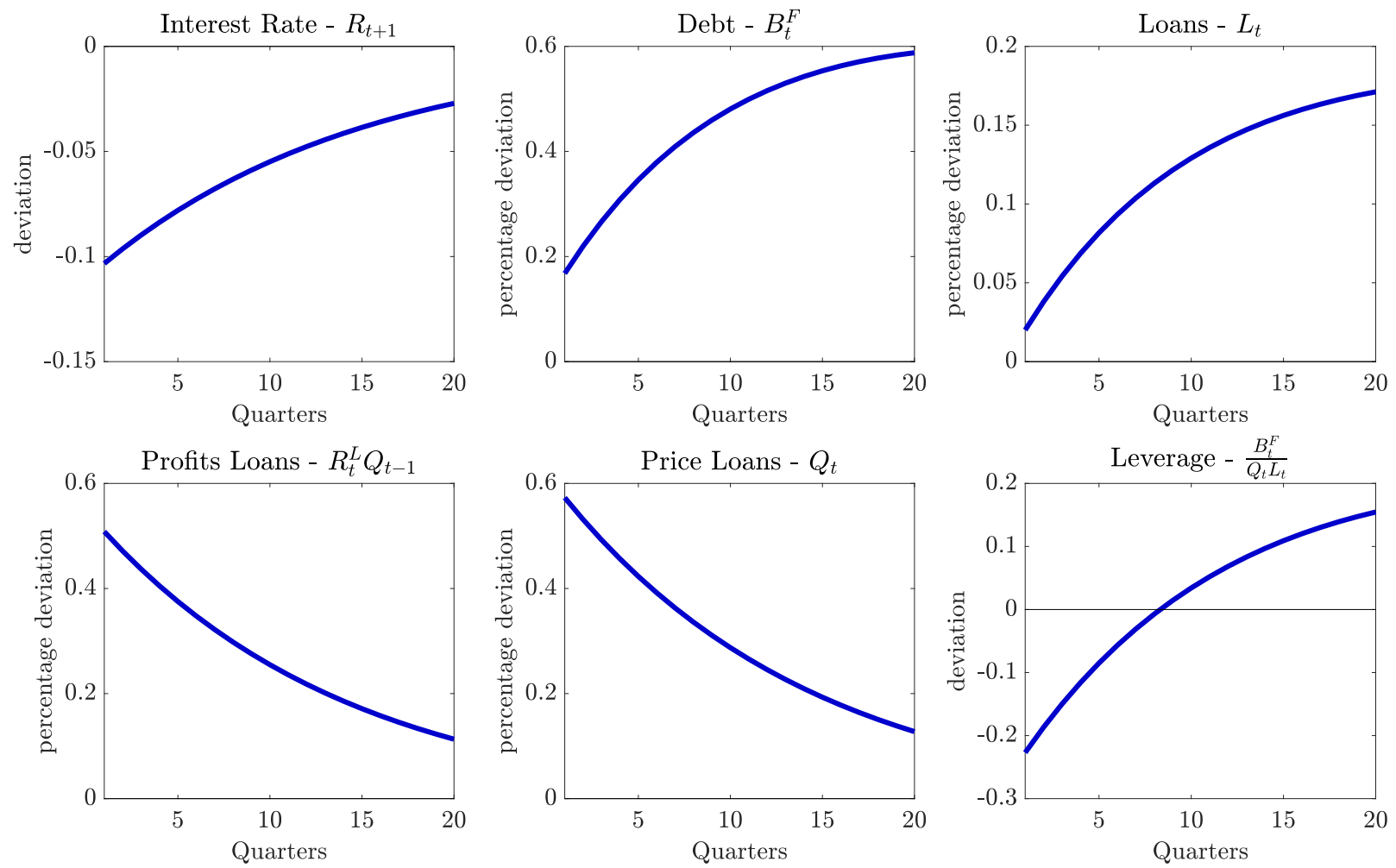

Figure 5: Impulse Responses. Impulse responses to a one-standard-deviation positive technology shock, starting at the stochastic steady state of the model, all deviations are multiplied by 100.

Following a positive technology shock, households want to smooth their consumption and increase their savings, leading to a fall in the real interest rate $R_{t+1}$. At the same time, intermediaries expand their balance sheets. They take on more debt $B_{t}^{F}$ to increase new lending, and the overall stock of loans $L_{t}$ therefore rises. In addition, the profitability of loans $R_{t}^{L} Q_{t-1}$ increases, largely due to the rise in the value of all outstanding loans $Q_{t}$. Intermediary market leverage $\frac{B_{t}^{F}}{Q_{t} L_{t}}$ initially decreases since the entire loan portfolio rises in value. Over time, intermediaries continue to take on more debt to issue new loans, raising leverage. The response of bank leverage therefore roughly matches the empirical counterpart in Figure 2 . The auxiliary variable $L e v_{t}^{*}$, as defined in (18), behaves very similarly and the response is therefore omitted for brevity. 


\subsection{Typical Financial Crises}

From time to time, financial intermediaries face the threat of a bank run and inefficiently liquidate a fraction of their existing loans to avoid a run as described in Section 2.5. Such a situation defines a financial crisis in the model and can in principle break out at any time if an adverse technology shock is sufficiently large. Hence, nothing in the model restricts crises to occur out of booms or recessions. However, financial crises are more likely to happen if certain conditions are met. To understand these conditions, I analyze the typical behavior of the model around crises. First, I simulate the model for 500,000 periods. Then, I collect the sequences of endogenous variables and shocks in a window of 30 quarters before and 20 quarters after a crisis. Figures 6, 7, and 8 plot period-by-period the median, $33^{\text {rd }}$, and $66^{\text {th }}$ percentiles across these sequences for each variable with respect to windows in which only one financial crisis occurs.
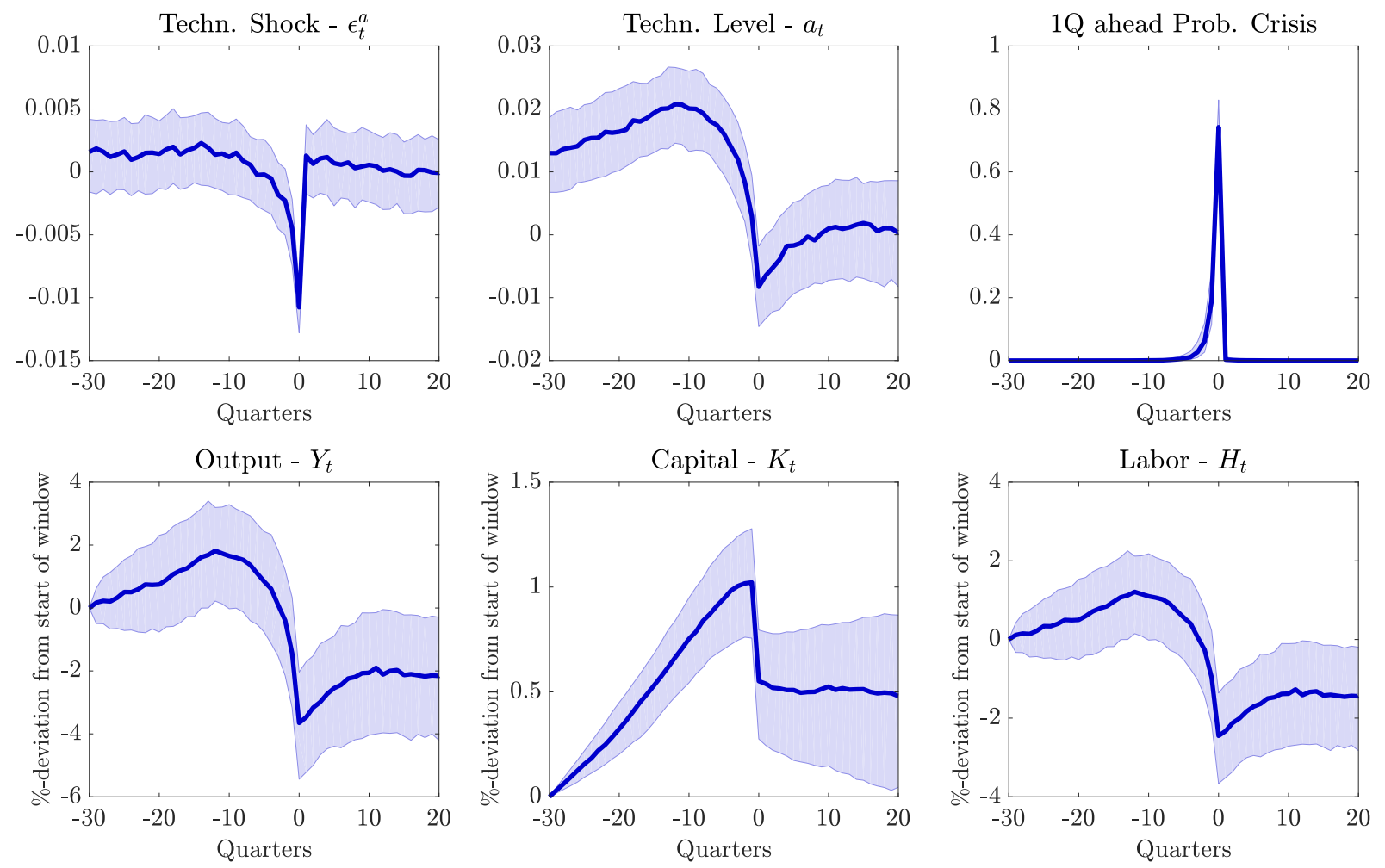

Figure 6: Typical Financial Crises. Event window around financial crisis at Quarter $=0$. Based on a simulation of 500, 000 periods. Median, $33^{\text {rd }}$, and $66^{\text {th }}$ percentiles are shown.

Based on the simulation of the model, crises are rare events. They occur around $2.4 \%$ of the time, as targeted by the calibration (see Section 3.2). In what follows, the median path for each variable is referred to as the "typical" path around a crisis. The first row in Figure 6 shows the typical behavior of the technology shock $\epsilon_{t}^{a}$ and the technology level $a_{t}$. A buildup period leading to a crisis is characterized by an elevated technology level, which reverses within a one-year window before a crisis. The median shock that triggers a crisis is a negative 1.58 standard deviation shock. Typical financial crises therefore occur out of prolonged productivity booms, followed by subsequent slowdowns, and the model does not need to rely on extremely large adverse shocks to initiate 
financial crises, one of the targets that I set out to match in the beginning.

The fall in productivity around the outbreak of a crisis is also consistent with the data, as shown in Paul (2018) and replicated in Figure 13 in Appendix A.4.2. However, while the productivity slowdown eventually triggers a crisis, it is the prior productivity boom that is essential for the buildup of risk, which can be illustrated with the following two exercises. First, when starting the economy from its stochastic steady state and feeding it with only the negative median-productivity-shocks that are shown in Figure 6, then the economy does not experience a crisis and the probability that a crisis will occur in the next quarter remains at its long-run average. Second, one can also ask how large a single shock has to be to move the economy from its steady state immediately into a crisis. In absolute size, such a negative shock has to be larger than 11.34 standard deviations, which has an unconditional probability that is close to zero. These two exercises show that the positive productivity shocks beforehand are key to move the economy closer to a crisis.

Output $Y_{t}$, capital $K_{t}$, and hours $H_{t}$ all increase in the buildup period and decrease sharply around the outbreak of a crisis. While the relative severity of financial crisis recessions to average recessions is one of the calibration targets (see Section 3.2), the model also matches the strength of each type of recession separately. $Y_{t}$ typically falls by $5.2 \%$ from peak to trough during a financial crisis, which is close to the empirical estimate of $5.31 \%$ based on the 1870-2013 sample of the macrohistory data described in Section 3.2. The corresponding moment for average recessions is $-3.88 \%$, which is again close to the historical experience of $-4.05 \%$ for the same sample. ${ }^{19}$ Thus, financial crisis recessions are severe events, much more so than average recessions.

Financial crises are "credit booms gone bust". During the boom, more new loans $Q_{t} L_{t}^{\text {new }}$ are issued and the overall stock of loans $L_{t}$ therefore increases. During the crisis, $L_{t}$ drops abruptly because banks liquidate a fraction of their loan portfolio to generate liquidity and thereby prevent a bank run. The model therefore matches another target that I set out in the introduction: crises occur out of prolonged credit-fueled boom periods.

\footnotetext{
${ }^{19}$ For this comparison, one should keep in mind that the data incorporates a trend and is not detrended, whereas the model does not consider trend growth. That is also the reason why I choose the relative severity of recessions as a calibration target in Section 3.2 as opposed to the absolute changes during recessions.
} 

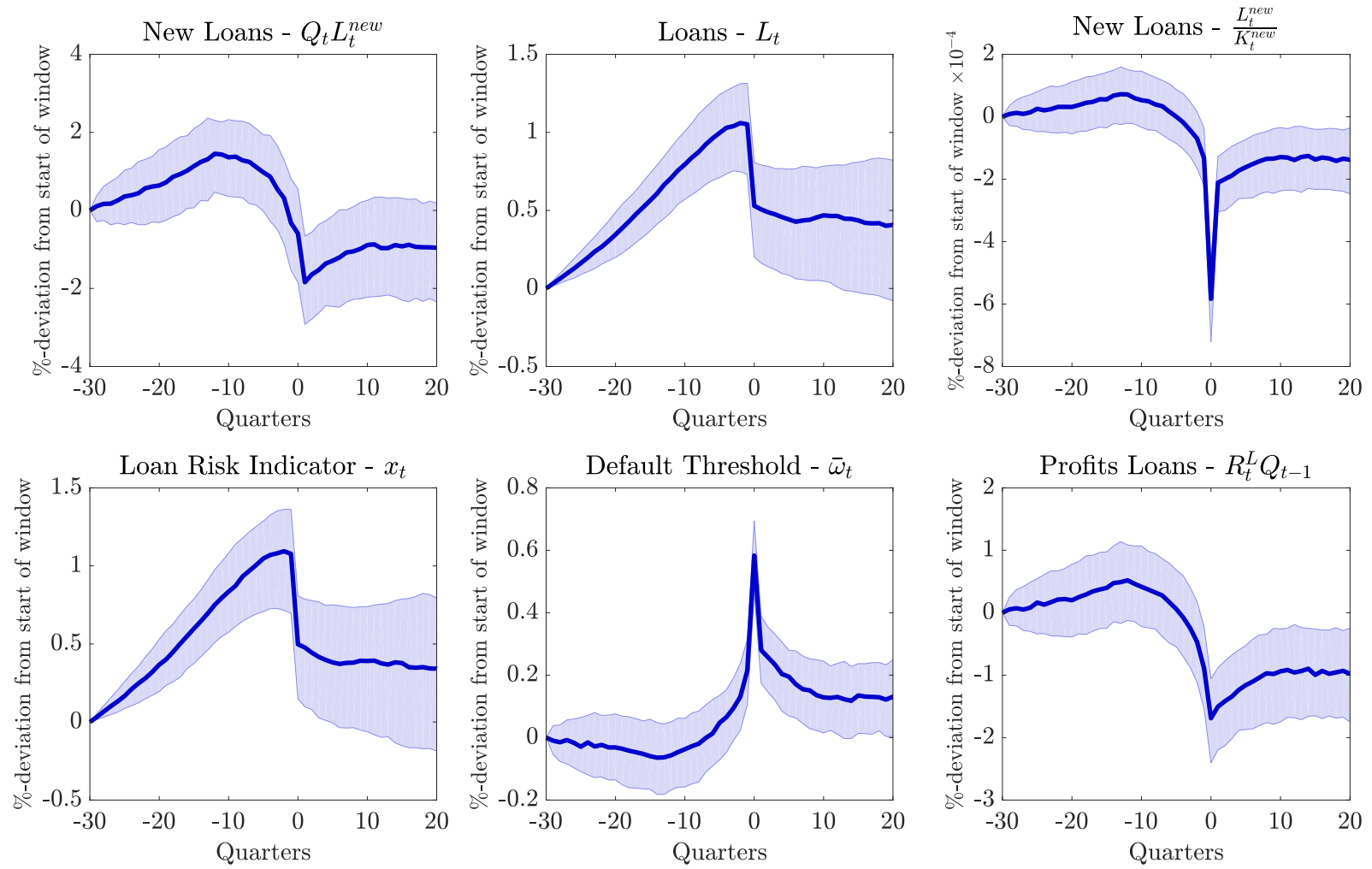

Figure 7: Typical Financial Crises. Event window around financial crisis at Quarter $=0$. Based on a simulation of 500, 000 periods. Median, $33^{\text {rd }}$, and $66^{\text {th }}$ percentiles are shown.

During the boom, not only the amount of loans but also their riskiness changes. Loans with higher loan-to-capital ratios $\frac{L_{t}^{\text {new }}}{K_{t}^{\text {new }}}$ are issued and the loan risk indicator $x_{t}$ increases as a result. The model is therefore able to match the empirical evidence by Demyanyk and Hemert (2011) and Justiniano et al. (2017). They show that loans that were issued closer to the 2007-09 financial crisis had higher default rates ex-post. That is also the case in the model since the default threshold in period $t$ for vintage $t-j$ is given by $\bar{\omega}_{t \mid t-j}=\frac{L_{t-j}^{\text {new }}}{R_{t}^{K} Q_{t-1}^{K} K_{t-j}^{n e w}}$ and $\bar{\omega}_{t \mid t-j}$ is higher for loans with higher $\frac{L_{t-j}^{\text {new }}}{K_{t-j}^{\text {new }}}$ ratios.

Banks' balance sheets and decisions are key to understand how crises arise. During the boom, banks' profits $R_{t}^{L} Q_{t-1}$ increase and they pay out more dividends $D_{t}$. Entrepreneurs are less likely to default, $\bar{\omega}_{t}$ declines, which makes it more attractive for banks to increase their loan issuance. The expansion of banks' balance sheets is financed by taking on additional debt $B_{t}^{F}$, leading to a buildup of leverage $\frac{B_{t}^{F}}{Q_{t} L_{t}}$, thereby increasing the risk of a crisis until $L e v_{t}^{*}$ is above the threshold $\kappa$ and the economy experiences a crisis. During a crisis, banks obtain additional liquidity from the early liquidation of loans, leading to a fall in the outstanding debt $B_{t}^{F}$, the interest rate $R_{t+1}$, and a slight recovery in the price of loans $Q_{t}$.

Leverage rises both during the boom and in the bust. The empirical impulse response of leverage in Figure 2 is key to understand this result. While leverage falls on impact to a positive shock, it actually rises following a sequence of positive shocks because the medium-term response of leverage in Figure 2 dominates. During a crisis, when the economy is hit by a negative shock, leverage also 
increases. However, on average, it does not take a large negative shock to push the economy over the cliff, since the prior sequence of positive shocks already resulted in an increase in leverage and therefore moved the economy closer to the bank run region. During a crisis, it is the impulse response on impact in Figure 2 that explains the behavior. Hence, it is important to match the empirical impulse response of leverage in Figure 2 for the model to generate the dynamics that are shown in Figures 6-8.
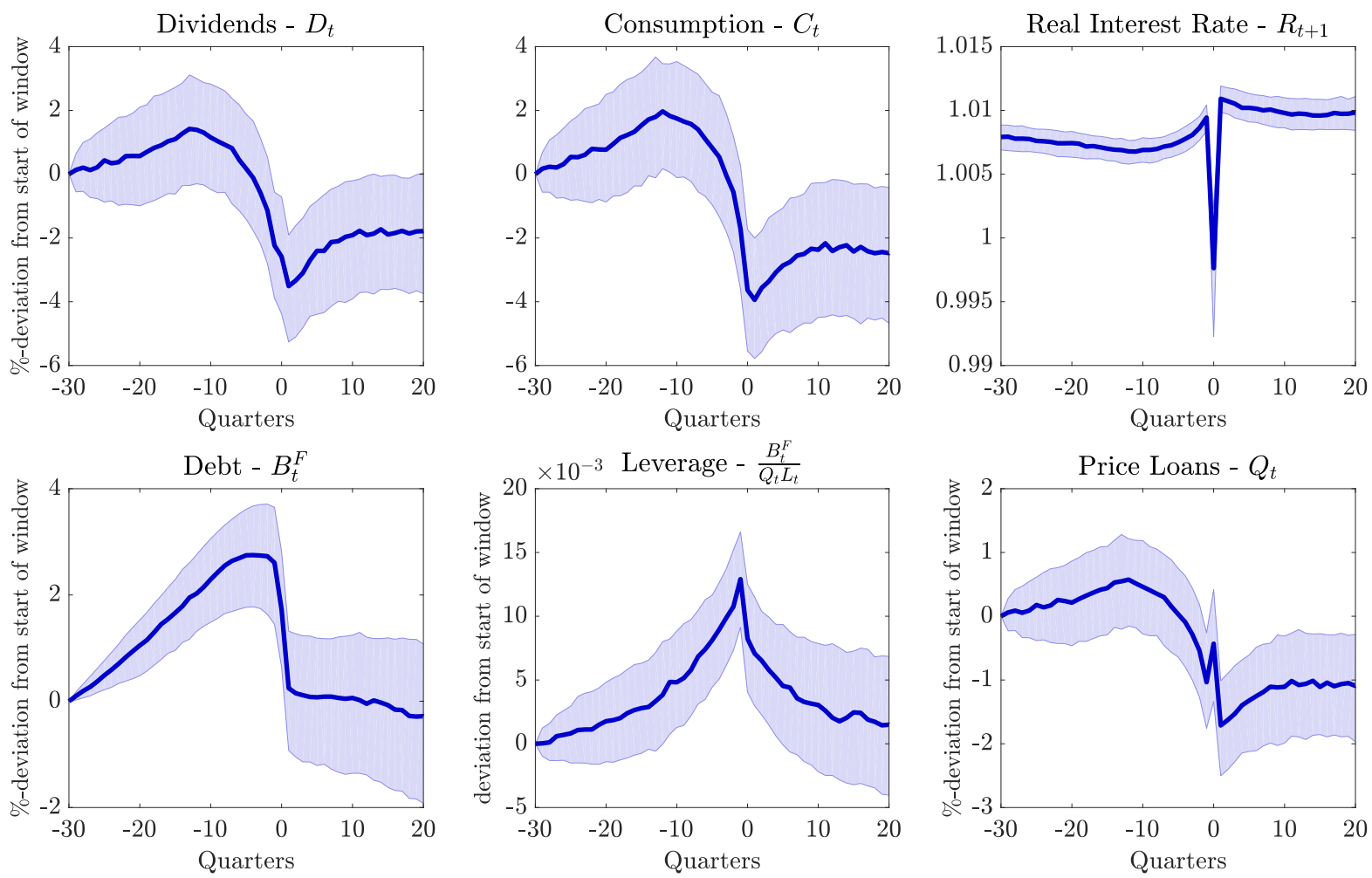

Figure 8: Typical Financial Crises. Event window around financial crisis at Quarter $=0$. Based on a simulation of 500, 000 periods. Median, $33^{\text {rd }}$, and $66^{\text {th }}$ percentiles are shown.

Next, I test whether the model is able to replicate several results from the literature. Based on the simulation of the model, Appendix A.5.4 reproduces the baseline regressions in Schularick and Taylor (2012) with the result that credit growth performs well in predicting financial crises. Moreover, in Appendix A.5.5, I replicate the findings by Jordà et al. (2013) that financial crises recessions that are preceded by an unusually large buildup of credit are deeper than the ones without such ex-ante trends. In Appendix A.5.6, I also show that credit spreads are good predictors of the severity of crises, following the empirical strategy by Krishnamurthy and Muir (2017).

The liquidation of outstanding credit and investment projects governs the severity of crises. To isolate the contribution of this mechanism towards the fall in total credit $L_{t}$, capital $K_{t}$, and ultimately output $Y_{t}$ during the bust, it is useful to compare the behavior of the economy with the same model that is subject to the same series of shocks, but which does not include crises. Such an exercise reveals that the total stock of loans $L_{t}$ and capital $K_{t}$ fall approximately by an additional $0.6 \%$ relative to the period before a crisis. Output drops on average by around $0.3 \%$ more, for some 
crises by as much as $1.5 \%$. To put these numbers into perspective, a 0.25 -standard-deviation and a 1.2-standard-deviation negative technology shock give similar responses of output on impact based on the same impulse response analysis as in Section 4.1. These effects are very persistent. Even 5 years after the crisis, this difference is roughly the same. That is because the liquidation of capital reduces the profits, the starting net worth, and the borrowing capacity of many future generations of entrepreneurs.

The key parameter that determines the severity of crises is $\mu$ - the fraction of capital that can be resold when loans are liquidated early. The lower $\mu$, the larger the fraction of loans that need to be liquidated to avoid a run, denoted by $\tau_{t}$. For the calibration in Section 3.2, I consider a conservative value of $\mu$ that gives a severity of crises at the lower end of what the historical data suggests. I recalibrate the model and consider a lower value of $\mu$, setting $\mu=0.1 .^{20}$ Based on a simulation of the model, financial recessions are now $44 \%$ deeper compared with average recessions, which lies in about the middle of the historical estimates (31\% - 56\%). Figures $15-17$ in Appendix A.5.3 show the typical behavior around crises based on this new calibration. Loans $L_{t}$ and capital $K_{t}$ now fall more sharply during a crisis, on average more than an additional $1 \%$ compared with a model without crises. On average, output now falls by around $0.6 \%$ more compared with the model without crises, and for some crises by as much as $4 \%$. Again, to put these numbers into perspective, a 0.6-standard-deviation and a 3.2-standard-deviation negative technology shock give similar reactions of output on impact based on the same impulse response analysis as in Section 4.1.

This comparison begs the question of what a reasonable parametrization for $\mu$ would be. The calibrated values may not be deemed excessively low, considering that capital is firesold in a recession and a large fraction of capital that has been previously used in a production process may be firm-specific. However, it is difficult to pin down $\mu$ based on micro-data. Instead, a good orientation is the implied fraction of loans that is liquidated early, denoted by $\tau_{t}$. For the baseline calibration, $\tau_{t}$ is on average $0.3 \%$, with a maximum value of $2.2 \%$. For the calibration with $\mu=0.1$, $\tau_{t}$ is on average $1 \%$, with a maximum value of $6.2 \%$. In comparison, Chodorow-Reich and Falato (2017) find that total long-term credit and commitments outstanding contracted by $5.8 \%$ in 2008 and $5.9 \%$ in 2009 in the United States because borrowers had their borrowing limit lowered by an unhealthy lender following a covenant violation. Hence, the model's implied value for $\tau_{t}$ is generally below the empirical counterparts, such that the model does not rely too heavily on this channel to generate large crises effects.

\subsection{Nonfinancial Recessions}

To understand how crises differ from "normal" recessions, I repeat the exercise of the last section around nonfinancial recessions (as defined in footnote 18). Figures 9 and 10 plot the typical paths around nonfinancial recessions for several variables (the remaining ones are shown in Appendix

\footnotetext{
${ }^{20}$ With this new calibration, banks occasionally get caught in constant liquidations for very long simulations. To ensure a stable simulation, I consider shorter 1000-period simulations.
} 
A.5.7). Compared with financial crises, the rise and decline in technology, output, capital, and labor around nonfinancial recessions is less pronounced. Moreover, nonfinancial recessions are not preceded by strong increases in credit $L_{t}$, the intermediary's debt $B_{t}^{F}$, market leverage $\frac{B_{t}^{F}}{Q_{t} L_{t}}$, or the loan risk indicator $x_{t}$, in contrast to the behavior of these variables in the buildup to financial crises.
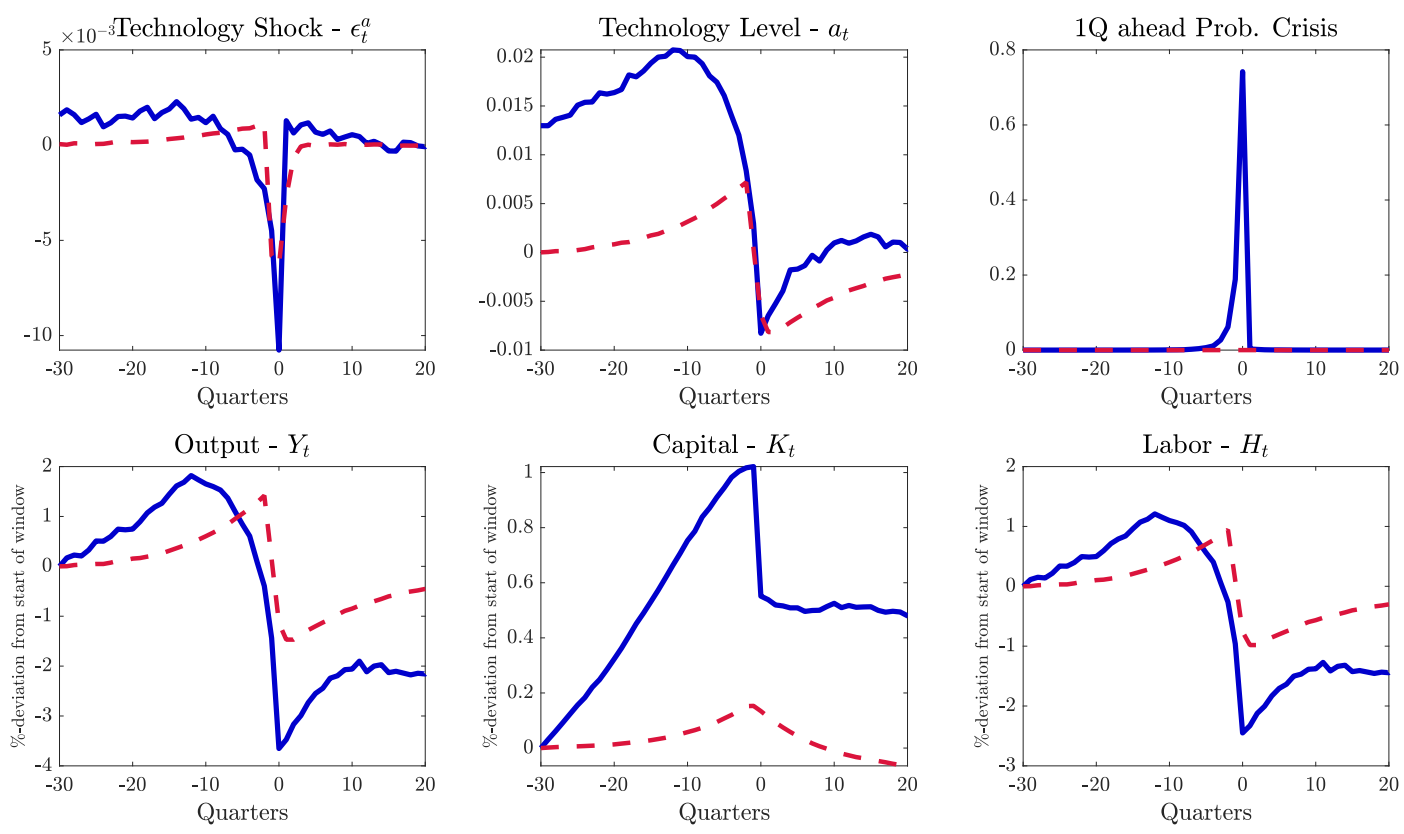

Figure 9: Typical Nonfinancial Recessions vs. Financial Crises. Event window around nonfinancial recession (red dotted line) or financial crisis (blue solid line) at Quarter $=0$. Based on a simulation of 500,000 periods. Median paths are shown.

During nonfinancial recessions, the weighted default threshold $\bar{\omega}_{t}$ and the intermediary's market leverage do not increase as strongly as during financial crises. Moreover, the fall in the intermediary's funding $B_{t}^{F}$ and new lending $Q_{t} L_{t}^{\text {new }}$ are stronger during financial crises. In addition, nonfinancial recessions are less severe and persistent compared with financial recessions. For example, the median duration of a financial recession is around 2.5 times longer compared with a nonfinancial recession. This difference is close to the empirical counterpart which shows that financial recessions are typically twice as long based on the macrohistory data by Jordà et al. (2017). Overall, this comparison shows that it is the financial sector's balance sheet that plays the crucial role during the boom-bust cycle around financial crises. In this regard, nonfinancial recessions are different. 

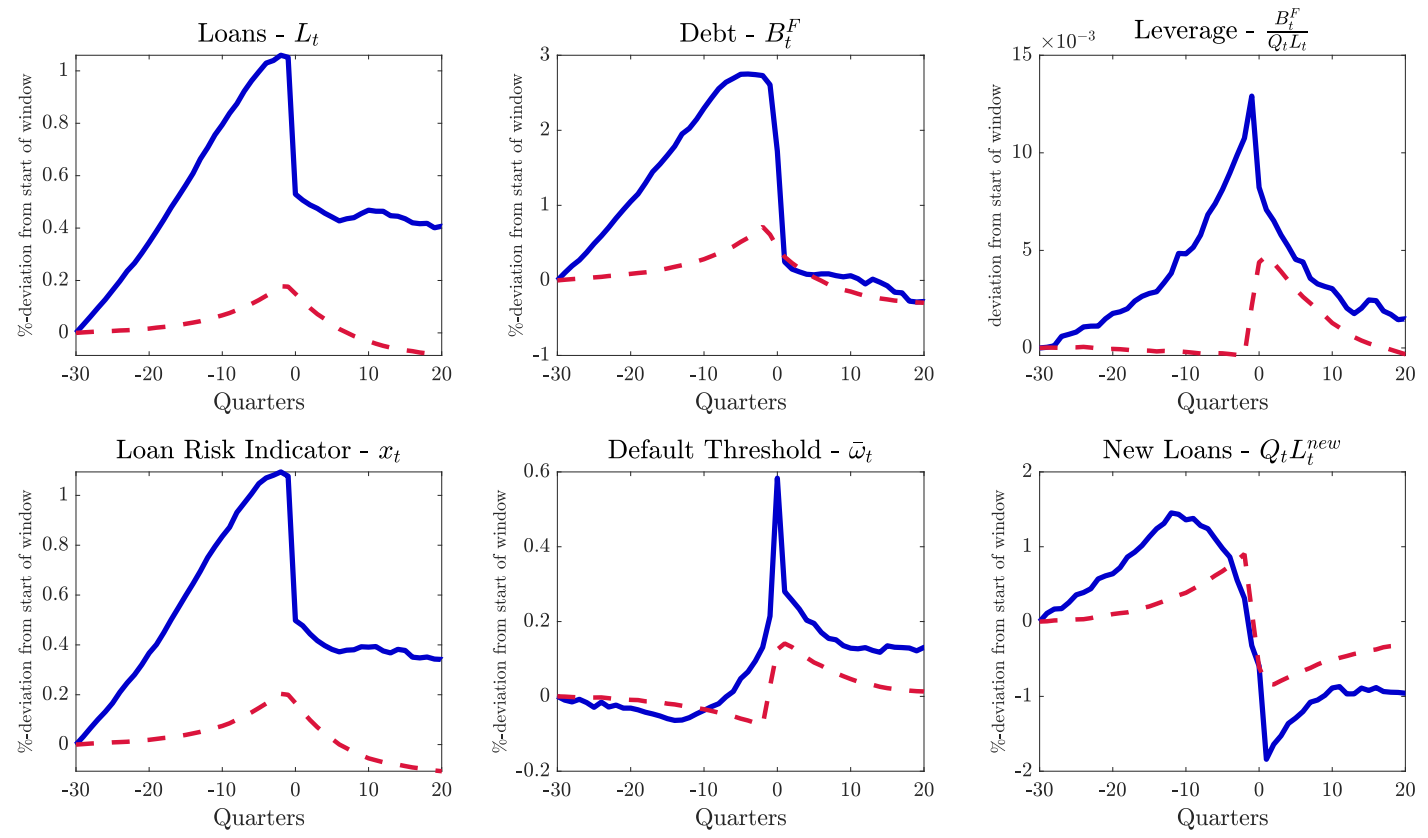

Figure 10: Typical Nonfinancial Recessions vs. Financial Crises. Event window around nonfinancial recession (red dotted line) or financial crisis (blue solid line) at Quarter $=0$. Based on a simulation of 500,000 periods. Median paths are shown.

\subsection{The 2007-09 Financial Crisis}

How well does the model perform in replicating the financial crisis of 2007-09? To test the model in this regard, I again use the historical series of structural technology shocks $\left\{\hat{\epsilon}_{t}^{a}\right\}-$ as discussed in Section 3 - and feed the model with this series. Given this series of shocks, I then check whether the model endogenously generates a crisis around the time when it actually occurred. At the beginning of the sample, I start the simulation from the stochastic steady state of the model. The results are given in Figure 11, showing the path of the technology level $a_{t}$, the probability that a financial crisis will occur in the next quarter, the evolution of intermediary market leverage, and the behavior of output.

During the boom period of 2000 to 2005, the technology level increases step-by-step and so does the intermediary's leverage. While there are many factors that drive leverage in the data, the behavior in the model actually closely aligns with the data over the sample, in particular around the 2007-09 financial crisis, giving additional support to the mechanism. However, since the model is not calibrated to match the exact level of leverage, the two differ as discussed in Section 3.1.2. 

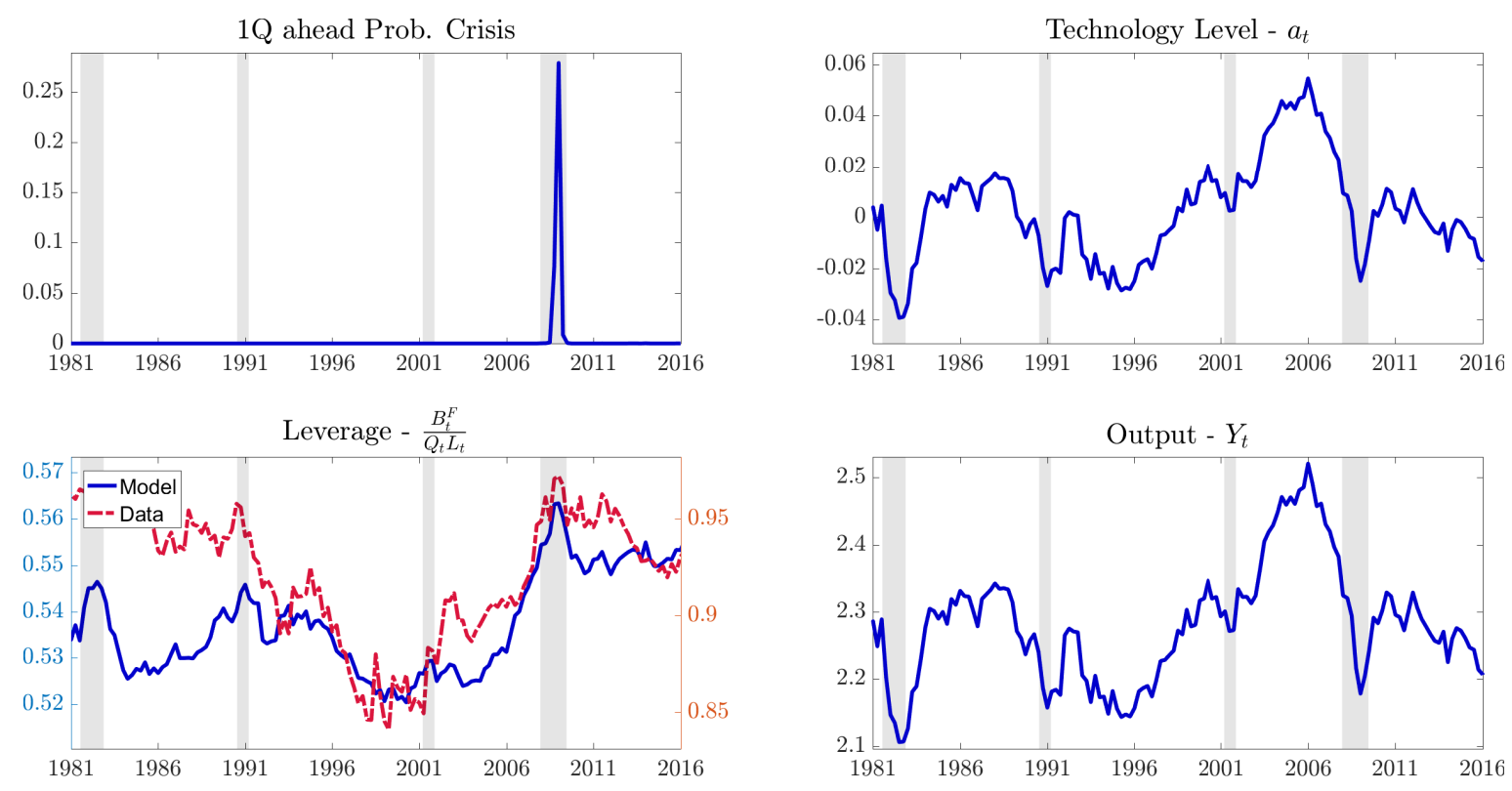

Figure 11: The 2007-09 Financial Crisis. Simulation results given a series of historical technology shocks for the U.S. economy, starting from the stochastic steady state of the model at the beginning of the sample. Left, bottom graph: Dashed red line denotes the behavior of market leverage for U.S. financial intermediaries (liabilities/(liabilities+market equity)), see Appendix A.4.1 for details). Gray bars denote NBER recessions.

The 2000-2005 boom period is followed by declines in the technology level. The probability that a crisis will occur in the next quarter jumps to around 25\% in 2008, while for the rest of the sample, the crisis probability is close to zero. A crisis endogenously occurs in 2009 when the intermediary's leverage at the beginning of a period $L e v_{t}^{*}$ is above the threshold $\kappa$. Hence, the model performs well in replicating the buildup path and the occurrence of the 2007-09 financial crisis.

A caveat is that the amount of liquidated loans $\tau_{t}$ is relatively small, with just $0.1 \%$. The impact of the mechanism through which output falls because of the liquidation of loans is therefore limited, to about an additional $0.1 \%$. However, I find that this result depends on the calibration of $\mu$ and the starting point of the simulation. For example, for the value of $\mu=0.1$ that gives a crisis severity in the mid-range of the historical estimates, output falls by an additional $0.3 \%$ through this mechanism, based on $\tau_{t}=0.25 \%$. Nonetheless, both calibrations give ratios of loan liquidations that are well below the estimates of Chodorow-Reich and Falato (2017) who find that total long-term credit and commitments outstanding contracted by 5.8\% in 2008 and 5.9\% in 2009 in the United States because borrowers had their borrowing limit lowered by an unhealthy lender following a covenant violation. This again suggests that the model does not rely too heavily on this channel and a calibration that gives a larger crisis severity would be supported by the data. 


\subsection{Additional Results}

Several additional results are left to the Appendix but briefly summarized next.

\subsubsection{Cyclicality of Leverage and Behavior around Crises}

The cyclicality of market leverage of U.S. financial intermediaries is one of the calibration targets (see Section 3.1.2), which is important for the model's dynamics. In Appendix A.5.8, I provide additional empirical evidence on financial and nonfinancial firm leverage and compare this evidence to the model. I show that the model also performs well in matching

1. the cyclicality of book leverage of U.S. financial intermediaries,

2. the evidence by Adrian and Shin (2014) that (i) changes in intermediary book leverage are positively correlated with changes in book assets and (ii) changes in intermediary market leverage are negatively correlated with changes in their market value,

3. the cyclicality of book and market leverage of U.S. nonfinancial firms,

4. the behavior of book and market leverage for financial and nonfinancial firms around the 2007-09 financial crisis, which is similar to the typical behavior of leverage around crises in the model.

\subsubsection{Anticipated Crises}

So far, I have treated crises as unanticipated events. That is, when solving their decision problems, agents do not take into account that a crisis may occur in the future due to the realization of future shocks. Allowing for crises to be anticipated provides additional technical challenges. In Appendix A.5.9, I discuss these challenges and show that a slightly modified version that simplifies the solution of the model gives similar crisis dynamics as the ones shown in Figures 6-8.

\subsubsection{Simplified Model without Loans}

Last, Appendix A.5.10 considers a simplified version of the model without loans to illustrate why bank leverage can be procyclical. The difference to the main model is that financial intermediaries invest directly in the capital stock of the representative good producer. There are no entrepreneurs and financial crises. Based on this simplified version, I show that the cyclicality of bank leverage depends on whether capital $K_{t}$ is endogenous. If $K_{t}$ is fixed at unity for all periods and supplied inelastically, then bank leverage is countercyclical. In contrast, if capital is allowed to be endogenous, then banks expand their balance sheets in response to a positive shock and finance their additional investment by borrowing from households. Bank leverage can then be procyclical depending on the calibration. Hence, expansions and contractions in the size of bank balance sheets explain why the model can generate procyclical leverage. 


\section{Conclusion}

In recent years, a quickly growing empirical literature has revealed common patterns across a range of historical financial crises. In this paper, I augment a textbook macroeconomic model to include long-term defaultable loans, financial intermediation, and occasional financial crises, and show that this framework is consistent with several stylized facts about financial crises.

Within my model, crises occur out of prolonged booms, during which financial fragility builds up when banks increase their lending and leverage. They also immediately follow low productivity, but it only takes a moderate adverse shock to initiate them. During financial crises, banks face the risk of a creditor run. To avoid a run, banks liquidate a fraction of their loans to generate additional liquidity, thereby sharply reducing aggregate output.

A simulation of the model matches the data in several ways. First, credit growth is a robust predictor of crises. Second, financial recessions are deeper and more persistent than nonfinancial recessions. The model behaves differently around nonfinancial recessions, as they are not preceded by a strong expansion of the financial sector's balance sheet or a credit boom. And third, the larger the buildup of credit prior to a crisis, the deeper the subsequent downturn in output.

The model is validated in three additional ways. First, when confronted with a historical series of structural shocks, the model replicates the occurrence of the 2007-09 financial crisis. Second, the behavior of leverage of financial and nonfinancial firms that is key to the buildup of risk in good times is consistent with the data. Third, the quantitative analysis of the model shows that the described mechanism based on the early liquidation of loans can generate substantial endogenous aggregate movements without relying on large exogenous shocks. The recent evidence by Chodorow-Reich and Falato (2017) confirms that this channel is also empirically relevant.

An interesting extension of the model would be to allow for creditor runs on some banks as during the 2007-09 financial crisis, likely adding to the endogenous amplification of shocks. Since the model matches key empirical characteristics of financial crises, it is a suitable laboratory to study

policy interventions that aim to reduce the likelihood and severity of financial crises. In future work, it would be interesting to consider such macro-prudential policy interventions. 


\section{References}

Adrian, T. and N. Boyarchenko (2012). Intermediary leverage cycles and financial stability. Federal Reserve Bank of New York - Staff Reports (567).

Adrian, T. and M. Brunnermeier (2016). Covar. American Economic Review 106(7), 1705-41.

Adrian, T. and H. S. Shin (2010). Liquidity and leverage. Journal of Financial Intermediation 19(3), $418-437$.

Adrian, T. and H. S. Shin (2014). Procyclical Leverage and Value-at-Risk. The Review of Financial Studies 27(2), 373403.

Akinci, O. and A. Queralto (2017). Credit spreads, financial crises, and macroprudential policy. Federal Reserve Bank of New York Staff Report No. 802.

Begenau, J., S. Bigio, J. Majerovitz, and M. Vieyra (2018). Banks adjust slowly. Unpublished Manuscript.

Bellman, R. E. (1961). Adaptive control processes - A guided tour. Princeton, New Jersey, U.S.A.: Princeton University Press.

Benigno, G., A. Foerster, C. Otrok, and A. Rebucci (2018). Estimating macroeconomic models of financial crises: An endogenous regime switching approach. Unpublished Manuscript.

Bernanke, B. and M. Gertler (1989). Agency Costs, Net Worth, and Business Fluctuations. American Economic Review 79(1), 14-31.

Bernanke, B., M. Gertler, and S. Gilchrist (1999). The financial accelerator in a quantitative business cycle framework. Chap. 21 in Handbook of Macroeconomics, ed. J. B. Taylor and M. Woodford. Amsterdam: Elsevier. 1C(6455).

Bianchi, J. (2011). Overborrowing and systemic externalities in the business cycle. American Economic Review 101(7), 3400-3426.

Bocola, L. (2016). The pass-through of sovereign risk. Journal of Political Economy 124(4), 879-926.

Boissay, F., F. Collard, and F. Smets (2016). Booms and banking crises. Journal of Political Economy 124(2), 489-538.

Bordalo, P., N. Gennaioli, and A. Shleifer (2018). Diagnostic expectations and credit cycles. The Journal of Finance 73(1), 199-227.

Boz, E. and E. G. Mendoza (2014). Financial innovation, the discovery of risk, and the U.S. credit crisis. Journal of Monetary Economics 62(C), 1-22.

Brunnermeier, M. K. and Y. Sannikov (2014). A macroeconomic model with a financial sector. American Economic Review 104(2), 379-421. 
Bry, G. and C. Boschan (1971). Cyclical analysis of time series: Selected procedures and computer programs. National Bureau of Economic Research, Inc.

Calvo, G. A. (1983). Staggered prices in a utility-maximizing framework. Journal of Monetary Economics 12(3), 383-398.

Carlstrom, C. T. and T. S. Fuerst (1997). Agency Costs, Net Worth, and Business Fluctuations: A Computable General Equilibrium Analysis. American Economic Review 87(5), 893-910.

Chatterjee, S. and B. Eyigungor (2012). Maturity, indebtedness, and default risk. American Economic Review 102(6), 2674-99.

Chodorow-Reich, G. and A. Falato (2017). The Loan Covenant Channel: How Bank Health Transmits to the Real Economy. NBER Working Paper (23879).

Christiano, L. J., M. Eichenbaum, and C. L. Evans (2005). Nominal Rigidities and the Dynamic Effects of a Shock to Monetary Policy. Journal of Political Economy 113(1), 1-45.

Cooley, T. and E. C. Prescott (1995). Economic growth and business cycles. in Cooley (ed) Frontiers of Business Cycle Research.

Del Negro, M., G. Eggertsson, A. Ferrero, and N. Kiyotaki (2017). The great escape? a quantitative evaluation of the fed's liquidity facilities. American Economic Review 107 (3), 824-57.

Demyanyk, Y. and O. V. Hemert (2011). Understanding the Subprime Mortgage Crisis. Review of Financial Studies 24(6), 1848-1880.

Diamond, D. W. and P. H. Dybvig (1983). Bank Runs, Deposit Insurance, and Liquidity. Journal of Political Economy 91(3), 401-19.

Elenev, V., T. Landvoigt, and S. Van Nieuwerburgh (2018). A macroeconomic model with financially constrained producers and intermediaries. NBER Working Paper (24757).

English, W. B., S. J. van den Heuvel, and E. Zakrajsek (2018). Interest rate risk and bank equity valuations. Journal of Monetary Economics 98, 80-97.

Faria-e-Castro, M. (2017). Fiscal multipliers and financial crises. Unpublished manuscript, New York University.

Fernald, J. (2014). A quarterly, utilization-adjusted series on total factor productivity. Federal Reserve Bank of San Francisco - Working Paper Series.

Gertler, M. and N. Kiyotaki (2010). Financial intermediation and credit policy in business cycle analysis. Handbook of Monetary Economics 3, 547-599.

Gertler, M. and N. Kiyotaki (2015). Banking, liquidity, and bank runs in an infinite horizon economy. American Economic Review 105(7), 2011-43. 
Gertler, M., N. Kiyotaki, and A. Prestipino (2017). A macroeconomic model with financial panics. NBER Working Paper (24126).

Gomes, J., U. Jermann, and L. Schmid (2016). Sticky leverage. American Economic Review 106(12), 3800-3828.

Gorton, G. and G. Ordoñez (2014). Collateral crises. American Economic Review 104(2), 343-78.

Gorton, G. and G. Ordoñez (2016). Good booms, bad booms. NBER Working Papers (22008).

Greenwood, J., Z. Hercowitz, and G. W. Huffman (1988). Investment, Capacity Utilization, and the Real Business Cycle. American Economic Review 78(3), 402-17.

He, Z. and A. Krishnamurthy (2014). A macroeconomic framework for quantifying systemic risk. NBER Working Paper 19885.

Iacoviello, M. (2015). Financial Business Cycles. Review of Economic Dynamics 18(1), 140-164.

Jordà, O. (2005). Estimation and inference of impulse responses by local projections. American Economic Review 95(1), 161-182.

Jordà, O., M. Schularick, and A. Taylor (2013). When credit bites back. Journal of Money, Credit and Banking 45(s2), 3-28.

Jordà, O., M. Schularick, and A. Taylor (2017). Macrofinancial history and the new business cycle facts. NBER Macroeconomics Annual 2016, Volume 31.

Judd, K. L. (1992). Projection methods for solving aggregate growth models. Journal of Economic Theory 58(2), 410-452.

Justiniano, A., G. Primiceri, and A. Tambalotti (2017). The mortgage rate conundrum. Unpublished manuscript.

Kiyotaki, N. and J. Moore (1997). Credit cycles. Journal of Political Economy 105(2), 211-48.

Kiyotaki, N. and J. Moore (2012). Liquidity, Business Cycles, and Monetary Policy. NBER Working Paper (17934).

Krishnamurthy, A. and T. Muir (2017). How credit cycles across a financial crisis. NBER Working Papers (23580).

Krishnamurthy, A. and A. Vissing-Jorgensen (2015). The impact of treasury supply on financial sector lending and stability. Journal of Financial Economics 118, 571-600.

Lorenzoni, G. (2008, 07). Inefficient credit booms. Review of Economic Studies 75(3), 809-833.

López-Salido, D., J. Stein, and E. Zakrajsek (2017). Credit-market sentiment and the business cycle. Quarterly Journal of Economics 132(3), 1373-1426. 
Malin, B. A., D. Krueger, and F. Kubler (2011). Solving the multi-country real business cycle model using a Smolyak-collocation method. Journal of Economic Dynamics and Control 35(2), 229-239.

Martinez-Miera, D. and J. Suarez (2012). A macroeconomic model of endogenous systemic risk taking. CEPR Discussion Papers (9134).

Mendoza, E. G. (2010). Sudden stops, financial crises, and leverage. American Economic Review 100(5), 1941-66.

Newey, W. K. and D. McFadden (1994). Large sample estimation and hypothesis testing. Volume 4 of Handbook of Econometrics, pp. 2111 - 2245. Elsevier.

Nuño, G. and C. Thomas (2017). Bank leverage cycles. American Economic Journal: Macroeconomics 9(2), 32-72.

Ospina, J. and H. Uhlig (2018). Mortgage-backed securities and the financial crisis of 2008: a post mortem. NBER Working Paper (24509).

Paul, P. (2018). Historical patterns of inequality and productivity around financial crises. Federal Reserve Bank of San Francisco Working Paper 2017-23.

Philippon, T. (2015). Has the US Finance Industry Become Less Efficient? On the Theory and Measurement of Financial Intermediation. American Economic Review 105(4), 1408-38.

Ravn, M. O. and H. Uhlig (2002). On adjusting the Hodrick-Prescott filter for the frequency of observations. The Review of Economics and Statistics 84(2), 371-375.

Schmitt-Grohe, S. and M. Uribe (2003). Closing small open economy models. Journal of International Economics 61(1), 163-185.

Schularick, M. and A. M. Taylor (2012). Credit booms gone bust: Monetary policy, leverage cycles, and financial crises, 1870-2008. American Economic Review 102(2), 1029-1061.

Smets, F. and R. Wouters (2007). Shocks and Frictions in US Business Cycles: A Bayesian DSGE Approach. American Economic Review 97(3), 586-606. 


\section{A ONLINE APPENDIX}

\section{A.1 The Entrepreneur's Decision Problem}

Given net worth $N_{t}$ and loan price $Q_{t}$, a risk-neutral new entrepreneur chooses the amount of debt $L_{t}^{\text {new }}$ and the units of capital $K_{t}^{\text {new }}$. The complete decision problem is given by

$$
\max _{K_{t}^{\text {new }}, L_{t}^{\text {new }}} V_{t}=\mathbb{E}\left[\sum_{j=1}^{\infty} \gamma^{j-1}\left\{(1-\gamma) \int_{\bar{\omega}_{t+j \mid t}}^{2}\left(\omega R_{t+j}^{K} Q_{t+j-1}^{K} K_{t}^{\text {new }}-L_{t}^{\text {new }}\right) d \Phi(\omega)+\gamma r_{t+j}^{K} K_{t}^{\text {new }}\right\}\right]
$$

subject to

$$
\begin{aligned}
Q_{t}^{K} K_{t}^{\text {new }} & =N_{t}+Q_{t} L_{t}^{\text {new }} \\
\bar{\omega}_{t+j \mid t} & =\frac{L_{t}^{\text {new }}}{R_{t+j}^{K} Q_{t+j-1}^{K} K_{t}^{\text {new }}} \text { for } j \in\{1,2, \ldots, \infty\} \\
L_{t}^{\text {new }} & \leq \theta Q_{t}^{K} K_{t}^{\text {new }}
\end{aligned}
$$

where $\Phi(\omega)$ is the c.d.f. for $\omega$. The entrepreneur's objective function $V_{t}$ captures both the profits from a maturing, nondefaulted loan - the first term in the curly bracket - as well as profits received until maturity - the second term in the curly bracket. Constraint (26) is the entrepreneur's budget constraint. The constraints summarized in (27) denote future default thresholds $\bar{\omega}_{t+j \mid t}$ and (28) states the borrowing constraint.

For a simulation of the calibrated model that assumes a binding borrowing constraint, I find that the derivative of $V_{t}$ is always positive with respect to $L_{t}^{\text {new }}$. Hence, new entrepreneurs would prefer to borrow more, but are constrained by (28).

\section{A.2 Derivations}

This section derives the simplified expression for the profits per loan $R_{t}^{L} Q_{t-1}$ shown in equation (13) and the evolution of entrepreneurs' net worth $N_{t}$ shown in equation (6). An important assumption that allows to derive these simplified expressions is that the idiosyncratic shock $\omega$ follows a uniform distribution, giving convenient expressions for cumulative distribution functions and partial expectations, which are

$$
\begin{aligned}
\Phi\left(\bar{\omega}_{t+j \mid t}\right) & =\frac{\bar{\omega}_{t+j \mid t}}{2}, \\
\int_{\omega_{t+j \mid t}}^{2} \omega d \Phi(\omega) & =\left(1-\frac{1}{4} \bar{\omega}_{t+j \mid t}^{2}\right),
\end{aligned}
$$

for $\omega \sim U[0,2]$. 


\section{A.2.1 Entrepreneur's Net Worth}

The evolution of the entrepreneur's net worth is given by

$$
N_{t}=(1-\gamma) \sum_{j=1}^{\infty} \int_{\bar{\omega}_{t \mid t-j}}^{2} \gamma^{j-1}\left(\omega R_{t}^{K} Q_{t-1}^{K} K_{t-j}^{n e w}-L_{t-j}^{n e w}\right) d \Phi(\omega)
$$

Using expressions (29) and (30), (31) can be written as

$$
N_{t}=(1-\gamma) \sum_{j=1}^{\infty} \gamma^{j-1}\left(R_{t}^{K} Q_{t-1}^{K} K_{t-j}^{n e w}\left(1-\frac{\bar{\omega}_{t \mid t-j}^{2}}{4}\right)-L_{t-j}^{\text {new }}\left(1-\frac{\bar{\omega}_{t \mid t-j}}{2}\right)\right) d \Phi(\omega)
$$

Noting that

$$
L_{t-j}^{n e w}=R_{t}^{K} Q_{t-1}^{K} K_{t-j}^{n e w} \bar{\omega}_{t \mid t-j} \text { for } j \geq 1
$$

(32) can be written as

$$
N_{t}=(1-\gamma)\left\{R_{t}^{K} Q_{t-1}^{K} K_{t-1}-L_{t-1}+\frac{1}{4} \frac{x_{t-1}}{R_{t}^{K} Q_{t-1}^{K}}\right\}
$$

where

$$
\begin{aligned}
& K_{t-1}=K_{t-1}^{n e w w}+\gamma K_{t-2}, \\
& L_{t-1}=L_{t-1}^{n e w}+\gamma L_{t-2}, \\
& x_{t-1}=L_{t-1}^{\text {new }} \cdot \frac{L_{t-1}^{\text {new }}}{K_{t-1}^{\text {new }}}+\gamma x_{t-2},
\end{aligned}
$$

are three aggregate state variables. The expression (33) is shown in (6).

\section{A.2.2 Return on Market Portfolio of Loans}

The return on the market portfolio of loans is given by

$$
R_{t}^{L}=\frac{\gamma Q_{t}+(1-\gamma) \frac{1}{L_{t-1}}\left\{\sum_{j=1}^{\infty}\left(1-\Phi\left(\bar{\omega}_{t \mid t-j}\right)\right) \gamma^{j-1} L_{t-j}^{n e w}+\sum_{j=1}^{\infty}\left[\int_{0}^{\bar{\omega}_{t \mid t-j}} \omega R_{t}^{K} Q_{t-1}^{K} \gamma^{j-1} K_{t-j}^{n e w w} d \Phi(\omega)\right]\right\}}{Q_{t-1}}
$$

$R_{t}^{L}$ captures both profits from nonmaturing loans $\gamma Q_{t}$, as well as from maturing loans across all vintages. The latter consist of repaid loans - the first term in the curly bracket - and the recovery from defaulted loans - the second term in the curly bracket. The two infinite sums in the numerator can be simplified in the following way. First, using the definition of the cumulative distribution function in (29), note that

$$
\sum_{j=1}^{\infty}\left(1-\Phi\left(\bar{\omega}_{t \mid t-j}\right)\right) \gamma^{j-1} L_{t-j}^{n e w}=L_{t-1}-\frac{1}{2} \frac{1}{R_{t}^{K} Q_{t-1}^{K}} x_{t-1}
$$


where

$$
\begin{aligned}
L_{t-1} & =L_{t-1}^{n e w}+\gamma L_{t-2}, \\
x_{t-1} & =\frac{\left(L_{t-1}^{\text {new }}\right)^{2}}{K_{t-1}^{\text {new }}}+\gamma x_{t-2} .
\end{aligned}
$$

Second, using the definition of the partial expectation in (30), rewrite

$$
\sum_{j=1}^{\infty}\left[\int_{0}^{\bar{\omega}_{t \mid t-j}} \omega R_{t}^{K} Q_{t-1}^{K} \gamma^{j-1} K_{t-j}^{n e w w} d \Phi(\omega)\right]=\frac{1}{4} \frac{1}{R_{t}^{K} Q_{t-1}^{K}} x_{t-1}
$$

Substituting (38) and (39) in (37) and rearranging gives

$$
R_{t}^{L} Q_{t-1}=\gamma Q_{t}+(1-\gamma)\left(1-\frac{x_{t-1}}{4 R_{t}^{K} Q_{t-1}^{K} L_{t-1}}\right)
$$

Next, define

$$
\bar{\omega}_{t} \equiv \frac{x_{t-1}}{R_{t}^{K} Q_{t-1}^{K} L_{t-1}}
$$

and use (41) to simplify (40) to

$$
R_{t}^{L} Q_{t-1}=\gamma Q_{t}+(1-\gamma)\left(1-\frac{\bar{\omega}_{t}}{4}\right)
$$

This is the expression that is stated in (13).

\section{A.2.3 Recovery on Liquidated Loans}

In a crisis, a fraction $\tau_{t}$ of loans is liquidated early with the payoff

$$
\tau_{t}\left[\sum_{j=1}^{\infty}\left(1-\Phi\left(\bar{\omega}_{t \mid t-j}^{*}\right)\right) \gamma^{j-1} L_{t-j}^{n e w}+\sum_{j=1}^{\infty}\left(\int_{0}^{\bar{\omega}_{t \mid t-j}^{*}} \omega Q_{t}^{K} \mu(1-\delta) \gamma^{j-1} K_{t-j}^{n e w} d \Phi(\omega)\right)\right]
$$

where the first term in the outer bracket captures repaid loans and the second term the recovery from defaulted loans. The vintage-specific default threshold $\bar{\omega}_{t \mid t-j}^{*}$ is defined as

$$
\bar{\omega}_{t \mid t-j}^{*}=\frac{L_{t-j}^{n e w}}{Q_{t}^{K} \mu(1-\delta) K_{t-j}^{n e w}}
$$

Again, using the definition of the cumulative distribution function in (29), note that

$$
\tau_{t}\left[\sum_{j=1}^{\infty}\left(1-\Phi\left(\bar{\omega}_{t \mid t-j}^{*}\right)\right) \gamma^{j-1} L_{t-j}^{n e w}\right]=\tau_{t}\left[L_{t-1}-\frac{1}{2} \frac{1}{Q_{t}^{K} \mu(1-\delta)} x_{t-1}\right],
$$

where $L_{t-1}$ and $x_{t-1}$ are defined in (35) and (36). Again, using the definition of the partial expectation in (30), rewrite 


$$
\tau_{t}\left[\sum_{j=1}^{\infty}\left(\int_{0}^{\bar{\omega}_{t \mid t-j}^{*}} \omega Q_{t}^{K} \mu(1-\delta) \gamma^{j-1} K_{t-j}^{n e w} d \Phi(\omega)\right)\right]=\tau_{t}\left[\frac{1}{4} \frac{x_{t-1}}{Q_{t}^{K} \mu(1-\delta)}\right] .
$$

Combining (42) and (43) gives

$$
\tau_{t} L_{t}\left(1-\frac{\bar{\omega}_{t}^{*}}{4}\right)
$$

where

$$
\bar{\omega}_{t}^{*}=\frac{x_{t-1}}{Q_{t}^{K} \mu(1-\delta) L_{t-1}},
$$

which is the expression stated in (19). 


\section{A.3 Model - Equilibrium Conditions \& Financial Crises}

Households \& Good Producer

$$
\begin{aligned}
E_{t}\left[\Lambda_{t, t+1} R_{t+1}\right] & =1 \\
\Lambda_{t, t+1} & =\beta^{H}\left(\frac{C_{t}-\chi \frac{H_{t}^{1+\phi}}{1+\phi}}{C_{t+1}-\chi \frac{H_{t+1}^{1+\phi}}{1+\phi}}\right) \\
(1-\alpha) Y_{t} & =\chi H_{t}^{1+\phi} \\
Y_{t} & =e^{a_{t}} K_{t-1}^{\alpha} H_{t}^{1-\alpha} \\
a_{t} & =\rho_{a} a_{t-1}+\epsilon_{t}^{a}
\end{aligned}
$$

\section{Entrepreneurs}

$$
\begin{aligned}
Q_{t}^{K} K_{t}^{\text {new }} & =N_{t}+Q_{t} L_{t}^{\text {new }} \\
L_{t}^{\text {new }} & =\theta Q_{t}^{K} K_{t}^{\text {new }} \\
N_{t} & =(1-\gamma)\left(R_{t}^{K} Q_{t-1}^{K} K_{t-1}-L_{t-1}+\frac{1}{4} \frac{x_{t-1}}{R_{t}^{K} Q_{t-1}^{K}}\right)
\end{aligned}
$$

\section{Banks}

$$
\begin{aligned}
D_{t}+Q_{t} L_{t}+B_{t-1}^{F} R_{t} & =B_{t}^{F}+R_{t}^{L} Q_{t-1} L_{t-1} \\
E_{t}\left[\beta^{F} \frac{\left(R_{t+1}+\psi B_{t}^{F}\right)}{D_{t+1}}\right] & =E_{t}\left[\beta^{F} \frac{1}{D_{t+1}} R_{t+1}^{L}\right]=\frac{1}{D_{t}} \\
L_{t} & =L_{t}^{\text {new }}+\gamma L_{t-1} \\
K_{t} & =K_{t}^{\text {new }}+\gamma K_{t-1} \\
x_{t} & =L_{t}^{\text {new }} \frac{L_{t}^{\text {new }}}{K_{t}^{\text {new }}}+\gamma x_{t-1} \\
R_{t}^{L} Q_{t-1} & =\gamma Q_{t}+(1-\gamma)\left(1-\frac{\bar{\omega}_{t}}{4}\right) \\
\bar{\omega}_{t} & =\frac{x_{t-1}}{R_{t}^{K} Q_{t-1}^{K} L_{t-1}}
\end{aligned}
$$

\section{Capital Producer and Resource Constraint}

$$
\begin{aligned}
Q_{t}^{K} & =1+\zeta\left(\frac{I_{t}}{K_{t-1}}-\delta\right) \\
I_{t} & =K_{t}-(1-\delta) K_{t-1} \\
\Phi_{t} & =I_{t}+\frac{\zeta}{2}\left(\frac{I_{t}}{K_{t-1}}-\delta\right)^{2} K_{t-1} \\
Y_{t} & =C_{t}+D_{t}+\Phi_{t} \\
R_{t}^{K} Q_{t-1}^{K} & =\left(Q_{t}^{K}(1-\delta)+\alpha \frac{Y_{t}}{K_{t-1}}\right)
\end{aligned}
$$




\section{Occasional Financial Crises}

Denote by $K_{t-1}^{\text {prev. }}, L_{t-1}^{\text {prev. }}$, and $x_{t-1}^{\text {prev. }}$ last period's capital stock, loan risk indicator, and overall loans absent a crisis. A crisis is triggered if

$$
\operatorname{Lev}_{t}^{*}=\frac{B_{t-1}^{F} R_{t}-(1-\gamma)\left(1-\frac{\bar{\omega}_{t}}{4}\right) L_{t-1}^{\text {prev. }}}{\gamma Q_{t} L_{t-1}^{\text {prev. }}}>\kappa .
$$

If a crisis occurs, then the fraction $\tau_{t}$ of loans is liquidated early, where $\tau_{t}$ solves

$$
B_{t-1}^{F} R_{t}=L_{t-1}^{\text {prev. }}\left\{\tau_{t}\left(1-\frac{\bar{\omega}_{t}^{*}}{4}\right)+\left(1-\tau_{t}\right)\left((1-\gamma)\left(1-\frac{\bar{\omega}_{t}}{4}\right)+\kappa \gamma Q_{t}\right)\right\}
$$

where

$$
\bar{\omega}_{t}^{*}=\frac{x_{t-1}^{\text {prev. }}}{Q_{t}^{K} \mu(1-\delta) L_{t-1}^{\text {prev. }}} .
$$

In (64) and (65), $Q_{t}, Q_{t}^{K}$, and $\omega_{t}$ are equilibrium values absent a crisis.

If a crisis occurs, the state variables $K_{t-1}^{\text {prev. }}, L_{t-1}^{\text {prev. }}$, and $x_{t-1}^{\text {prev. }}$ change to $K_{t-1}=\left(1-\tau_{t}\right) K_{t-1}^{\text {prev. }}$, $L_{t-1}=\left(1-\tau_{t}\right) L_{t-1}^{\text {prev. }}$, and $x_{t-1}=\left(1-\tau_{t}\right) x_{t-1}^{\text {prev. }}$. The amount $\tau_{t} \mu K_{t-1}^{\text {prev. }}$ is additionally sold on the capital good market, affecting the price of capital and aggregate investment, such that the equilibrium values during a crisis are given by

$$
\begin{aligned}
Q_{t}^{K} & =1+\zeta\left(\frac{I_{t}}{K_{t-1}+\mu \tau_{t} K_{t-1}^{\text {prev. }}}-\delta\right) \\
I_{t} & =K_{t}-(1-\delta)\left(K_{t-1}+\mu \tau_{t} K_{t-1}^{\text {prev. }}\right) \\
\Phi_{t} & =I_{t}+\frac{\zeta}{2}\left(\frac{I_{t}}{K_{t-1}+\mu \tau_{t} K_{t-1}^{\text {prev. }}}-\delta\right)^{2}\left(K_{t-1}+\mu \tau_{t} K_{t-1}^{\text {prev. }}\right)
\end{aligned}
$$

In a crisis, banks' budget constraint changes to

$$
D_{t}+Q_{t} L_{t}+B_{t-1}^{F} R_{t}=B_{t}^{F}+R_{t}^{L} Q_{t-1} L_{t-1}+\tau_{t} L_{t-1}^{\text {prev. }}\left(1-\frac{\bar{\omega}_{t}^{*}}{4}\right)
$$

where

$$
\bar{\omega}_{t}^{*}=\frac{x_{t-1}}{Q_{t}^{K} \mu(1-\delta) L_{t-1}},
$$

and $Q_{t}^{K}$ is the price of capital during a crisis. 


\section{A.3.1 Solution Technique}

Given the optimality conditions to the agents' decision problems and the clearing of goods, labor, and debt markets, the equilibrium conditions of the model for $t=0,1, \ldots, \infty$ are listed in Appendix A.3, given an initial state $S_{0}$. The endogenous variables can be separated into a vector of nonstate variables $X_{t}$ and a vector of state variables $S_{t} . X_{t+1}$ is unknown in period $t$ and $S_{t}=\left\{\bar{S}_{t}, \hat{S}_{t}\right\}$ comprises both exogenous state variables $\bar{S}_{t}$ and endogenous state variables $\hat{S}_{t} . \bar{S}_{t}=\left\{\rho_{a} a_{t-1}+\epsilon_{t}^{a}\right\}$ includes the technology shock $\epsilon_{t}^{a}$ and the probability distribution of this shock is known to all agents. The realization $\epsilon_{t+1}^{a}$ is unknown in period $t . \hat{S}_{t}=\left\{K_{t-1}, L_{t-1}, x_{t-1}, R_{t} B_{t-1}\right\}$ collects the endogenous state variables and $\hat{S}_{t+1}$ is known in period $t$. Overall, the model has five state variables. One is linked to the shock, three arise from the loan contracts $\left(K_{t-1}, L_{t-1}\right.$, and $\left.x_{t-1}\right)$, and $R_{t} B_{t-1}$ accounts for the outstanding debt of financial intermediaries.

Definition 1. A competitive general equilibrium is a solution of the model which is given by a set of policy functions $\hat{S}_{t+1}=f_{\hat{S}}\left(S_{t}\right)$ and $X_{t}=f_{X}\left(S_{t}\right)$ that satisfy the model's equilibrium conditions listed in Appendix A.3 for $t=0,1, \ldots, \infty$ in the relevant state space.

Based on this definition, I obtain the policy functions $\hat{S}_{t+1}=f_{\hat{S}}\left(\mathbb{S}_{t}\right)$ and $X_{t}=f_{X}\left(\mathbb{S}_{t}\right)$ using a projection algorithm. In the description below, I differentiate between 'anticipated' and 'unanticipated' crises. With anticipated crises, agents take into account that crises may occur in the future depending on the realization of future shocks. This amounts to an additional step in the iteration procedure. With unanticipated crises, agents assume that there will never be a crisis in the future.

Broadly, one has to make three choices when selecting a projection algorithm. First, one has to choose a grid on which the model is solved. Second, a parameterization of the policy functions has to be determined. Third, given an initial parameterization, one has to choose an iteration procedure. These three choices structure the description below.

Grid. The model is solved on a Smolyak sparse grid due to the curse of dimensionality (Bellman, 1961). The construction of the Smolyak sparse grid works as follows. The grid points in the space $[-1,1]$ for each state variable are obtained by tensor-products of nested sets of Chebyshev extrema and the application of the Smolyak rule for a given level of approximation that controls how many of these tensor-products are included in the grid (see also Malin, Krueger, and Kubler, 2011). I select 4 for the level of approximation, giving 801 grid points for the five state variables. Next, the grid points are transformed from the space $[-1,1]$ into the relevant space given the model's calibration. To determine the relevant space, I solve the model first with a third-order perturbation method around a deterministic steady state (ignoring the occasional financial crises), simulate the model for 500, 000 periods, and choose the 2.5 and 97.5 percentile cut-offs for each state variable as bounds for the associated ones in the grid (denoted $L_{B}$ and $\left.U_{B}\right)$. A linear transformation $(x+$ 1) $\frac{\left(U_{B}-L_{B}\right)}{2}+L_{B}$ is used to transform each grid point $x$ from $[-1,1]$ into $\left[L_{B}, U_{B}\right]$, giving the full set of grid points $j=1, \ldots, M$ in the relevant state space. 
Parameterization of policy functions. I parameterize several non-state variables using thirdorder ordinary polynomials. In particular, let $X_{t}^{P}$ be a parameterized variable where

$$
X_{t}^{P} \in\left\{K_{t}^{\text {new }}, \frac{1}{D_{t}}, R_{t+1}\right\}
$$

and let $r_{t}$ be an indicator function determining whether there is a financial crisis in period $t$, in which case $r_{t}=1$, or not, such that $r_{t}=0$. Then, $X_{t}^{P}\left(S_{t}\right)$ is parameterized using the piecewise flexible form with separate coefficients $\beta_{r_{t}=0}^{X}$ and $\beta_{r_{t}=1}^{X}$ (each a $1 \times 56$ vector)

$$
X_{t}^{P}\left(S_{t}\right)=\left(1-r_{t}\right) \beta_{0}^{X} T\left(S_{t}\right)+r_{t} \beta_{1}^{X} T\left(S_{t}\right)
$$

where $T\left(S_{t}\right)$ is a $56 \times 1$ vector collecting the basis functions. The number of grid points is larger than the number of coefficients. Hence, the outlined solution algorithm does not give an exact solution on the grid points, as opposed to collocation methods (see for example Malin, Krueger, and Kubler, 2011).

Iteration. Given an initial guess for the coefficients $\beta_{0}^{X}$ and $\beta_{1}^{X}$, the iteration proceeds as follows.

1. Obtain the vector collecting the basis functions $T\left(S_{t, j}\right)$ for a given grid point $j$. Assume that there is no crisis in period $t$ and calculate the parameterized variables $X_{t, j}^{P}\left(S_{t, j} ; r_{t}=0\right)$ via (66). Substitute $X_{t, j}^{P}\left(S_{t, j} ; r_{t}=0\right)$ into the set of equations summarized in Appendix A.3. Using the equilibrium conditions, solve for the rest of the variables. Check whether the financial intermediary's leverage $L e v_{t}^{*}$ exceeds the threshold $\kappa$. If so, go back to the beginning, set $r_{t}=1$, use the parameterization $X_{t, j}^{P}\left(S_{t, j} ; r_{t}=1\right)$ instead, and implement the early liquidation of loans as discussed in Appendix A.3. This separates the grid points into two sets: a set of points for which there is no crisis and a set for which there is one.

2. Having solved for all period $t$ variables at grid point $j$, one obtains next period's endogenous state variables $\hat{S}_{t+1, j}$. To approximate integrals arising from expectation operators in intertemporal equations, I use five Hermite-Gaussian quadrature nodes and weights for period $t+1$. This gives next period's exogenous state variables $\bar{S}_{t+1, j, i}$ and therefore $S_{t+1, j, i}$ for each node $i \in\{1,2, \ldots, 5\}$ in period $t+1$ at each grid point $j$. Assume that there is no crisis in period $t+1$ at node $i$ for grid point $j$. Use the initial parameterization $X_{t+1, j, i}^{P}\left(S_{t+1, j, i} ; r_{t+1}=\right.$ 0 ) again and solve for the rest of the variables at node $i$ in period $t+1$.

Additional step with anticipated crises. If $r_{t}=0$, check whether the financial intermediary's leverage $L e v_{t+1}^{*}$ in period $t+1$ exceeds threshold $\kappa$. If so, use the parameterization $X_{t+1, j, i}^{P}\left(S_{t+1, j, i} ; r_{t+1}=1\right)$ instead, and again implement the liquidation of loans as described in A.3. If a crisis occurs, profits to loans are given by $R_{t}^{L} Q_{t-1}=\tau_{t}\left(1-\frac{\bar{\omega}_{t}^{*}}{4}\right)+\left(1-\tau_{t}\right)\left(\gamma Q_{t}+\right.$ $(1-\gamma)\left(1-\frac{\overline{\omega_{t}}}{4}\right)$. If crises are anticipated, then banks take this change into account depending on the realization of future shocks.

3. Having solved for all period $t+1$ variables, compute the expectation integrals in the equilibrium conditions. The intertemporal equations give an estimate $X_{t, j}^{P *}\left(S_{t, j}\right)$ for each of the 
initially parameterized variables $X_{t, j}^{P}\left(S_{t, j}\right)$ at each grid point $j$. A fixed point is obtained when the initially assumed value $X_{t, j}^{P}\left(S_{t, j}\right)$ is equal to $X_{t, j}^{P *}\left(S_{t, j}\right)$.

4. Until a fixed point is reached, iterate over the coefficients $\beta_{0}^{X}$ and $\beta_{1}^{X}$ in the policy functions (66). Collect the vectors of basis functions $T\left(S_{t, j}\right)$ for all grid points for which there is no crisis in period $t$, combine them in a matrix $T_{0}\left(S_{t}\right)$ and project these on the obtained estimates $X_{t, j}^{P *}\left(\mathrm{~S}_{t, j}\right)$, giving

$$
\hat{\beta}_{0}^{X} \equiv\left(T_{0}\left(\mathbf{S}_{t}\right)^{\prime} T_{0}\left(\mathbf{S}_{t}\right)\right)^{-1} T_{0}\left(\mathbf{S}_{t}\right)^{\prime} X_{t \mid r_{t}=0}^{P *}
$$

where $X_{t \mid r_{t}=0}^{P *}$ is a vector collecting the obtained estimates $X_{t, j}^{P *}\left(S_{t, j}\right)$ for which there is no crisis. Repeat the same for all grid points for which there is a crisis in period $t$, resulting in

$$
\hat{\beta}_{1}^{X} \equiv\left(T_{1}\left(\mathrm{~S}_{t}\right)^{\prime} T_{1}\left(\mathrm{~S}_{t}\right)\right)^{-1} T_{1}\left(\mathrm{~S}_{t}\right)^{\prime} X_{t \mid r_{t}=1}^{P *}
$$

5. Compute the coefficients $\beta_{0}^{X^{\prime}}$ and $\beta_{1}^{X^{\prime}}$ that are used for the next iteration via

$$
\begin{aligned}
& \beta_{0}^{X^{\prime}}=(1-\xi) \hat{\beta}_{0}^{X}+\xi \beta_{0}^{X}, \\
& \beta_{1}^{X^{\prime}}=(1-\xi) \hat{\beta}_{1}^{X}+\xi \beta_{1}^{X},
\end{aligned}
$$

where $0<\xi<1$ is a dampening parameter which helps convergence ( $\xi=0.1$ is used).

6. After several initial iterations, check for convergence and end iteration if

$$
\frac{1}{3} \sum_{X_{t}^{P} \in A} \frac{1}{M-M b} \sum_{j=1}^{M}\left|\frac{X_{t, j}^{P *}-X_{t, j \mid r_{t}=0}^{P}}{X_{t, j}^{P} \mid r_{t}=0}\right|<\eta \quad
$$

and

$$
\frac{1}{3} \sum_{X_{t}^{P} \in A} \frac{1}{M b} \sum_{j=1}^{M}\left|\frac{X_{t, j}^{P *}-X_{t, j \mid r_{t}=1}^{P}}{X_{t, j \mid r_{t}=1}^{P}}\right|<\eta,
$$

where $A=\left\{K_{t}^{\text {new }}, \frac{1}{D_{t}}, R_{t+1}\right\}, M$ denotes the number of points in the state space, and $M b$ the number of binding grid points. $\eta=5^{-04}$ is used. I find that setting $\eta$ to a lower value does not strongly increase the accuracy of the solution away from the grid points or change any of the results, but results in a significant increase in computational time.

Given the policy functions $X_{t}^{P}\left(S_{t}\right)$, one can use the model's equations to obtain the full set of policy functions $\hat{S}_{t+1}=f_{\hat{S}}\left(S_{t}\right)$ and $X_{t}=f_{X}\left(S_{t}\right)$ for a solution of the model as given in Definition 1. The accuracy of the solution is confirmed by analyzing the absolute residual equation errors

$$
\left|\frac{X_{t}^{P *}-X_{t}^{P}}{X_{t}^{P}}\right|
$$

in a simulation of the model as suggested by Judd (1992), where $X_{t}^{P *}$ is obtained in the same way as described above. I simulate the model for 50,000 periods and compute the decimal log of the absolute residual equation errors for each period $t$ and for each $X_{t}^{P} \in\left\{R_{t+1}, \frac{1}{D_{t}}, K_{t}^{\text {new }}\right\}$. In Figure (12), I plot histograms of those errors for each parametrized variable, where red lines indicate 
means. The means all lie below -5 . Given the reasoning in Judd (1992), one can consider the solution to be accurate.
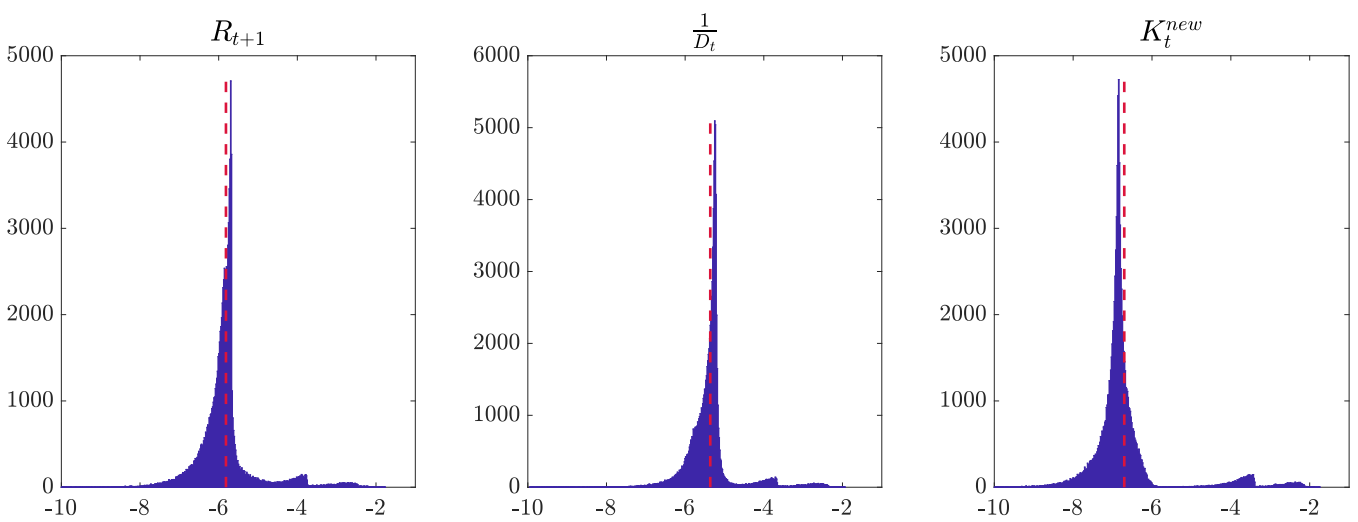

Figure 12: Accuracy. Histograms for absolute residual equation errors in decimal log basis, based on a 50,000-period simulation of the model. Red lines indicate means. 


\section{A.4 Data}

\section{A.4.1 Leverage Data}

Measures of the U.S. financial and the nonfinancial sector's book and market leverage for the period 1980 Q1-2016 Q4 are obtained as follows (see Adrian and Brunnermeier (2016) for similar calculations). Equity and balance sheet data for commercial banks, investment banks, and nonfinancial firms are collected from CRSP and Compustat. Commercial banks are indicated by the SIC Codes 60,61, and 6712. Nonfinancial firms are the remaining ones, excluding agriculture, forestry, and fishing as well as public administration. From CRSP, monthly time series for the market capitalization of firms are obtained. From Compustat, quarterly total assets and total liabilities are collected. The quarterly data are converted into a monthly frequency using linear interpolation. The two data sets are merged via Cusip and Permno identifiers. I repeat this exercise for the following selected investment banks: Bear Stearns, Citigroup, Credit Suisse, Goldman Sachs, HSBC, JP Morgan, Lehmann Brothers, Merrill Lynch, and Morgan Stanley. Applying these steps gives 502 financial and 3170 nonfinancial firms at the end of 2011.

Book Leverage. The measure of book leverage in the analysis is based on the following definition

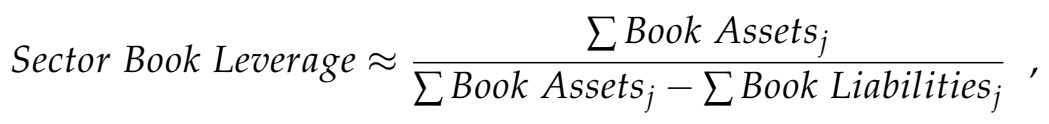

where the sums are taken over the available observations for a particular sector.

Market Leverage. The market leverage of a firm cannot be computed exactly since it requires either data on the market value of assets or the market value of liabilities - both of which are only observed in terms of their book values. To approximate market leverage, one can either assume that

$$
\text { Market Assets } \approx \text { Book Assets }
$$

or

$$
\text { Market Liabilities } \approx \text { Book Liabilities . }
$$

Given one of these assumptions, the market leverage of an industry is then approximated by

$$
\text { Sector Market Leverage } \approx \frac{\sum{\text { Book } \text { Assets }_{j}}_{\text {Market Equity }}}{\sum \text { Mark }}
$$

or

$$
\text { Sector Market Leverage } \approx \frac{\sum \text { Market Equity } j+\sum \text { Book Liabilities }_{j}}{\sum \text { Market Equity }},
$$

where the sums are taken over the observations within an industry. Approximation (68) is likely to be a better one than (67) due to the shorter maturity of liabilities and hence the more frequent updating on a balance sheet. I therefore primarily work with definition (70) and check robustness using definition (69). All of the results in the paper are robust to using definition (69). 


\section{A.4.2 Macrohistory Data}

The calibration targets for the frequency and the severity of financial crises are obtained from the Jorda-Schularick-Taylor Macrohistory Database (Jordà et al., 2017). This annual data set covers the years 1870-2013 and includes the following advanced economies (and their abbreviations used below): AUS $=$ Australia, BEL $=$ Belgium, CAN = Canada, CHE $=$ Switzerland, DEU $=$ Germany, DNK = Denmark, ESP $=$ Spain, FIN = Finland, FRA $=$ France, GBR $=$ Great Britain, $\mathrm{ITA}=$ Italy, JPN = Japan, NLD = Netherlands, NOR = Norway, PRT = Portugal, SWE = Sweden, USA $=$ United States. Following Jordà et al. (2013), I exclude war periods (WWI and WWII). For these countries, the data set contains information on a number of macroeconomic and financial variables and also incorporates indicators of financial crises events. Using a wide variety of sources, financial crises are identified as "events during which a country's banking sector experiences bank runs, sharp increases in default rates accompanied by large losses of capital that result in public intervention, bankruptcy, or forced merger of financial institutions"' (Schularick and Taylor, 2012). Table 2 lists all the financial crises dates. To identify recessions, I follow the same methodology as Jordà et al. (2013). They use the Bry and Boschan (1971) algorithm to determine local minima and maxima in real GDP to distinguish troughs and peaks. If a financial crisis occurs within the neighborhood of a business cycle peak, then the following recession is defined as a "financial recession". The remaining recessions are termed "nonfinancial recessions".

\begin{tabular}{lllllllllll}
\hline \hline & & & & & & & & \\
AUS & 1893 & 1989 & & & & & & \\
BEL & 1870 & 1885 & 1925 & 1931 & 1934 & 1939 & 2008 & & \\
CAN & 1907 & & & & & & & & \\
CHE & 1870 & 1910 & 1931 & 1991 & 2008 & & & & \\
DEU & 1873 & 1891 & 1901 & 1907 & 1931 & 2008 & & & \\
DNK & 1877 & 1885 & 1908 & 1921 & 1931 & 1987 & 2008 & & \\
ESP & 1883 & 1890 & 1913 & 1920 & 1924 & 1931 & 1977 & 2008 & \\
FIN & 1877 & 1900 & 1921 & 1931 & 1991 & & & & \\
FRA & 1882 & 1889 & 1930 & 2008 & & & & & \\
GBR & 1890 & 1974 & 1991 & 2007 & & & & & \\
ITA & 1873 & 1887 & 1893 & 1907 & 1921 & 1930 & 1935 & 1990 & 2008 \\
JPN & 1871 & 1890 & 1907 & 1920 & 1927 & 1997 & & & \\
NLD & 1893 & 1907 & 1921 & 1939 & 2008 & & & & \\
NOR & 1899 & 1922 & 1931 & 1988 & & & & & \\
PRT & 1890 & 1920 & 1923 & 1931 & 2008 & & & & \\
SWE & 1878 & 1907 & 1922 & 1931 & 1991 & 2008 & & & \\
USA & 1873 & 1893 & 1907 & 1929 & 1984 & 2007 & & & \\
& & & & & & & & & \\
\hline \hline
\end{tabular}

Table 2: Financial Crises Dates. 
Credit

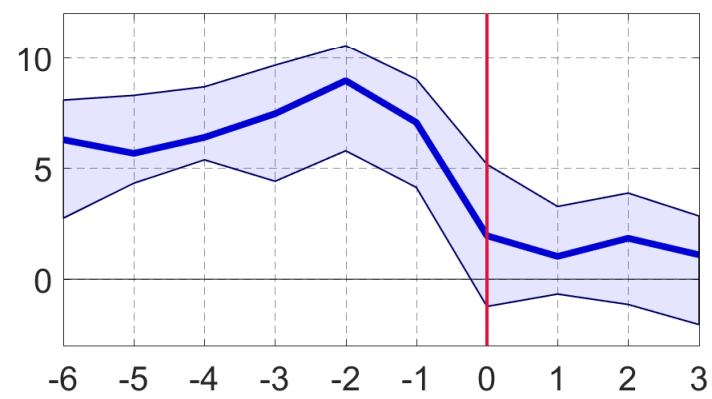

TFP

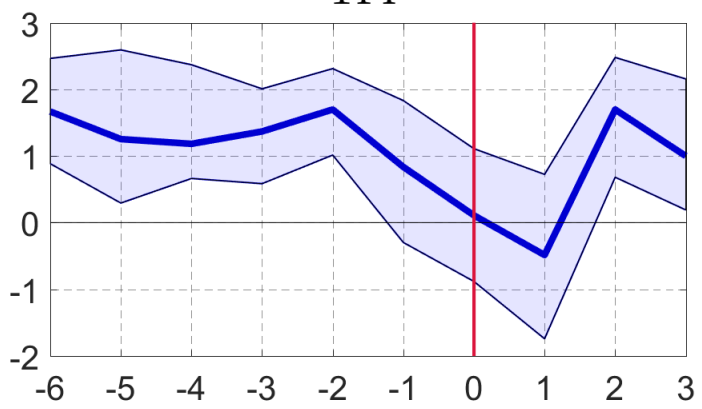

Labor Productivity

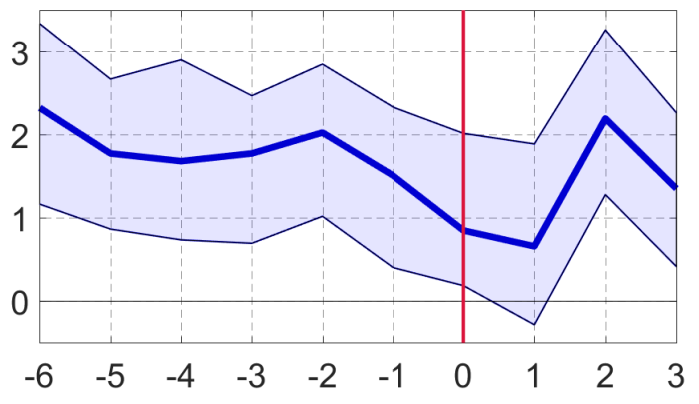

Util.-adj. TFP

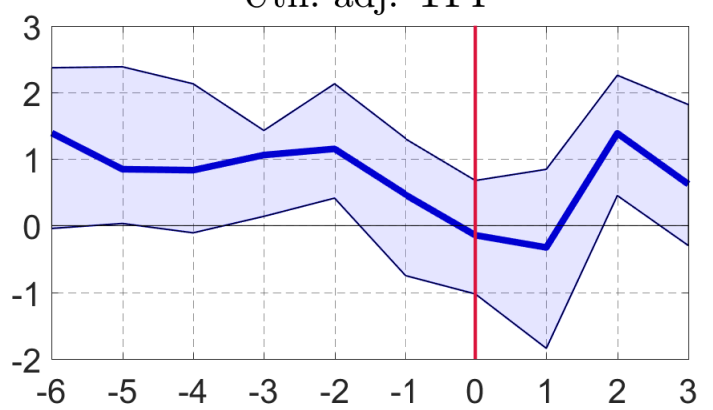

Figure 13: Macroeconomic Trends around Financial Crises. Annual percentage growth of aggregate bank credit (Source: Jordà et al., 2017) and various productivity measures (Source: Paul, 2018) around financial crises (year zero denotes start of a crisis based on the dates in Jordà et al., 2017). Median, 33 ${ }^{\text {rd }}$, and $66^{\text {th }}$ percentiles are shown.

\section{A.4.3 Maturity Data}

I compute measures of the maturity of assets and liabilities held by U.S. commercial banks using the data that banks report in the Call Reports for the sample 1997 Q2-2016 Q4 (see schedules RC-B, RC-C, and RC-E therein). To this end, I follow the assumptions in English et al. (2018). In the Call Reports, assets and liabilities are categorized by placing them into different buckets depending on their remaining maturity or next repricing date (e.g., remaining maturity between 1 and 3 years). For each interval, English et al. (2018) choose the midpoint as the representative maturity for all assets and liabilities within a particular bucket (e.g., 2 years for the interval 1-3 years). English et al. (2018) also assume that assets reported as having remaining maturity or next repricing date of over 15 years have a repricing/maturity period of 20 years on average (similarly for securities and time deposits with over 3 years that are assumed to have a repricing/maturity period of 5 years). In addition, I assume that mortgage and nonmortgage loans with maturity 5-15 years are assumed to have a maturity of 5 years, mortgage loans with maturity $>15$ years are assumed to have a maturity of 7 years, and non-mortgage loans with maturity $>15$ years are assumed to have a maturity of 15 years. Further, I assume that all liabilities apart from time deposits have a zero contractual maturity (e.g., demand, savings, and transaction deposits). Given these assumptions, I find that the average maturity of assets is 3.49 years and of liabilities 0.35 years. 


\section{A.5 Additional Results}

\section{A.5.1 Calibration - Additional Impulse Responses}
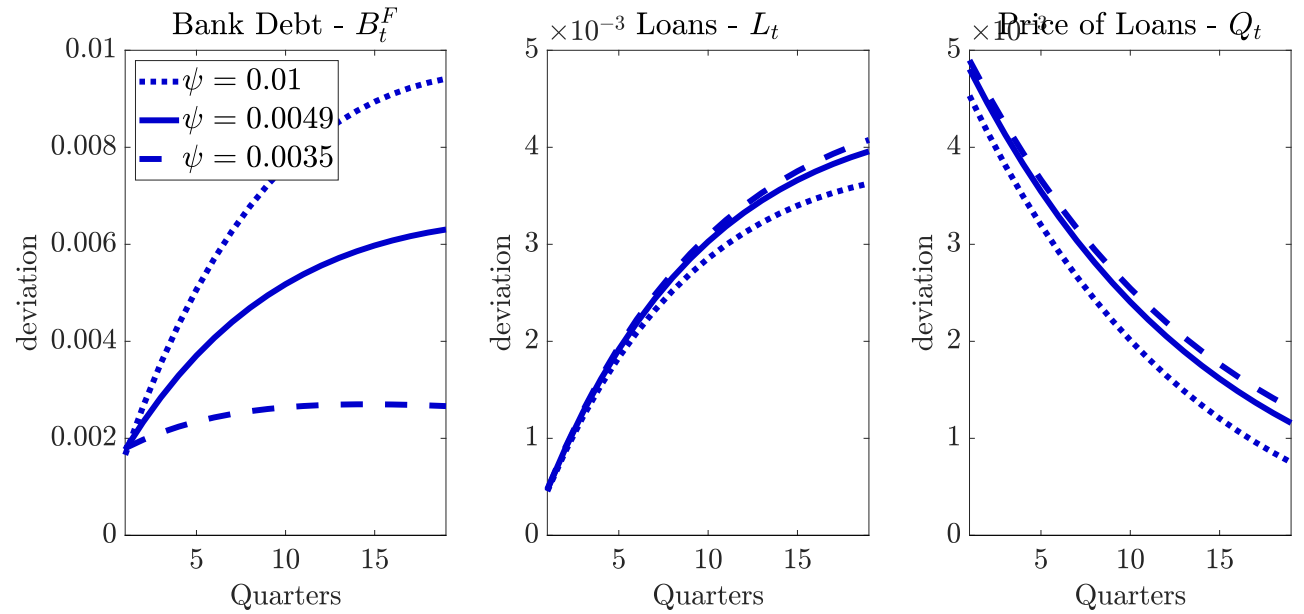

Figure 14: Impulse Responses for different values of $\psi$. Impulse responses of bank debt $B_{t}^{F}$, loans $L_{t}$, and price of loans $Q_{t}$ to a one-standard-deviation positive technology shock, starting from the deterministic steady state.

\section{A.5.2 Stochastic Steady State}

\begin{tabular}{ccc|ccc}
\hline Description & Variable & Value & Description & Variable & Value \\
\hline \hline & & & & & \\
Consumption & $C_{S S}$ & 1.87 & Asset-to-Equity-Ratio & $\frac{Q_{S S} L_{S S}}{Q_{S S} L_{S S}-B_{S S}}$ & 2.16 \\
Hours & $H_{S S}$ & 1.00 & Dividends & $D_{S S}$ & 0.02 \\
Output & $Y_{S S}$ & 2.27 & Return to loans & $R_{S S}^{L}$ & 1.015 \\
Capital & $K_{S S}$ & 15.34 & Loans & $L_{S S}$ & 2.35 \\
Return capital & $R_{S S}^{K}$ & 1.02 & Net worth & $N_{S S}$ & 1.34 \\
New loans & $Q_{S S} L_{S S}^{\text {new }}$ & 0.20 & Price long-term loans & $Q_{S S}$ & 0.84 \\
& & & & & \\
\hline
\end{tabular}

Table 3: Stochastic Steady State. Value of endogenous variables at the stochastic steady state. 


\section{A.5.3 Crisis Severity}
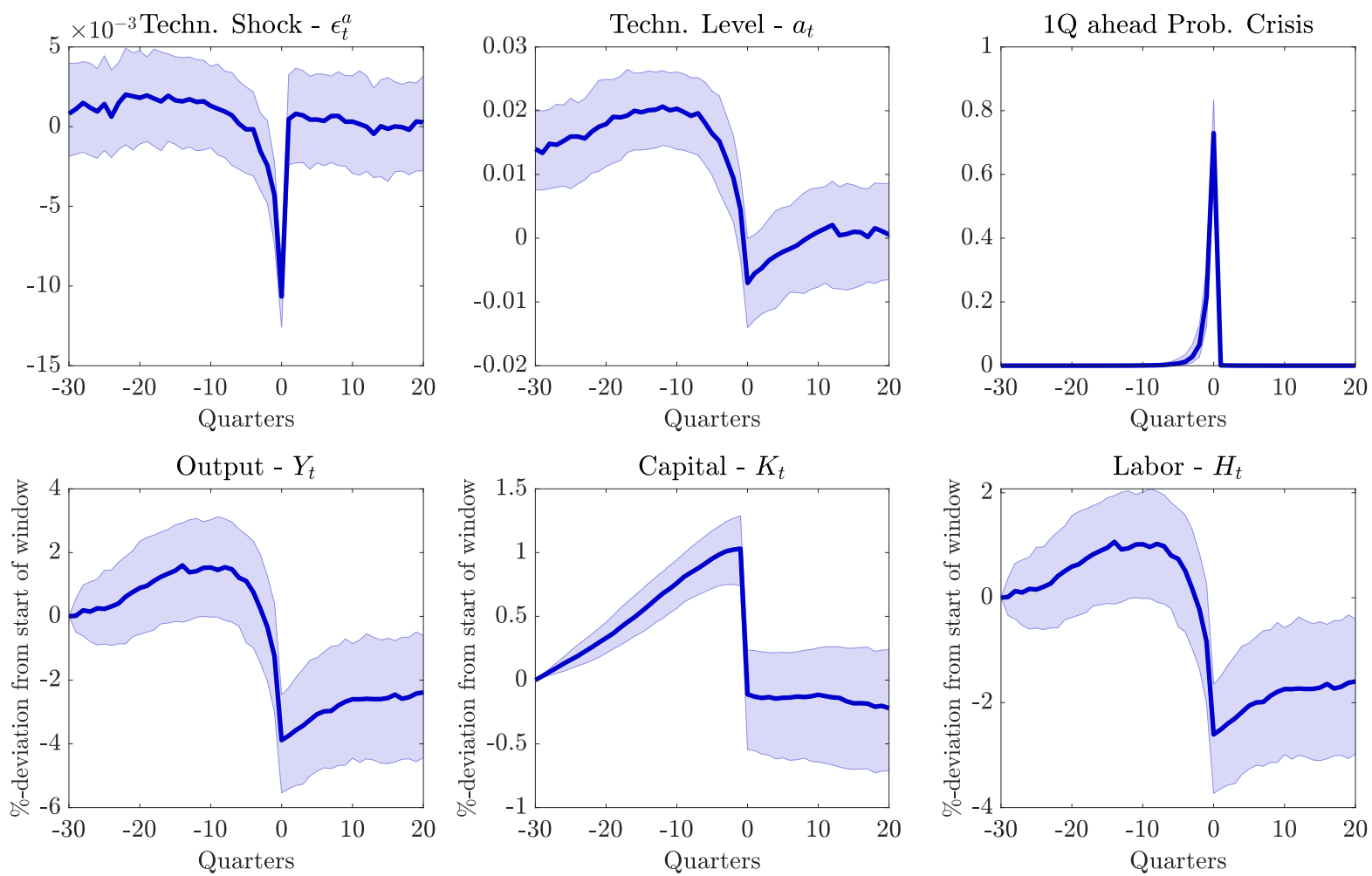

Figure 15: Typical Financial Crises - Sensitivity to $\mu$. Event window around financial crisis at Quarter $=0$. Based on a simulation of 500,000 periods. Median paths are shown. 

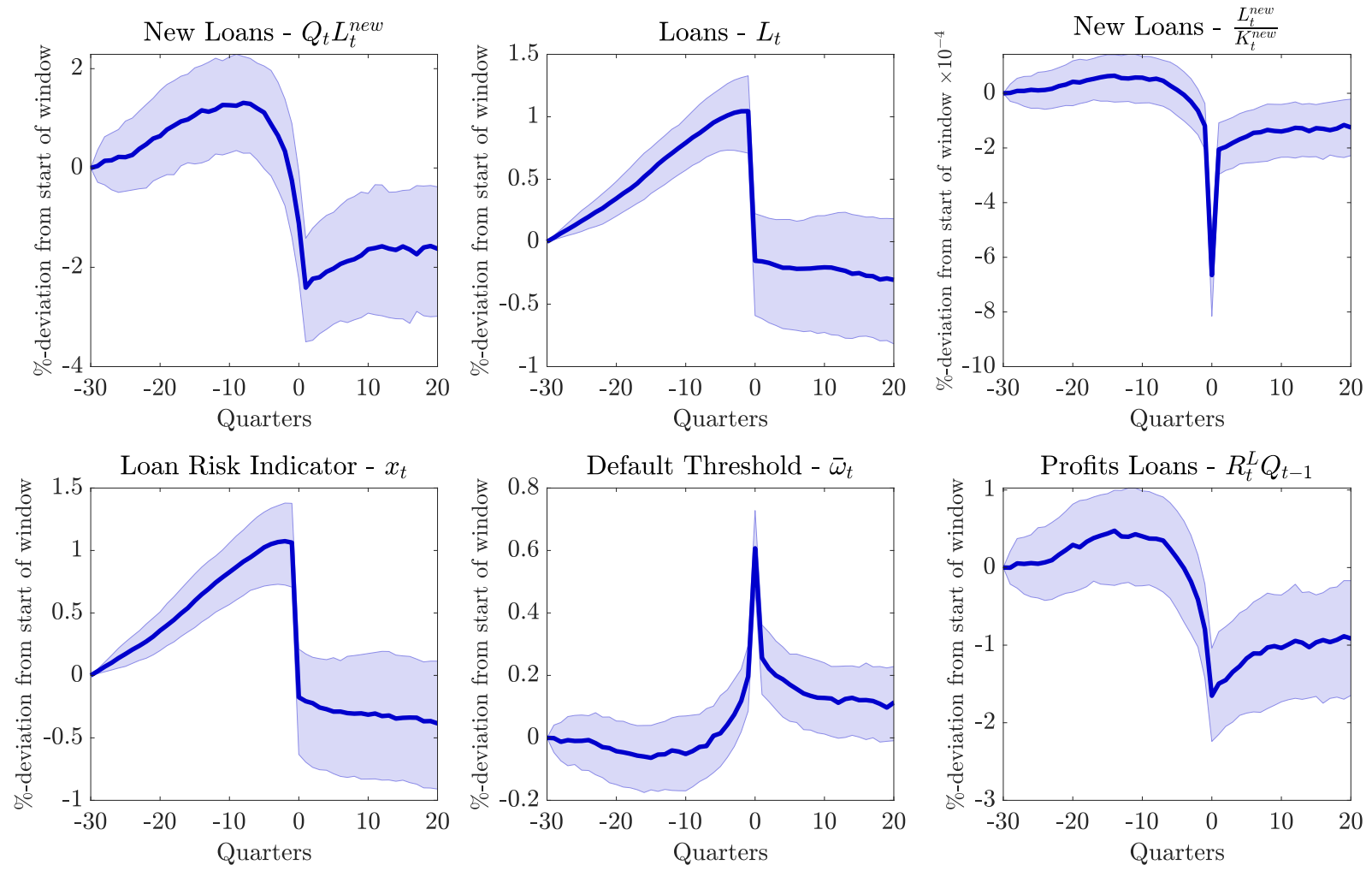

Figure 16: Typical Financial Crises - Sensitivity to $\mu$. Event window around financial crisis at $Q$ uarter $=0$. Based on a simulation of 500,000 periods. Median paths are shown.
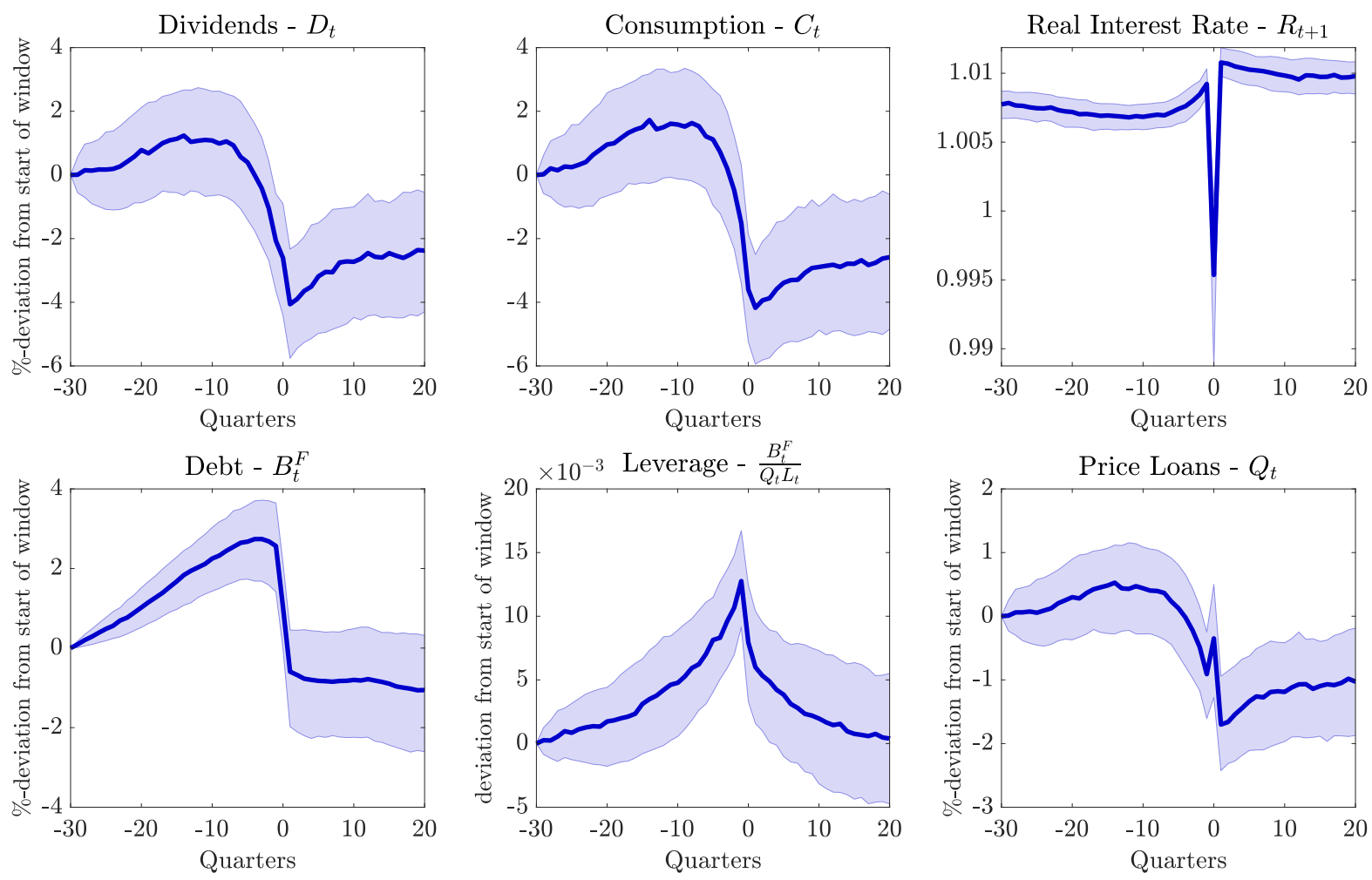

Figure 17: Typical Financial Crises - Sensitivity to $\mu$. Event window around financial crisis at Quarter $=0$. Based on a simulation of 500,000 periods. Median paths are shown. 


\section{A.5.4 Replicating Schularick \& Taylor (2012)}

This section replicates the baseline regressions in Schularick and Taylor (2012). In particular, consider the probabilistic model with the log-odds ratio

$$
\log \left(\frac{P\left[F C_{t}=1 \mid \cdot\right]}{P\left[F C_{t}=0 \mid \cdot\right]}\right)=\alpha+\beta_{1} \Delta_{4} \log \left(L_{t-1}\right)+\beta_{2} \Delta_{4} \log \left(Y_{t-1}\right)+u_{t}
$$

where $F C_{t}$ is equal to one if a financial crisis breaks out at time $t$ and zero otherwise. The log-odds ratio of $F C_{t}$ is assumed to be a function of a constant $\alpha$, the annual change of variable $L$ from period $t-5$ to $t-1$ denoted by $\Delta_{4} \log \left(L_{t-1}\right)$, and the annual change of output from period $t-5$ to $t-1$, denoted by $\Delta_{4} \log \left(Y_{t-1}\right)$. I consider additional annual lags of each regressor. For $L$, I use either the total stock of loans as defined in (8) or the book value of all loans as defined in (72). I also report the estimates of the Pseudo- $R^{2}$ and AUROC, which tend to be close to the empirical estimates by Schularick and Taylor (2012).

\begin{tabular}{ccccc}
\hline & Logit & Logit + GDP & Logit & Logit + GDP \\
\hline \hline Constant & $-5.8^{* * *}$ & $-5.8^{* * *}$ & $-5.3^{* * *}$ & $-5.4^{* * *}$ \\
$\Delta_{4} \log \left(L_{t-1}\right)$ & $91.4^{* * *}$ & $287.4^{* * *}$ & $-23.0^{* * *}$ & $159.1^{* * *}$ \\
$\Delta_{4} \log \left(L_{t-5}\right)$ & $210.5^{* * *}$ & $319.1^{* * *}$ & $66.8^{* * *}$ & $173.9^{* * *}$ \\
$\Delta_{4} \log \left(L_{t-9}\right)$ & $179.8^{* * *}$ & $241.6^{* * *}$ & $37.2^{* * *}$ & $117.1^{* * *}$ \\
$\Delta_{4} \log \left(L_{t-13}\right)$ & $76.6^{* * *}$ & $138.1^{* * *}$ & $21.7^{* * *}$ & $64.2^{* * *}$ \\
$\Delta_{4} \log \left(L_{t-17}\right)$ & $370.5^{* * *}$ & $115.1^{* * *}$ & $85.0^{* * *}$ & $-30.8^{* * *}$ \\
& & & & \\
\hline Book Value Loans & & & $\mathrm{X}$ & $\mathrm{X}$ \\
5 lags GDP growth & & $\mathrm{X}$ & & $\mathrm{X}$ \\
Pseudo $R^{2}$ & 0.015 & 0.014 & 0.004 & 0.006 \\
AUROC & 0.83 & 0.85 & 0.71 & 0.75 \\
\hline
\end{tabular}

Table 4: Notation: ${ }^{* *} p<0.01,{ }^{* *} p<0.05,{ }^{*} p<0.1$. 


\section{A.5.5 Replicating Jorda, Schularick \& Taylor (2013)}

This section replicates the baseline regressions in Jordà et al. (2013). In particular, consider the set of local projections

$$
\begin{gathered}
\left(\log \left(Y_{t+k}\right)-\log \left(Y_{t-1}\right)\right) \cdot 100=\alpha^{k}+\beta^{k}\left(\log \left(L_{t-1}\right)-\log \left(L_{t-9}\right)\right) \cdot 100+u_{t}^{k} \\
\text { for } \mathrm{k}=4,8,12,16,20
\end{gathered}
$$

where the dependent variable is the percentage change in output from period $t-1$ to $t+k$. The regressors are a horizon-specific constant $\alpha^{k}$ and the percentage change of total loans from $t-9$ to $t-1$, a two-year window. The results are robust to considering a one-year, three-year, four-year, or five-year window for loans instead. The set of regressions is estimated only for periods when a crisis takes place at time $t$. The coefficient $\alpha^{k}$ therefore gives the average percentage change in output from $t-1$ to $t+k$ and $\beta^{k}$ captures the additional percentage change in output when credit expanded by one percent more than on average.

\begin{tabular}{cccccc}
\hline $\mathrm{k}$ & 4 & 8 & 12 & 16 & 20 \\
\hline \hline$\alpha^{k}$ & $-1.55^{* * *}$ & $-1.33^{* * *}$ & $-1.02^{* * *}$ & $-0.91^{* * *}$ & $-0.74^{* * *}$ \\
$\beta^{k}$ & $-1.63^{* * *}$ & $-2.87^{* * *}$ & $-3.90^{* * *}$ & $-4.71^{* * *}$ & $-5.55^{* * *}$ \\
& & & & & \\
\hline$R^{2}$ & 0.05 & 0.10 & 0.13 & 0.16 & 0.20 \\
\hline
\end{tabular}

Table 5: Notation: ${ }^{* * *} p<0.01,{ }^{* *} p<0.05,{ }^{*} p<0.1$. 


\section{A.5.6 Replicating Krishnamurthy \& Muir (2017)}

Given the different maturity of long-term loans and short-term debt, I define credit spreads as

$$
\text { Spread }_{t}=\frac{1}{Q_{t}}-\left(R_{t}\right)^{\left(\frac{1}{1-\gamma}\right)} .
$$

Moreover, denote the change in output from peak to trough during a financial crisis as $y_{\text {peak }}, t_{r o u g h} h_{t+k}$ and the change in output from $t$ to $t+3$ as $y_{t, t+3}$. Following Krishnamurthy and Muir (2017), I obtain evidence on the predictive power of spreads using the regressions

$$
y_{\text {peak }}, \text { trough }_{t+k}=\alpha+\beta_{1} \text { Spread }_{t}+u_{t},
$$

and

$$
y_{t, t+3}=\alpha+\beta_{2} \cdot \text { crisis }_{t} \cdot \text { Spread }_{t}+\beta_{3} \cdot\left(1-\text { crisis }_{t}\right) \cdot \text { Spread }_{t}+u_{t}
$$

where crisis $_{t}$ is a binary financial crisis indicator. I find that $\beta_{1}, \beta_{2}$, and $\beta_{3}$ are all estimated to be negative. Hence, higher credit spreads are associated with deeper financial crises and declines in output in the near future, even in non-crisis periods (see also López-Salido, Stein, and Zakrajsek, 2017). 


\section{A.5.7 Nonfinancial Recessions}
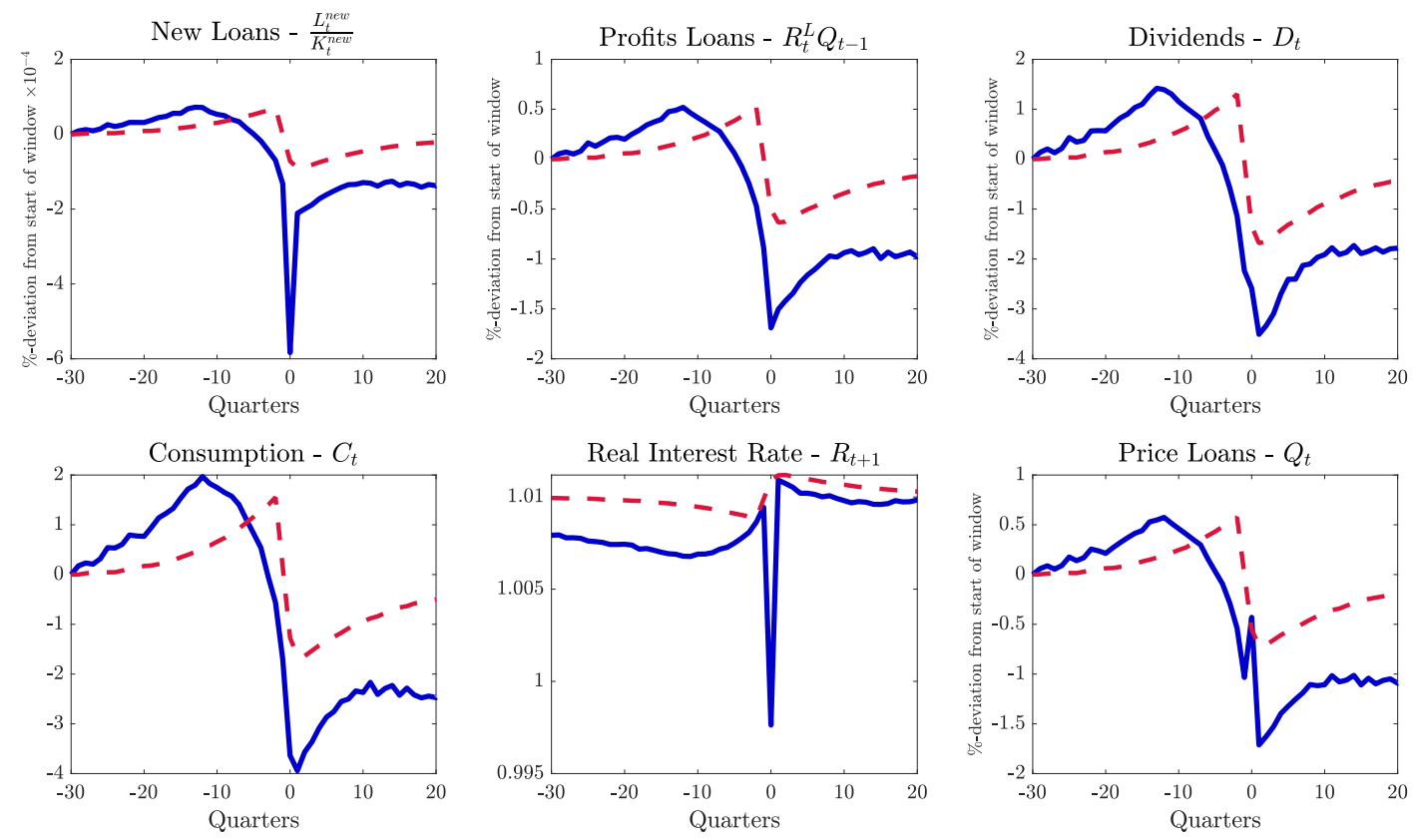

Figure 18: Typical Nonfinancial Recessions vs. Financial Crises. Event window around nonfinancial recession (red dotted line) or financial crisis (blue solid line) at Quarter $=0$. Based on a simulation of 500,000 periods. Median paths are shown. 


\section{A.5.8 Cyclicality of Leverage and Behavior around Crises}

The model is calibrated to match the cyclicality of market leverage for U.S. financial firms. Next, I show that the model also aligns with additional empirical evidence about leverage of financial and nonfinancial firms.

For what follows, it is useful to distinguish between book and market leverage - in the model and in the data. In the model, I have worked with the definition of the financial sector's market leverage $\frac{B_{t}^{F}}{Q_{t} L_{t}}$ so far, but one can also define a measure of book leverage as

$$
\text { Book Leverage FI } \equiv \frac{B_{t}^{F}}{B A_{t}^{F}},
$$

where $B A_{t}^{F}$ stands for book assets of the financial sector, defined recursively

$$
B A_{t}^{F}=Q_{t} L_{t}^{n e w}+\gamma B A_{t-1}^{F},
$$

such that new loans are recorded on the balance sheet with the value at which they were given out and held constant until they mature. Similarly, define leverage of the nonfinancial sector as

$$
\text { Market Leverage NF } \equiv \frac{L_{t}}{Q_{t}^{K} K_{t}} \quad, \quad \text { Book Leverage NF } \equiv \frac{L_{t}}{B A_{t}^{N F}} \quad \text {, }
$$

where $B A_{t}^{N F}$ stands for book assets of the nonfinancial sector, again defined recursively

$$
B A_{t}^{N F}=Q_{t}^{K} K_{t}^{n e w}+\gamma B A_{t-1}^{N F}
$$

such that newly acquired capital is recorded on firms' balance sheets with the value at which it was acquired and held constant until a firm's project ends. Equipped with these definitions, one can compare the behavior of leverage in the model with the data. As described in Appendix A.4.1, I obtain empirical measures for these two types of leverage for the U.S. financial and nonfinancial sectors by combining equity and balance sheet firm-level data sets. ${ }^{21}$

Replicating Evidence by Adrian \& Shin. Adrian and Shin (2010) show that leverage of certain financial institutions is procyclical based on book value data. More specifically, Adrian and Shin $(2010,2014)$ term leverage to be procyclical when (percentage) changes in book leverage are positively correlated with (percentage) changes in banks' book assets. In Figure 19, I replicate two key graphs from Adrian and Shin (2014, Figure 3) based on a simulation of the model. As in the data, changes in financial sector book leverage are positively correlated with changes in the size of banks' balance sheets. Changes in the enterprise value are negatively correlated with changes in enterprise value leverage.

\footnotetext{
${ }^{21}$ As a proxy for the U.S. financial sector leverage, I use firm-level data for commercial and investment banks. This data has the disadvantage that it is not possible to net-out interbank loans for the sector as a whole. Krishnamurthy and Vissing-Jorgensen (2015) address this issue, but their approach does not allow to compute market leverage ratios.
} 

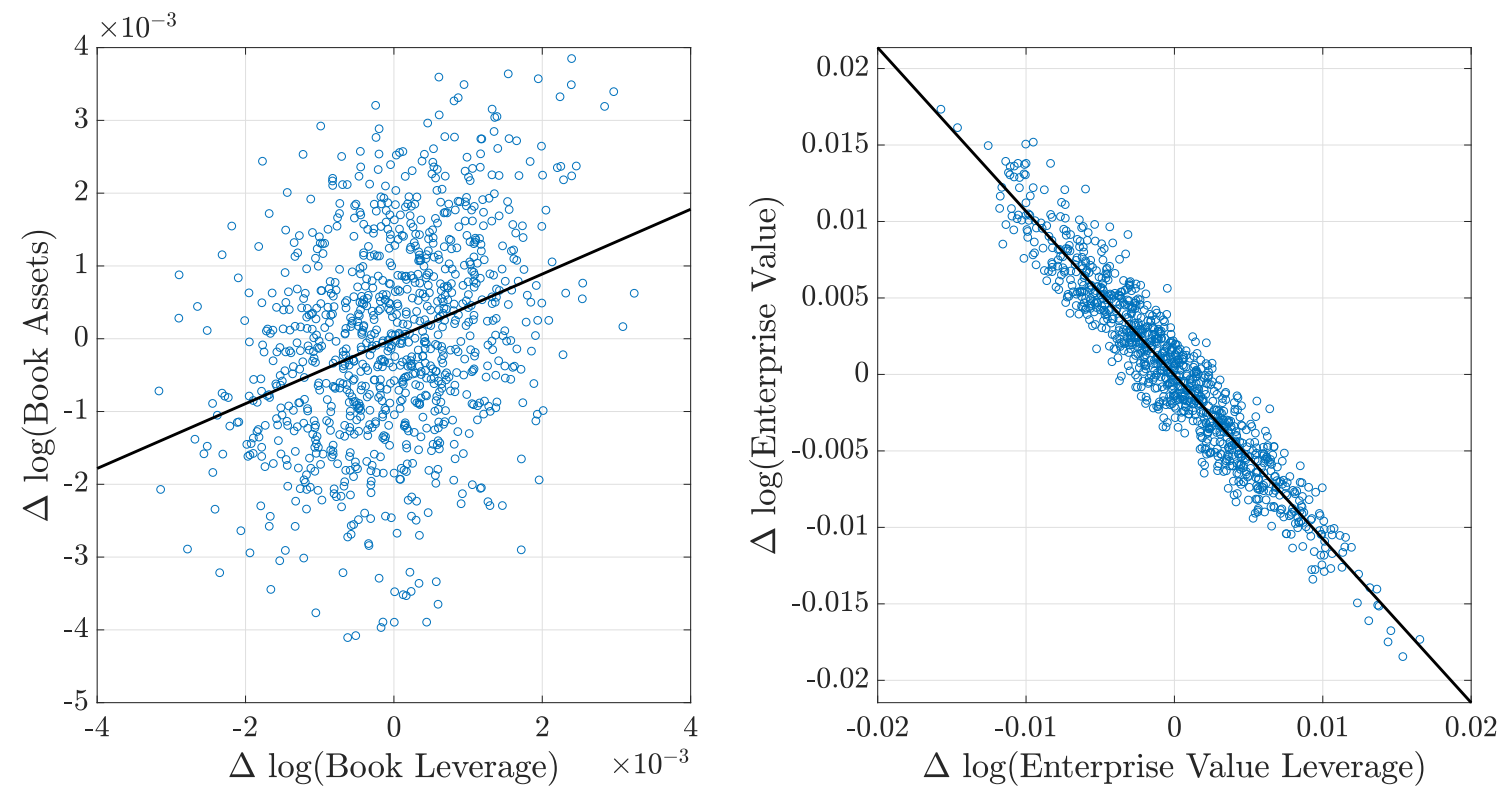

Figure 19: Cyclicality of Book Leverage and Enterprise Value Leverage. The two graphs replicate Figure 3 in Adrian and Shin (2014) based on a 1.000-period-simulation of the model. The left graph shows a scatter-plot of the percentage change in the financial sector's book assets (as defined in equation (72)) against the percentage change in the financial sector's book leverage (as stated in (71)). The right graph shows a scatter-plot of the percentage change in the financial sector's enterprise value (given by the market value of assets, $Q_{t} L_{t}$ ) against the percentage change in the financial sector's market leverage (given by $\left.\frac{Q_{t} L_{t}}{Q_{t} L_{t}-B_{t}}\right)$.

Cyclicality of Leverage. Here, I use a different definition of cyclicality that naturally fits the business cycle setup of the model. Following Cooley and Prescott (1995), Table 6 shows the correlation between the cyclical component of book leverage, differentiated by sectors, and real industrial production as a proxy for economic activity at a monthly frequency. ${ }^{22}$ Two samples are considered, one including and one excluding the Great Recession.

\begin{tabular}{c|c|c|c}
\hline & \multicolumn{2}{|c|}{ Data } & \multirow{2}{*}{ Model } \\
\cline { 2 - 4 } & 1980 M1-2007 M12 & 1980 M1-2016 M12 & \\
\hline \hline & & $0.16^{* * *}$ & \\
Financial & $0.22^{* * *}$ & $-0.22^{* * *}$ & 0.24 \\
Nonfinancial & -0.06 & & \\
& & & \\
\hline
\end{tabular}

Table 6: Cyclicality of Book Leverage. Correlation between cyclical component of book leverage and real industrial production. Notation: ${ }^{* * *} p<0.01,{ }^{* *} p<0.05,{ }^{*} p<0.1$.

\footnotetext{
${ }^{22}$ I use a monthly measure of economic activity to capture the correlation with higher-frequency movements in asset prices, as the ones that drive market leverage. Real industrial production is used as a proxy for economic activity at a monthly frequency. However, the results for real GDP at a quarterly frequency are much the same. The logarithm of industrial production and leverage are detrended using a Hodrick-Prescott filter (a smoothing parameter of 129,600 for monthly data is applied following Ravn and Uhlig, 2002). The results are not specific to using this filter and its decomposition. In particular, I find that the results are similar when using a Baxter-King Filter that associates the cycle with frequencies between two months and eight years, i.e. conventional business cycle frequencies, or longer-term cycles up to 12 years that may better capture so-called financial cycles.
} 
For the financial sector, book leverage is procyclical and significantly different from zero at the $99 \%$ confidence level for both samples. For the nonfinancial sector, book leverage is countercyclical but only mildly based on the sample that ends before the Great Recession. The model's implied correlation between output $Y_{t}$ and book leverage is largely in line with this empirical evidence. For the nonfinancial sector, the correlation is close to zero. That is because of the borrowing constraint (10), which eliminates most of the fluctuations in the book leverage of new entrepreneurs. For the financial sector, the correlation matches the data well.

In Table 7, I repeat the exercise for market leverage. Financial sector market leverage is either mildly procyclical or countercyclical in the data, depending on the sample. Nonfinancial sector market leverage is countercyclical for both samples. The model's implied cyclicality of market leverage is close to this empirical evidence. For the financial sector, it is very close to the sample that excludes the Great Recession. For the nonfinancial sector, it is slightly more negative than in the data.

\begin{tabular}{c|c|c|c}
\hline & \multicolumn{2}{|c|}{ Data } & \multirow{2}{*}{ Model } \\
\cline { 2 - 3 } & 1980 M1-2007 M12 & 1980 M1-2016 M12 & \\
\hline \hline & & $-0.27^{* * *}$ & \\
Financial & 0.04 & $-0.38^{* * *}$ & 0.07 \\
Nonfinancial & $-0.14^{* *}$ & & -0.45 \\
& & & \\
\hline
\end{tabular}

Table 7: Cyclicality of Market Leverage. Correlation between cyclical component of market leverage and real industrial production. Notation: ${ }^{* * *} p<0.01,{ }^{* *} p<0.05,{ }^{*} p<0.1$.

Behavior of Leverage around Crises. Next, I compare the behavior of leverage around crises. Figure 20 shows the evolution of the U.S. financial sector's leverage around the 2007-09 financial crisis, comparing it with the typical behavior of leverage around crises in the model. In both model and data, market leverage increases sharply around a crisis. In contrast, book leverage rises in the run-up and decreases during a crisis. In the data, book leverage barely moves compared to market leverage. Figure 21 repeats the exercise for nonfinancial firm leverage. Book leverage in the model decreases around crises, in contrast to the data, where it barely moves. Nonfinancial sector market leverage shows a stronger increase around the crisis, in line with the data. 

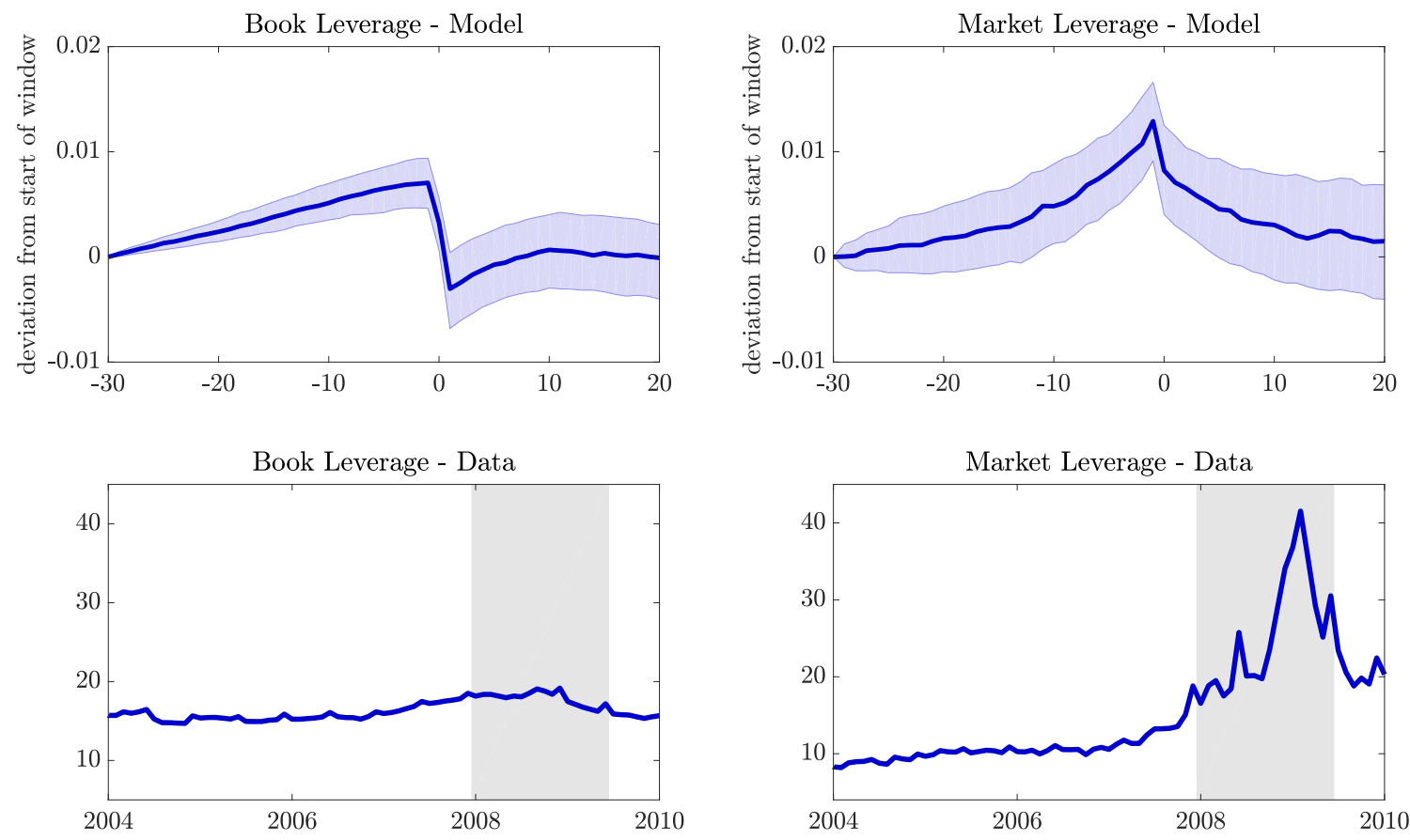

Figure 20: Financial Sector Leverage. Top graphs: Typical behavior of financial sector's leverage based on simulation of the model as in Section 4.2. Bottom graphs: U.S. financial sector's leverage around the 2007-09 financial crisis.
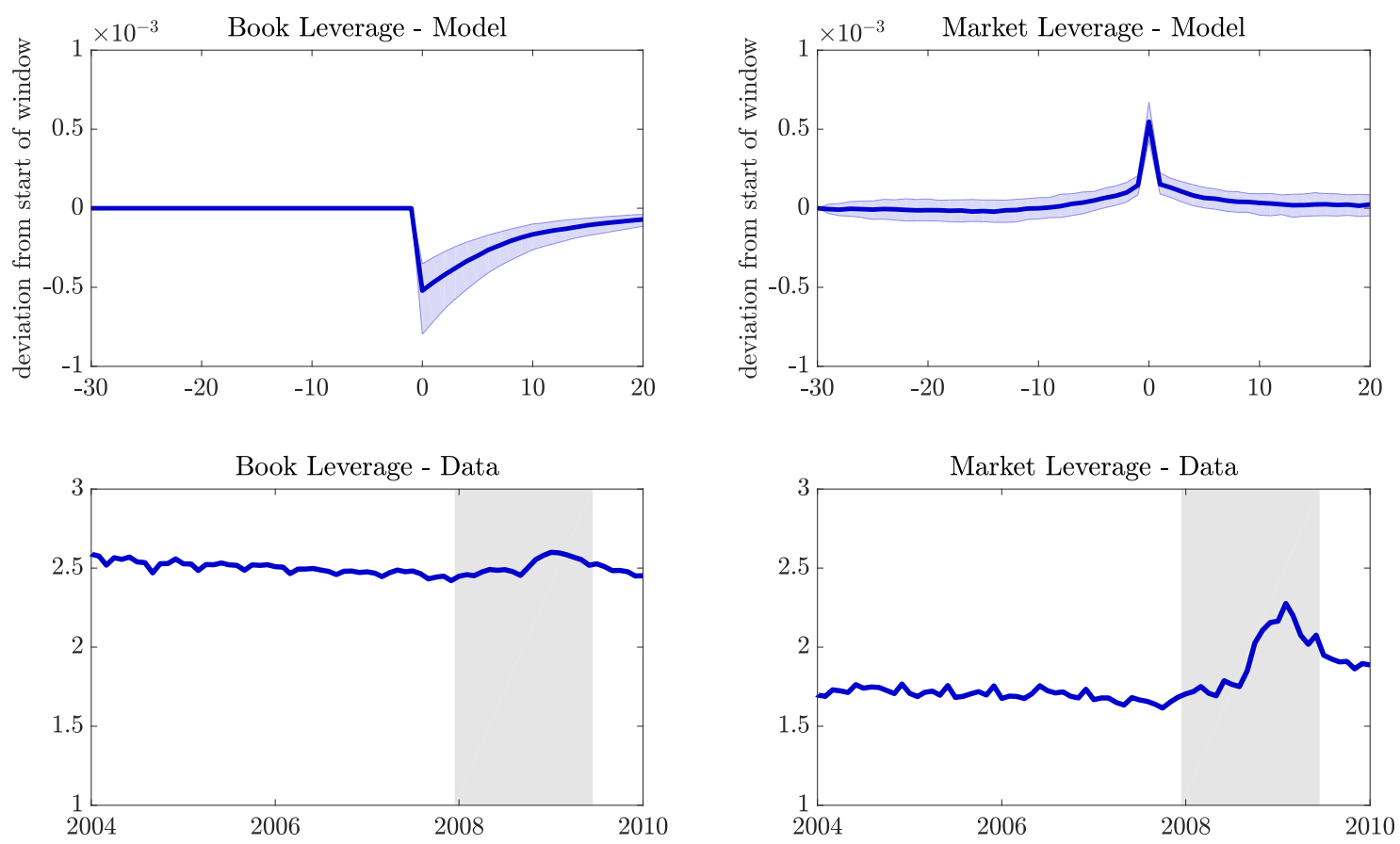

Figure 21: Nonfinancial Sector Leverage. Top graphs: Typical behavior of nonfinancial sector's leverage based on simulation of the model as in Section 4.2. Bottom graphs: U.S. nonfinancial sector's leverage around the 2007-09 financial crisis. 


\section{A.5.9 Anticipated Crises}

In this section, I allow for crises to be anticipated. That is, when making their decisions, agents take into account that crises may occur in the future due to the realization of future shocks. A challenge that arises in this regard is that the liquidation of loans and the selling of liquidated capital adds substantial variation and nonlinearity to the model. To ensure convergence of the solution, I therefore simplify the model and assume that whenever a run equilibrium is possible according to (18), banks liquidate a constant fraction of their loans instead of $\tau_{t}$ being determined endogenously according to (20). I set $\tau_{t}=0.7 \%$, in the mid-range of the simulations based on the two calibrations considered in Section 4.2. To ensure the stability of the model, I further assume that crises cannot occur for two consecutive periods.

Moreover, from the perspective of banks, crises are not necessarily "bad" events. On one hand, for the simulation of the model, it is not optimal to liquidate loans since the payoff of a liquidated loan is always lower than from a loan that is not liquidated as described in Section 2.5. However, on the other hand, once loans are liquidated, they generate additional liquidity and potentially higher dividend payouts during crises. Intertemporal consumption smoothing therefore does not necessarily imply that banks aim to operate with a lower leverage to stay away from crises regions. In fact, they may be drawn towards them. I find that a lower value of $\mu=0.05$ balances well the opposing incentives of losses from liquidated loans versus additional resources to pay out dividends. The remaining parameters are kept at their previous values.

The solution technique for the model with anticipated crises is described in Appendix A.3.1. Figures 22-24 show how the economy typically behaves around crises. Crises are slightly more frequent $(5 \%)$ but as severe as in the model with unanticipated crises. Overall, the patterns are very similar to the ones shown in Section 4.2. 

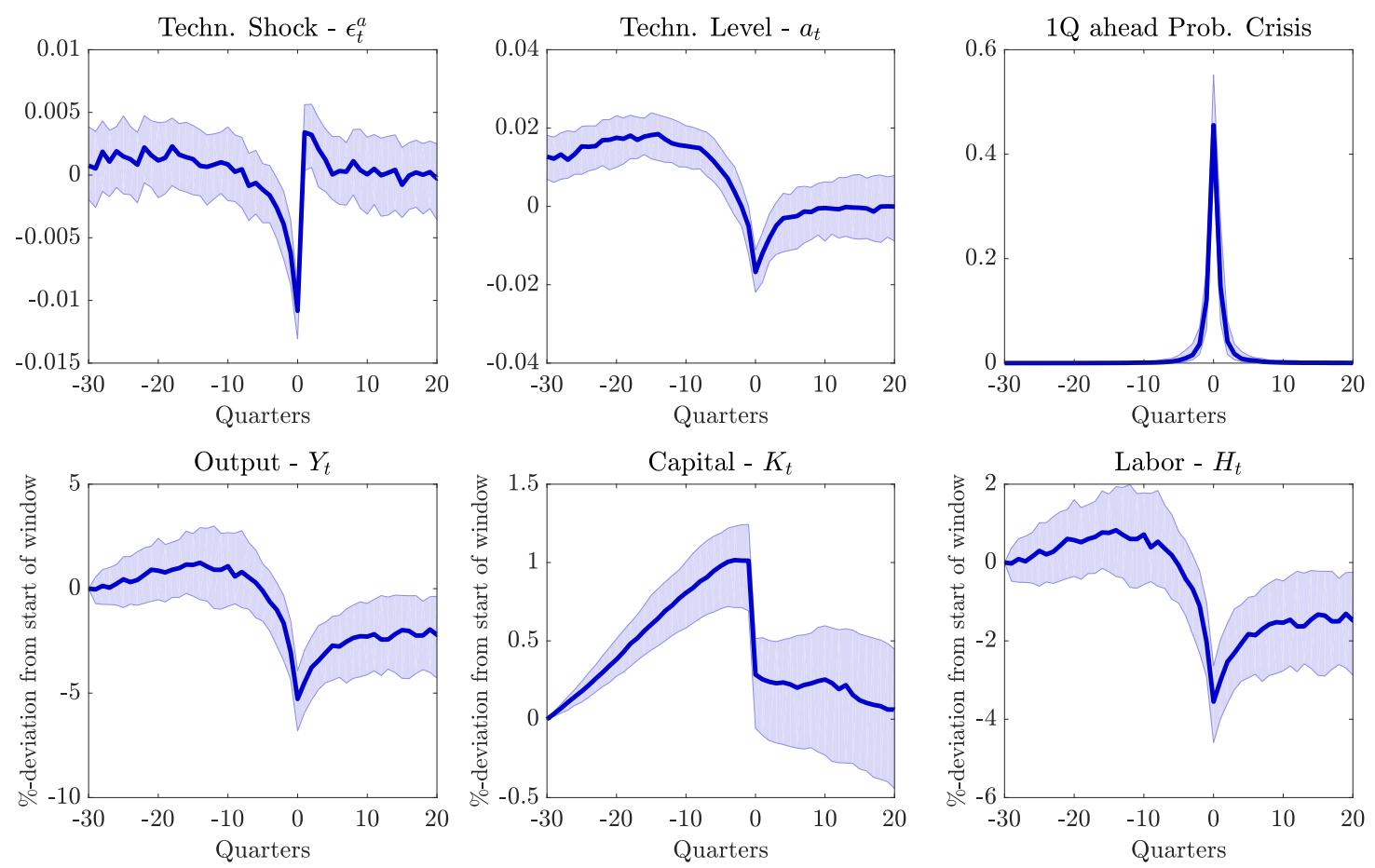

Figure 22: Typical Financial Crises. Event window around financial crisis at Quarter $=0$. Based on a simulation of 500, 000 periods. Median, $33^{\text {rd }}$, and $66^{\text {th }}$ percentiles are shown.
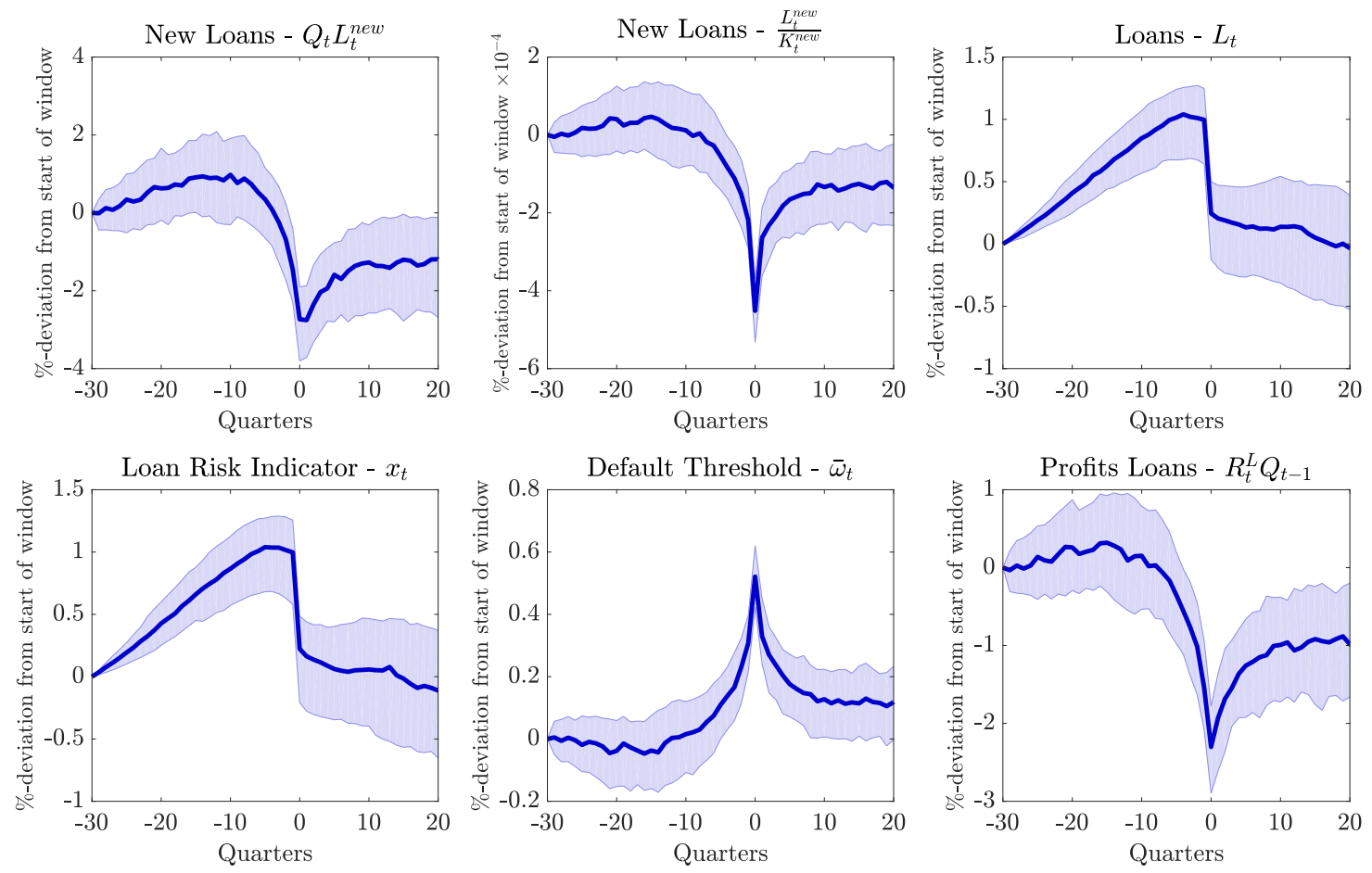

Figure 23: Typical Financial Crises. Event window around financial crisis at Quarter $=0$. Based on $a$ simulation of 500, 000 periods. Median, $33^{\text {rd }}$, and $66^{\text {th }}$ percentiles are shown. 

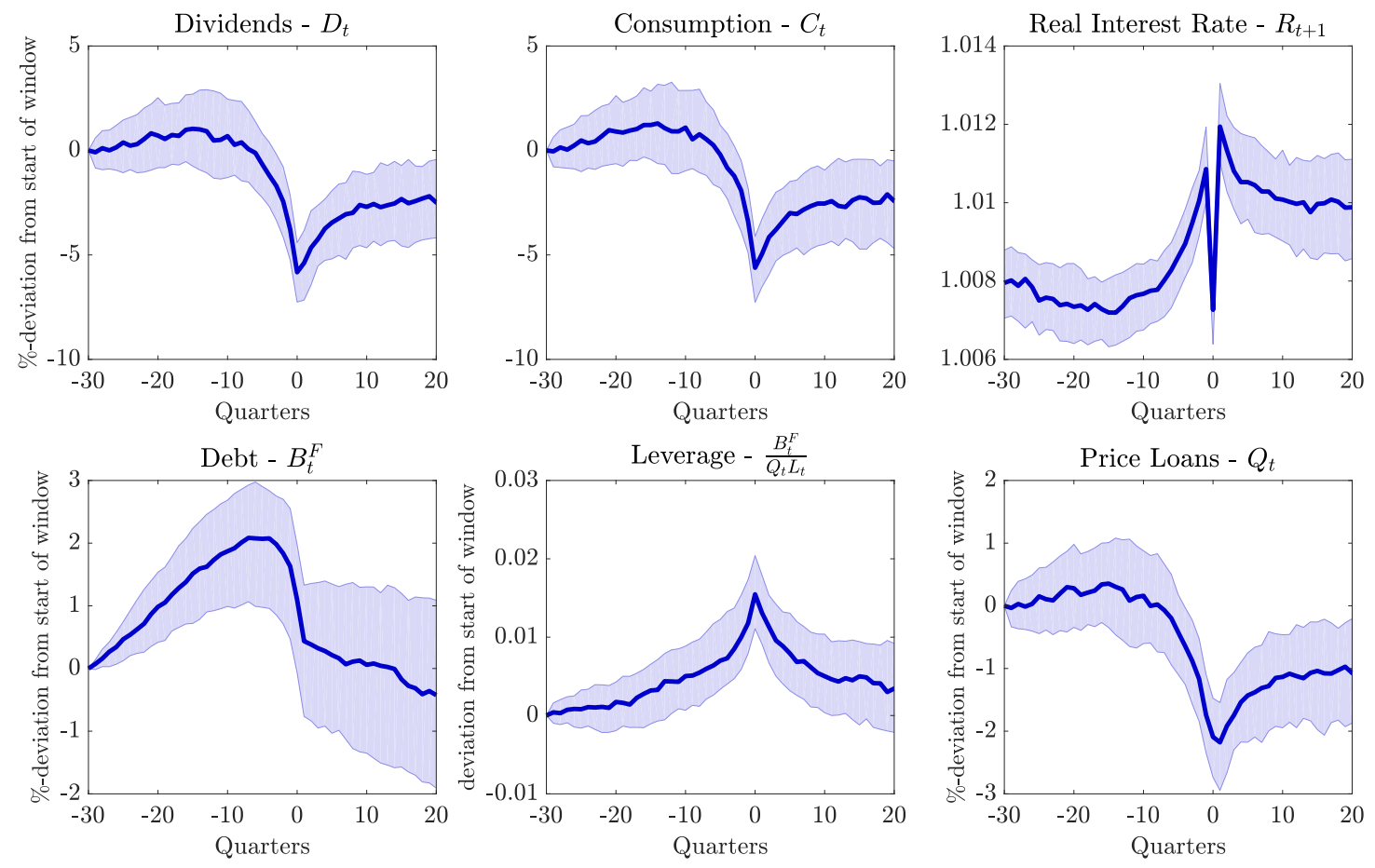

Figure 24: Typical Financial Crises. Event window around financial crisis at Quarter $=0$. Based on $a$ simulation of 500, 000 periods. Median, $33^{\text {rd }}$, and $66^{\text {th }}$ percentiles are shown.

\section{A.5.10 Simplified Model without Loans}

This section considers a simplified model without loans. I keep the description of the model relatively brief since most equilibrium conditions and the notation remain the same.

Households and Good Producer. The problem for households remains unchanged compared with Section 2.1. Since there are no entrepreneurs in the model, households do not receive lumpsum transfers $T_{t}^{H}$. The problem of the representative good producer is also the same as described in Section 2.2. The combined equilibrium conditions for households and the good producer are stated in (44)-(48).

Financial Intermediaries. The decision problem for financial intermediaries changes compared with the one in Section 2.4. Taking prices and interest rates as given, a bank maximizes

$$
E_{t}\left[\sum_{k=0}^{\infty}\left(\beta^{F}\right)^{k} U^{F}\left(D_{t+k}\right)\right]
$$

subject to

$$
D_{t}+Q_{t}^{K} K_{t}+B_{t-1}^{F} \widetilde{R}_{t} \leq B_{t}^{F}+R_{t}^{K} Q_{t-1}^{K} K_{t-1}+T_{t}^{F}
$$

such that intermediaries directly invest in capital $K_{t}$. The interest rate $\widetilde{R}_{t}$ is again given by $\widetilde{R}_{t}=$ $R_{t}+\psi B_{t-1}^{F}$ and $T_{t}^{F}=\psi\left(B_{t-1}^{F}\right)^{2}$. Bank leverage is now denoted by $\frac{B_{t}^{F}}{Q_{t}^{K} K_{t}}$. The solution to the 
intermediary's problem is given by two intertemporal optimality conditions,

$$
\begin{aligned}
\frac{1}{D_{t}} & =\beta^{F} E_{t}\left[\frac{1}{D_{t+1}}\right] \widetilde{R}_{t+1}, \\
\frac{1}{D_{t}} & =\beta^{F} E_{t}\left[\frac{R_{t+1}^{K}}{D_{t+1}}\right],
\end{aligned}
$$

where $R_{t+1}^{K}=\frac{Q_{t+1}^{K}(1-\delta)+\alpha \frac{\gamma_{t+1}}{K_{t}}}{Q_{t}^{K}}$.

Capital Good Producer and Resource Constraint. The problem of the representative capital good producer and the resource constraint remain the same as in Section 2.6. The equilibrium conditions are stated in (59)-(63).

The next two sections consider two special cases of this basic environment to clearly illustrate what drives bank leverage.

\section{A.5.11 Model I: Constant Capital and Labor}

First, I assume that capital and labor are constant, equal to unity in all periods, $H_{t}=1$ and $K_{t}=1 \forall t$, and supplied inelastically. Production simplifies to $Y_{t}=A_{t}$, the wage is given by $w_{t}=(1-\alpha) A_{t}$, and the rental rate of capital is equal to $r_{t}^{K}=\alpha A_{t}$. Since households supply one unit of labor inelastically in all periods, I set $\chi=0$ and equation (1) is not part of the household's optimality conditions. The household's stochastic discount factor simplifies to $\Lambda_{t, t+1}=\beta^{H}\left(\frac{C_{t}}{C_{t+1}}\right)$. Further, I assume that $\delta=0$ and that there are no capital good producers and no investment. The price of capital $Q_{t}^{K}$ is then determined by the asset pricing equation (77). With these restrictions, households and banks simply receive stochastic endowment streams. All parameters are calibrated as in Section 3, that is $\rho_{a}=0.93, \sigma_{a}=0.68 \%, \alpha=0.3, \beta^{H}=0.99, \beta^{F}=0.985$. I set $\psi=0.0005$ to obtain an asset-to-equity ratio for intermediaries of around 2 in steady state, as implied by the calibration of the main model and therefore simplifying cross-comparisons.

Impulse Responses. The model is solved with a first-order perturbation method around the deterministic steady state. The impulse responses to a positive one-standard-deviation technology shock are shown in Figure (25). Output $Y_{t}$, household consumption $C_{t}$, and dividends $D_{t}$ increase. Both agents would prefer to save part of their additional income. However, in equilibrium, the incentives for banks to save dominate and $B_{t}^{F}$ falls. That is because banks have a lower steady-state level of consumption than households, and consumption smoothing dictates that less resources are used to increase consumption and more of the additional income is saved. In equilibrium, the real interest rate $R_{t+1}$ declines as well as the premium for borrowing $\psi B_{t}^{F}$. In addition, the value of capital $Q_{t}^{K}$ increases, such that intermediary leverage $\frac{B_{t}^{F}}{Q_{t}^{K}}$ unambigiously falls. The correlation between output and leverage is -0.5 . Hence, in this environment with constant capital and labor, bank leverage is countercyclical. 

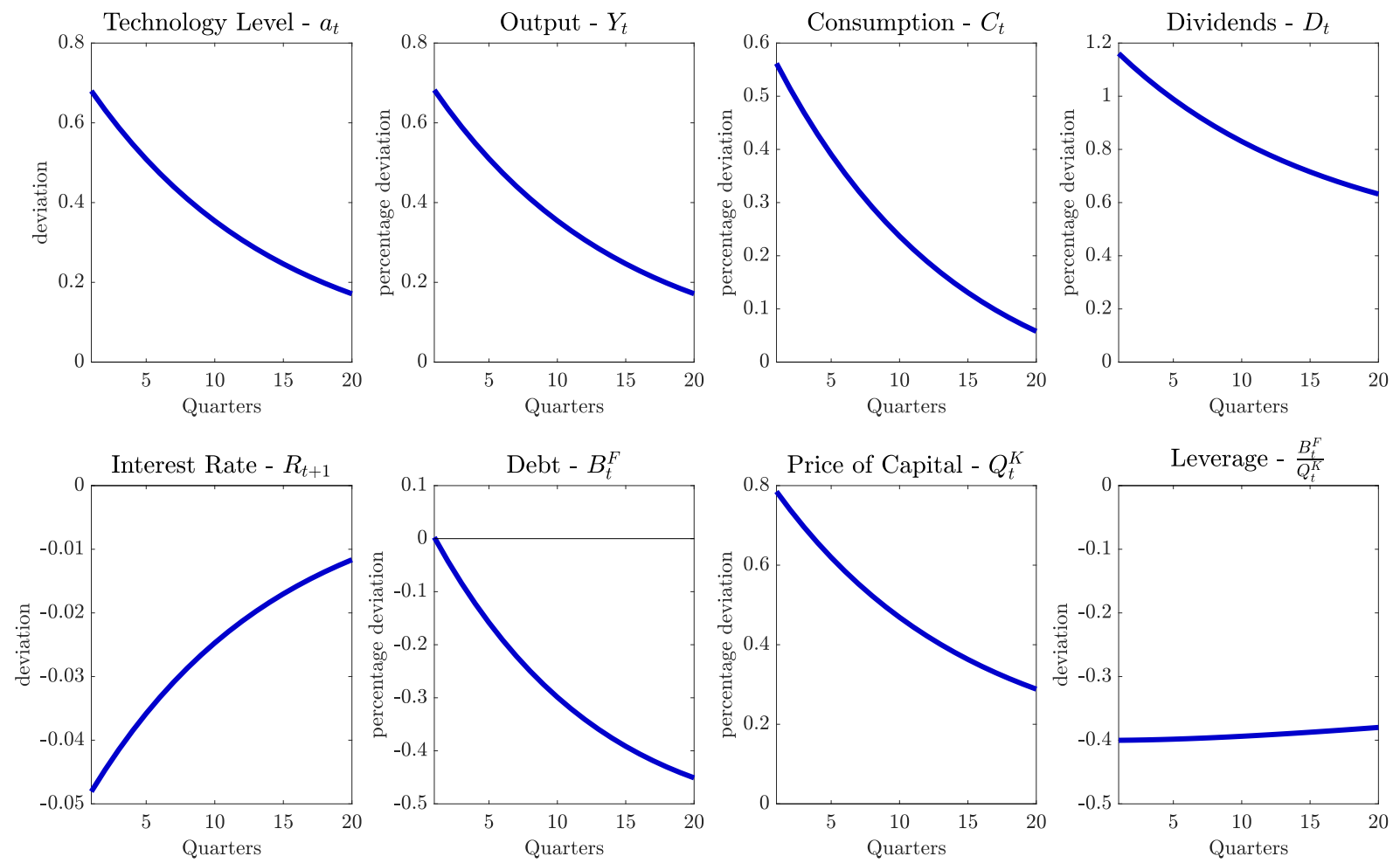

Figure 25: Impulse Responses - Model with Constant Capital and Labor. Impulse responses to a positive one-standard-deviation technology shock, all responses are multiplied by 100.

These results are driven by the differences in discount factors. Figure 26 shows the response of leverage $\frac{B_{t}^{F}}{Q_{t}^{K}}$ for different values of $\beta^{F}$, leaving the remaining parameters unchanged. If $\beta^{F}>\beta^{H}$, then intermediary leverage increases after a positive shock for a range of calibrations. If $\beta^{F}=\beta^{H}$, then $\frac{B_{t}^{F}}{Q_{t}^{K}}=0 \forall t$.

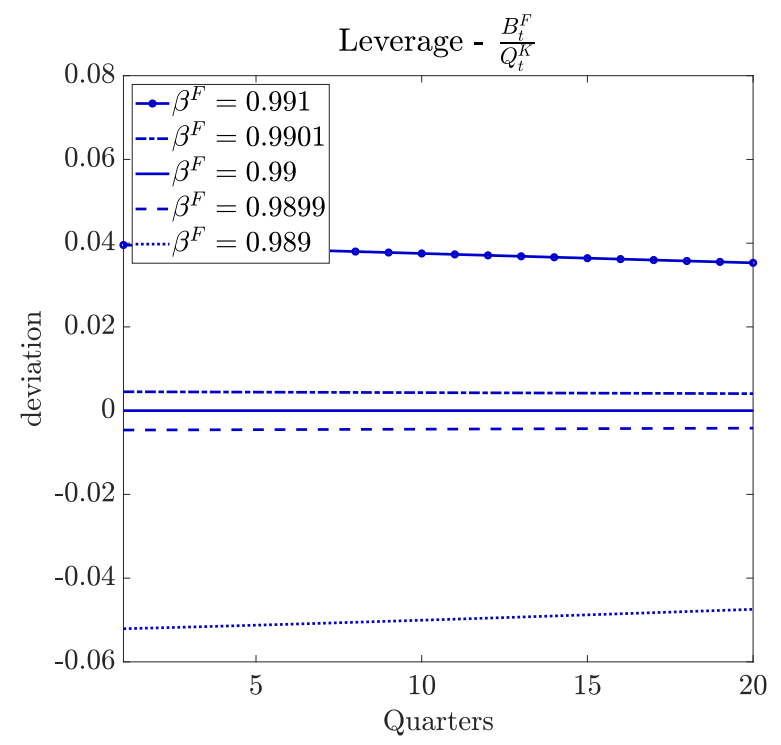

Figure 26: Impulse Responses - Model I. Impulse responses to a one-standard-deviation positive technology shock for different values of the intermediary's discount factor $\beta^{F}$, holding constant all other calibrated parameters as described in Section A.5.11. Responses are multiplied by 100. 


\section{A.5.12 Model II: Endogenous Capital}

Next, I show that the cyclicality and the dynamics of leverage depend on whether capital is allowed to change or not. To this end, I endogenize capital but keep labor fixed at unity for simplicity. Allowing for endogenous labor does not change the results. Capital now evolves according to (22) and the value of capital $Q_{t}^{K}$ is determined by the capital good producer's optimality condition (21). In addition to the previous parameters, I calibrate $\delta=0.025$ and $\zeta=3$ as in the main model. I find that $\psi=0.000625$ matches well the impulse response and the cyclicality of leverage in the data, giving an asset-to-equity ratio of around 2 for the intermediary.

Impulse Responses. Given the new version of the model, the impulse responses to a positive technology shock are shown in Figure 27. Output, consumption, dividends, and the interest rate $R_{t+1}$ behave similar to the ones above and are omitted for brevity. Banks' balance sheets now undergo larger expansions and contractions since capital is endogenous. Following a positive technology shock, the capital stock $K_{t}$ and the value of capital $Q_{t}^{K}$ increase. Banks finance the additional capital by acquiring new debt $B_{t}^{F}$. Hence, intermediary leverage $\frac{B_{t}^{F}}{Q_{t}^{K} K_{t}}$ could either increase or decrease. For the chosen calibration, leverage falls initially as asset prices rise immediately. However, over time, the debt-financed balance sheet expansion dominates and the response of leverage turns positive after a few quarters as in the data. Overall, intermediary leverage is mildly procyclical. The correlation between output and leverage is 0.03 .
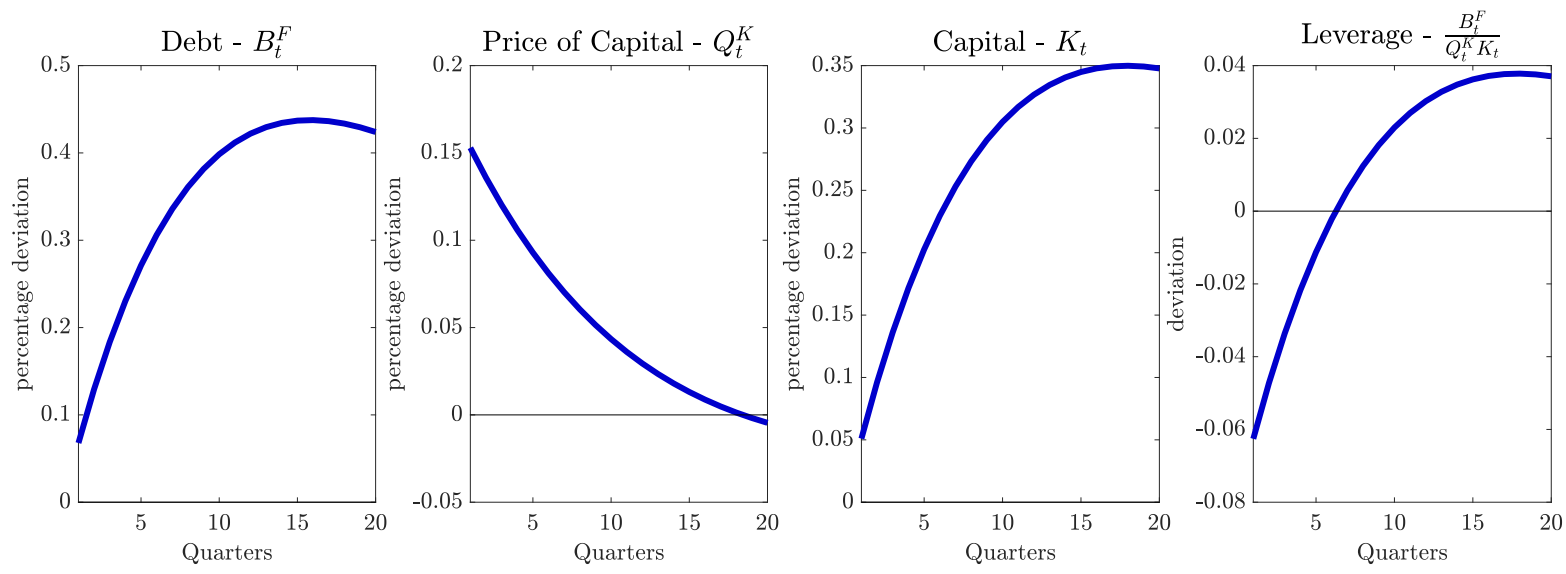

Figure 27: Impulse Responses - Model with Endogenous Capital. Impulse responses to a positive one-standard-deviation technology shock, all responses are multiplied by 100.

Figure 28 shows again the response of leverage for different values of $\beta^{F}$, leaving the remaining parameters unchanged. The higher $\beta^{F}$, the lower steady-state bank leverage, and the more positive the response of leverage to a positive technology shock since the initial increase in asset prices does not lower leverage as much. These results can also be achieved by altering $\psi$ while keeping the remaining parameters unchanged. 


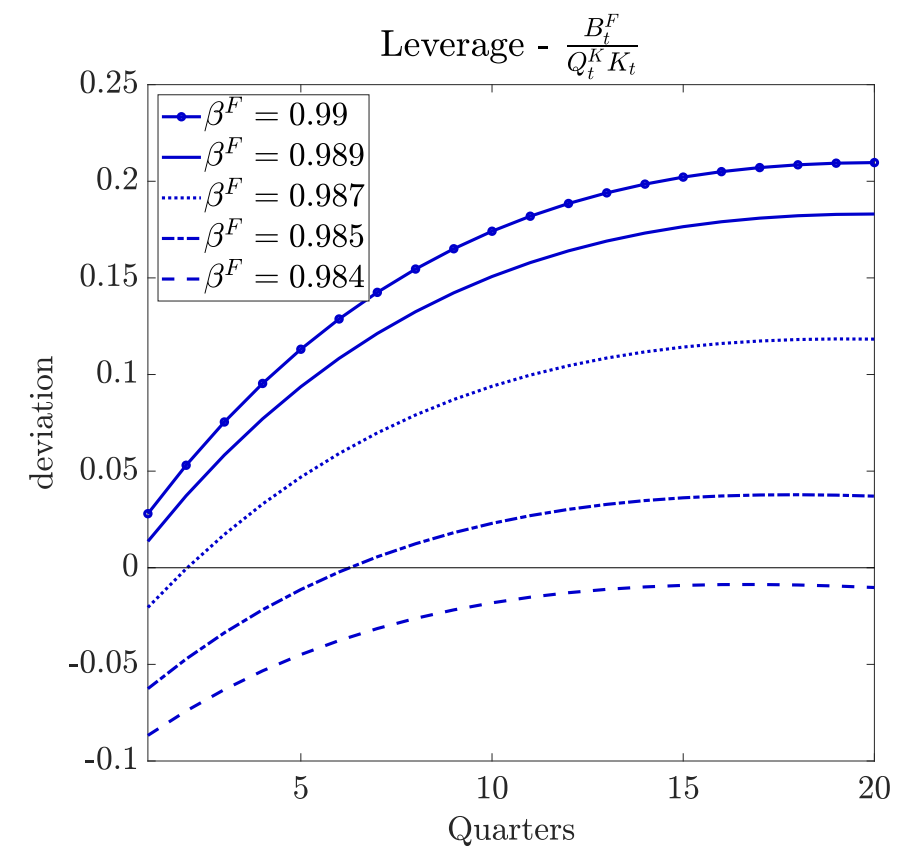

Figure 28: Impulse Responses - Model II. Impulse responses to a one-standard-deviation positive technology shock for different values of the intermediary's discount factor $\beta^{F}$, holding constant all other calibrated parameters as described in Section A.5.12. Responses are multiplied by 100. 